Chemical Technology Division Chemical Technology Division Chemical Technology Division

\section{Radiolysis and Hydrolysis of Magnetically Assisted Chemical Separation Particles}

by B. A. Buchholz, L. Nuñez, and G. F. Vandegrift

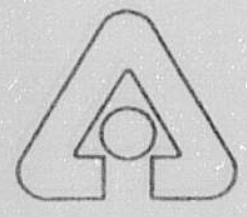

Argonne National Laboratory, Argonne, Illinois 60439 operated by The University of Chicago

for the United States Department of Energy under Contract W-31-109-Eng-38
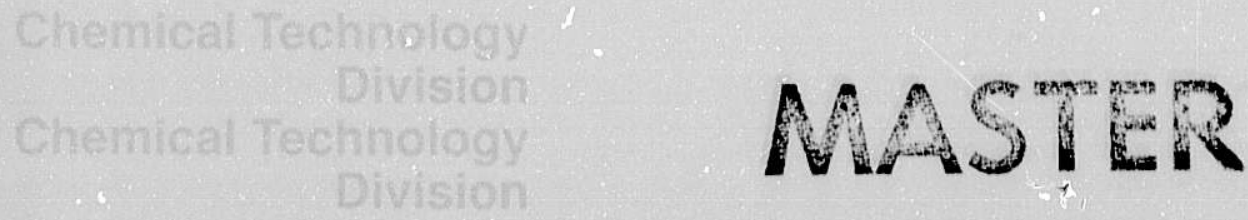
Argonne National Laboratory, with facilities in the states of Illinois and Idaho, is owned by the United States government, and operated by The University of Chicago under the provisions of a contract with the Department of Energy.

\section{DISCLAIMER}

This report was prepared as an account of work sponsored by an agency of the United States Government. Neither the United States Government nor any agency thereof, nor any of their employees, makes any warranty, express or implied, or assumes any legal liability or responsibility for the accuracy, completeness, or usefulness of any information, apparatus, product, or process disclosed, or represents that its use would not infringe privately owned rights. Reference herein to any specific commercial product, process, or service by trade name, trademark, manufacturer, or otherwise, does not necessarily constitute or imply its endorsement, recommendation, or favoring by the United States Government or any agency thereof. The views and opinions of authors expressed herein do not necessarily state or reflect those of the United States Government or any agency thereof.

Reproduced from the best available copy.

Available to DOE and DOE contractors from the Office of Scientific and Technical Information

P.O. Box 62

Oak Ridge, TN 37831

Prices available from (615) 576-8401

Available to the public from the National Technical Information Service

U.S. Department of Commerce

5285 Port Royal Road

Springfield, VA 22161 
Distribution Category:

Defense Waste Management (UC-721)

\section{ARGONNE NATIONAL LABORATORY \\ 9700 South Cass Avenue \\ Argonne, IL 60439}

\section{RADIOLYSIS AND HYDROLYSIS OF MAGNETICALLY ASSISTED CHEMICAL SEPARATION PARTICLES}

\section{by}

B. A. Buchholz, L. Nuñez, and G. F. Vandegrift

Chemical Technology Division 
ABSTRACT

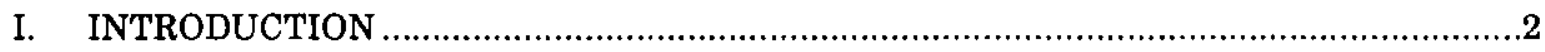

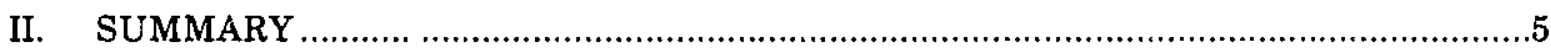

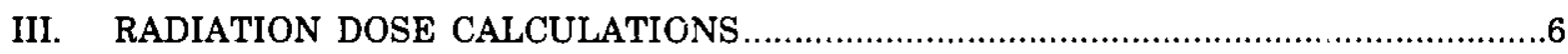

A. Dose/Cycle Estimates for TRU Extraction ...........................................................

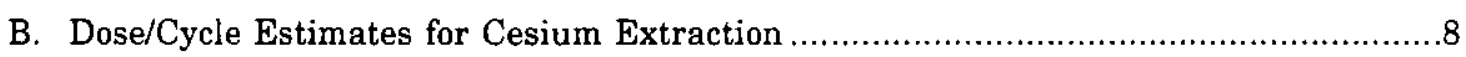

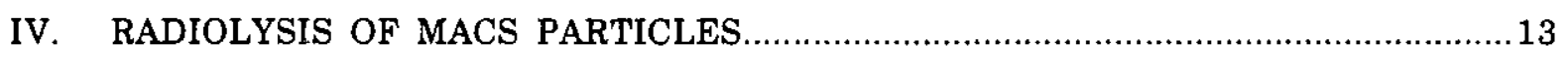

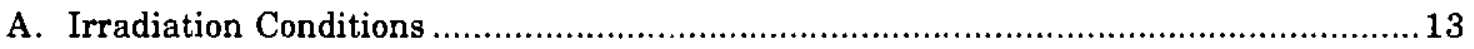

B. Relation between Dose and Cycles ................................................................ 13

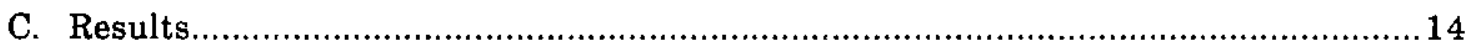

1. Change in $\mathrm{K}_{\mathrm{d}}(\mathrm{Am})$ with Radiation Dose and Suspension Solution ......................14

2. Variation in $\mathrm{K}_{\mathrm{d}}(\mathrm{Am})$ with CMPO/TBP Concentration ....................................16

3. Physical Changes in Suspension Solutions................................................... 18

4. Physical Changes in Particles ....................................................................... 18

5. Electron Micrographs of Particles Irradiated in PFP Waste Simulant ...............18

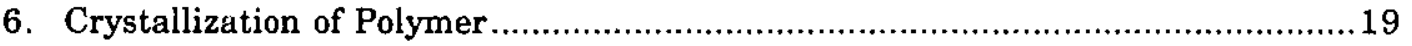

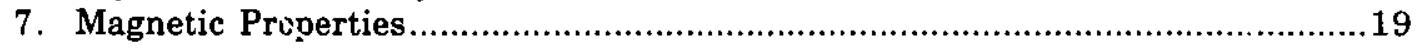

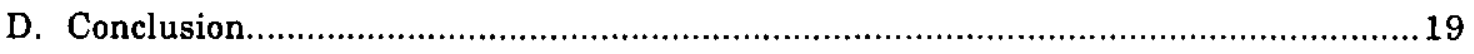

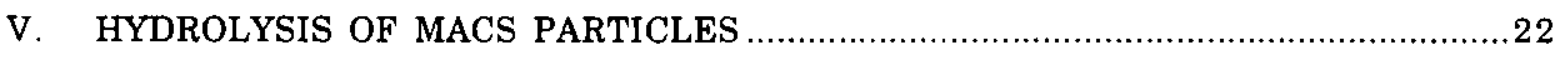

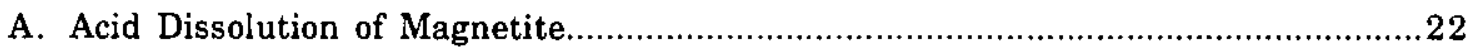

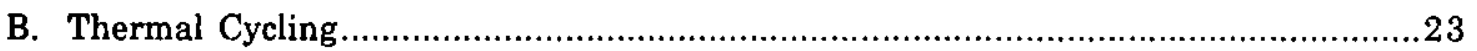

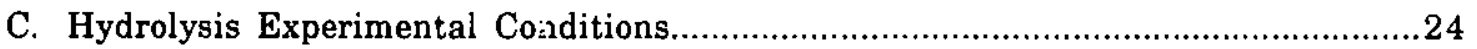

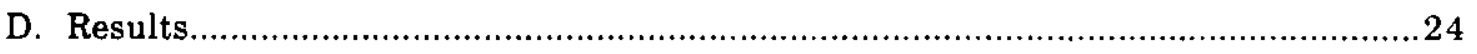

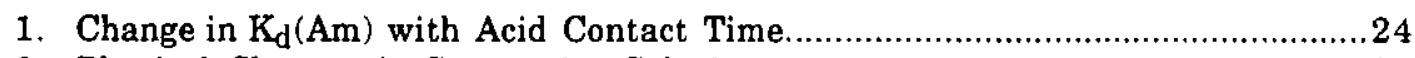

2. Physical Changes in Suspension Solutions......................................................25

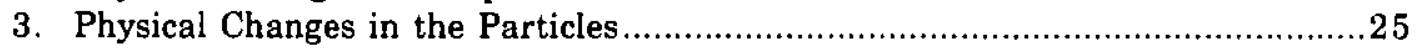

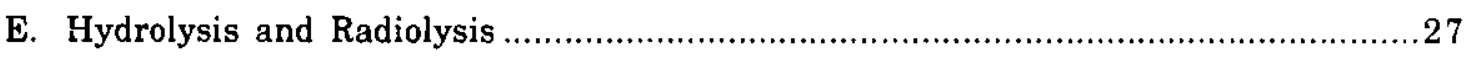

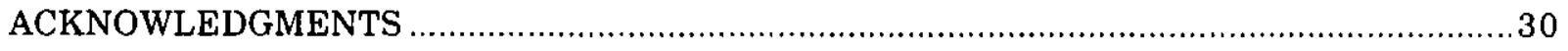




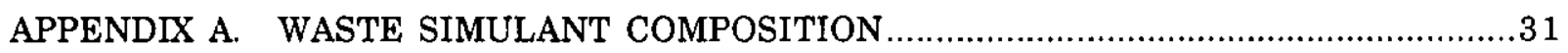

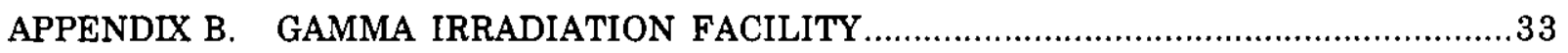

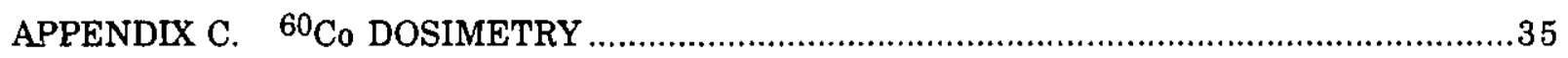

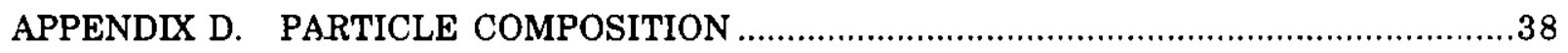

APPENDIX E. PROCEDURES FOR SEALING AND OPENING VIALS ...........................43

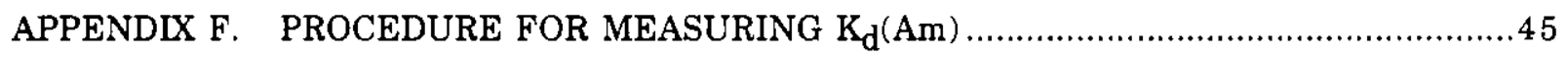

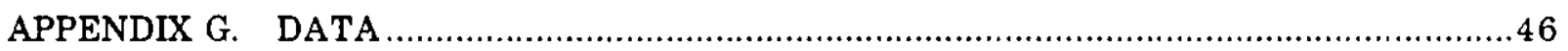

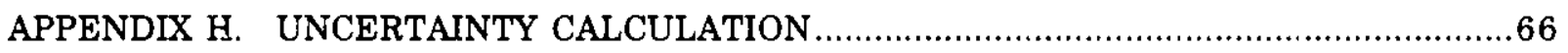

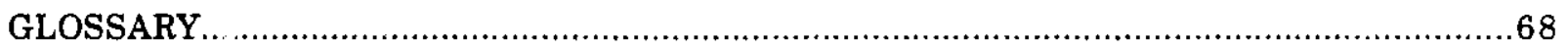

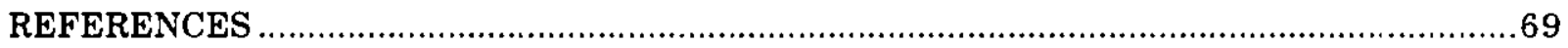




\section{LIST OF FIGURES}

No.

I-1. Octyl(phenyl)-N,N-diisobutylcarbamoylmethylphosphine Oxide (CMPO)

IV-1. $\quad \mathrm{K}_{\mathrm{d}}(\mathrm{Am})$ vs. Radiation Dose for MDZ-1089-22A Particles Coated with 1.2M CMPO/TBP.

IV-2. $\quad K_{d}(A m)$ vs. Radiation Dose for MDZ-1089-58A Particles Coated with 1.2 CMPO/TBP.

IV-3. $\quad K_{d}(A m)$ vs. Radiation Dose for MDZ-1089-60A Particles Coated with 1.36 $\mathrm{M}$ CMPO/TBP

IV-4. $\quad \mathrm{K}_{\mathrm{d}}(\mathrm{Am})$ vs. Radiation Dose for Particles Suspended in $0.1 \underline{\mathrm{M}} \mathrm{HNO}_{3}$ during Irradiation.

IV-5. $\quad \mathrm{K}_{\mathrm{d}}(\mathrm{Am})$ vs. Radiation Dose for Particles Suspended in $2 \underline{\mathrm{M}} \mathrm{HNO}_{3}$ during Irradiation.

IV-6. $\quad \mathrm{K}_{\mathrm{d}}(\mathrm{Am})$ vs. Radiation Dose for Particles Suspended in $5 \underline{\mathrm{M}} \mathrm{HNO}_{3}$ during Irradiation.

IV-7. TEM Micrographs of Charcoal-Polymer-Magnetite Particles.................................20

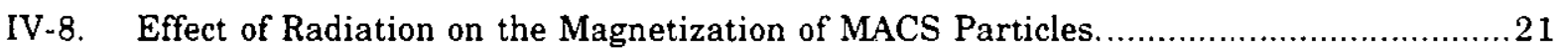

V-1. Concentration of Dissolved Iron in Solution vs, $\mathrm{HNO}_{3}$ Concentration...........................23

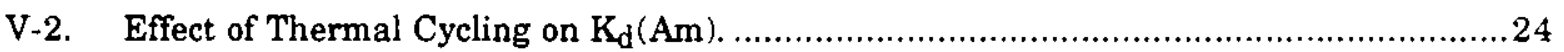

V-3. $\mathrm{K}_{\mathrm{d}}(\mathrm{Am})$ from $2 \mathrm{M} \mathrm{HNO}_{3}$ vs. Solution Contact Time for Particles Coated with $1.2 \underline{\mathrm{M}}$ CMPO/TBP.

V-4. $\quad \mathrm{K}_{\mathrm{d}}(\mathrm{Am})$ from $2 \mathrm{M} \mathrm{HNO}_{3}$ vs. Solution Contact Time and Aqueous Phase Composition for Particles Coated with 1.36 $\underline{\mathrm{M}}$ CMPO/TBP

V-5. $\quad \mathrm{K}_{\mathrm{d}}(\mathrm{Am})$ from $2 \mathrm{M} \mathrm{HNO}_{3}$ vs. Solution Contact Time for Particles Coated with $0.58 \underline{\mathrm{M}} \mathrm{CMPO} / \mathrm{TBP}$.

V-6. $\mathrm{K}_{\mathrm{d}}(\mathrm{Am})$ from $2 \mathrm{M} \mathrm{HNO}_{3}$ vs. Solution Contact Time and Radiation Dose for MDZ-1089-60A Particles Coated with 1.36M CMPO/TBP in Contact with $0.1 \mathrm{M} \mathrm{HNO}_{3}$.

V-7. $K_{d}(A m)$ from $2 \underline{M} H_{3}$ vs. Solution Contact Time and Radiation Dose for MDZ-1089-60A Particles Coated with 1.36⿳ CMPO/TBP in Contact with $2 \mathrm{M} \mathrm{HNO}_{3}$.

V.8. $\mathrm{K}_{\mathrm{d}}(\mathrm{Am})$ from $2 \underline{\mathrm{M}} \mathrm{HNO}_{3}$ vs. Solution Contact Time and Radiation Dose for MDZ-1089-60A Particles Coated with 1.36 $\mathrm{M}$ CMPO/TBP in Contact with $5 \underline{\mathrm{M}} \mathrm{HNO}_{3}$ 
B-1. Layout of Gamma Irradiation Facility .34

D-1. TEM Micrograph of Unirradiated Charcoal-Polymer-Magnetite Particles...... .42

G-1. Variation in $\mathrm{K}_{\mathrm{d}}(\mathrm{Am})$ from $2 \mathrm{M} \mathrm{HNO}_{3}$ with Absorbed Dose for MACS Particles MDK-1064-113 Coated with 1.36M CMPO/TBF.

G-2. Variation in $\mathrm{K}_{\mathrm{d}}(\mathrm{Am})$ from $2 \mathrm{M} \mathrm{HNO}_{3}$ with Absorbed Dose for MACS Particles MDK-1064-119 Coated with 1.36M CMPO/TBP.

G-3. Variation in $\mathrm{K}_{\mathrm{d}}(\mathrm{Am})$ from $2 \mathrm{M} \mathrm{HNO}_{3}$ with Absorbed Dose for MACS Particles MDZ-1089-22A Coated with 1.2M CMPO/TBP.

G-4. Variation in $\mathrm{K}_{\mathrm{d}}(\mathrm{Am})$ from $2 \mathrm{M} \mathrm{HNO}_{3}$ with Absorbed Dose for MACS Particles MDZ-1089-46A Coated with 1.5M CMPO/TBP.

G-5. Variation in $\mathrm{K}_{\mathrm{d}}(\mathrm{Am})$ from $2 \mathrm{M} \mathrm{HNO}_{3}$ with Absorbed Dose for MACS Particles MDZ-1089-53A Coated with 0.8M CMPO/TBP.

G-6. Variation in $\mathrm{K}_{\mathbf{d}}(\mathrm{Am})$ from $2 \mathrm{M} \mathrm{HNO}_{3}$ with Absorbed Dose for MACS Particles LMC-1064-55 Coated with 1.5 $\underline{\mathrm{M}}$ CMPO/TBP.

G-7. Variation in $\mathrm{K}_{\mathrm{d}}(\mathrm{Am})$ from $2 \mathrm{M} \mathrm{HNO}_{3}$ with Absorbed Dose for MACS Particles MDZ-1089-58A Coated with 1.2 $\underline{\mathrm{M}} \mathrm{CMPO} / \mathrm{TBP}$.

G-8. Variation in $\mathrm{K}_{\mathrm{d}}(\mathrm{Am})$ from $2 \mathrm{M} \mathrm{HNO}_{3}$ with Absorbed Dose for MACS Particles MDK-1089-60A Coated with 1.36⿳一巛工 CMPO/TBP.

G-9. Variation in $\mathrm{K}_{\mathrm{d}}(\mathrm{Am})$ from $2 \mathrm{M} \mathrm{HNO}_{3}$ with Absorbed Dose for MACS Particles MDK-1089-65B Coated with 0.58 M CMPO/TBP

G-10. Variation in $\mathrm{K}_{\mathrm{d}}(\mathrm{Am})$ from $2 \mathrm{M} \mathrm{HNO}_{3}$ with Absorbed Dose for Particles Contacted with Deionized Water during Irradiation.

G-11. Variation in $\mathrm{K}_{\mathrm{d}}(\mathrm{Am})$ from $2 \mathrm{M} \mathrm{HNO}_{3}$ with Absorbed Dose for Particles Contacted with $0.1 \underline{\mathrm{M}} \mathrm{HNO}_{3}$ during Irradiation.

G-12. Variation in $\mathrm{K}_{\mathrm{d}}(\mathrm{Am})$ from $2 \mathrm{M} \mathrm{HNO}_{3}$ with Absorbed Dose for Particles Contacted with $2 \underline{\mathrm{M}} \mathrm{HNO}_{3}$ during Irradiation.

G-13. Variation in $\mathrm{K}_{\mathrm{d}}(\mathrm{Am})$ from $2 \mathrm{M} \mathrm{HNO}_{3}$ with Absorbed Dose for Particles Contacted with $5 \mathrm{M} \mathrm{HNO}_{3}$ during Irradiation.

G-14. Variation in $\mathrm{K}_{\mathrm{d}}(\mathrm{Am})$ from $2 \mathrm{M} \mathrm{HNO}_{3}$ with Absorbed Dose for Particles Contacted with Dissolved PFP Sludge Simulant during Irradiation.

G-15. Variation in $\mathrm{K}_{\mathrm{d}}(\mathrm{Am})$ from $2 \mathrm{M} \mathrm{HNO}_{3}$ with Solution Contact Time for MACS Particles MDZ-1089-58A Coated with 1.2 1 CMPO/TBP. 
G-16. Variation in $\mathrm{K}_{\mathrm{d}}(\mathrm{Am})$ from $2 \mathrm{M} \mathrm{HNO}_{3}$ with Solution Contact Time for MACS Particles MDZ-1089-60A Coated with $1.36 \mathrm{M}$ CMPO/TBP....

G-17. Variation in $\mathrm{K}_{\mathrm{d}}(\mathrm{Am})$ from $2 \mathrm{M} \mathrm{HNO}_{3}$ with Solution Contact Time for MACS Particles MDZ-1089-65B Coated with 0.58M CMPO/TBP.

G-18. Variation in $\mathrm{K}_{\mathrm{d}}(\mathrm{Am})$ from $2 \mathrm{M} \mathrm{HNO}_{3}$ with Solution Contact Time and Radiation

Dose for MACS Particles MDZ-1089-58A Coated with 1.2M CMPO/TBP in

Contact with Deionized Water.

G-19. Variation in $\mathrm{K}_{\mathrm{d}}(\mathrm{Am})$ from $2 \mathrm{M} \mathrm{HNO}_{3}$ with Solution Contact Time and Radiation

Dose for MACS Particles MDZ-1089-58A Coated with 1.2M CMPO/TBP in

Contact with $0.1 \underline{\mathrm{M}} \mathrm{HNO}_{3}$.....

G-20. Variation in $\mathrm{K}_{\mathrm{d}}(\mathrm{Am})$ from $2 \mathrm{M} \mathrm{HNO}_{3}$ with Solution Contact Time and Radiation

Dose for MACS Particles MDZ-1089-58A Coated with 1.2M CMPO/TBP in

Contact with $2 \underline{\mathrm{M}} \mathrm{HNO}_{3}$

G-21. Variation in $\mathrm{K}_{\mathrm{d}}(\mathrm{Am})$ from $2 \mathrm{M} \mathrm{HNO}_{3}$ with Solution Contact Time and Radiation

Dose for MACS Particles MDZ-1089-58A Coated with 1.2M CMPO/TBP in

Contact with $5 \underline{\mathrm{M}} \mathrm{HNO}_{3}$

G-22. Variation in $\mathrm{K}_{\mathrm{d}}(\mathrm{Am})$ from $2 \mathrm{M} \mathrm{HNO}_{3}$ with Solution Contact Time and Radiation

Dose for MACS Particles MDZ-1089-60A Coated with 1.36M CMPO/TBP in

Contact with $0.1 \underline{\mathrm{M}} \mathrm{HNO}_{3}$.

G-23. Variation in $\mathrm{K}_{\mathrm{d}}(\mathrm{Am})$ from $2 \mathrm{M} \mathrm{HNO}_{3}$ with Solution Contact Time and Radiation

Dose for MACS Particles MDZ-1089-60A Coated with 1.36ㅆ CMPO/TBP in

Contact with $2 \mathrm{M} \mathrm{HNO}_{3}$

G-24. Variation in $\mathrm{K}_{\mathrm{d}}(\mathrm{Am})$ from $2 \mathrm{M} \mathrm{HNO}_{3}$ with Solution Contact Time and Radiation

Dose for MACS Particles MDZ-1089-60A Coated with 1.36M CMPO/TBP in

Contact with $5 \underline{\mathrm{M}} \mathrm{HNO}_{3}$

G-25. Variation in $\mathrm{K}_{\mathrm{d}}(\mathrm{Am})$ from $2 \mathrm{M} \mathrm{HNO}_{3}$ with Solution Contact Time and Radiation Dose for MACS Particles MDZ-1089-65B Coated with 0.58 M CMPO/TBP in Contact with $0.1 \underline{\mathrm{M}} \mathrm{HNO}_{3}$

G-26. Variation in $\mathrm{K}_{\mathrm{d}}(\mathrm{Am})$ from $2 \mathrm{M} \mathrm{HNO}_{3}$ with Solution Contact Time and Radiation

Dose for MACS Particles MDZ-1089-65B Coated with 0.58 $\mathrm{M}$ CMPO/TBP in Contact with $2 \mathrm{M} \mathrm{HNO}_{3}$

G-27. Variation in $\mathrm{K}_{\mathrm{d}}(\mathrm{Am})$ from $2 \mathrm{M} \mathrm{HNO}_{3}$ with Solution Contact Time and Radiation Dose for MACS Particles MDZ-1089-65B Coated with 0.58M CMPO/TBP in Contact with $5 \underline{\mathrm{M}} \mathrm{HNO}_{3}$ 


\section{LIST OF TABLES}

No. Title

I-1. Components of TRUEX Solvents and MACS Coating....... 3

III-1. Concentrations of TRU Contributing to Radiation Dose in PFP Waste. 6

III-2. TRU Dose Estimates for Magnetic Particles..................................................

III-3. Dose Absorbed by Cesium Specific Magnetic Particles .........................................12

IV-1. Theoretical Dose Rates for Most Probable Particle Compositions ..............................13

IV-2. Relation between Experimental Doses and Equivalent Contact Cycles for TRU Removal.

V-1. Percentage of Iron Dissolved from Particles Coated with 1.5 M CMPO/TBP during Two-Week Contact with 2-mL Portions

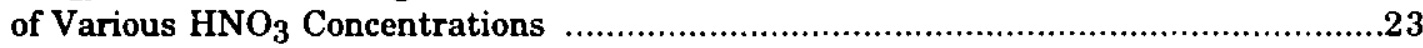

A-1. Composition of PFP Dissolved Sludge Simulant....................................................

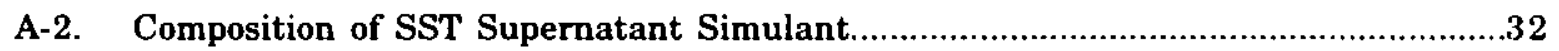

C-1. Electron Density of Magnetic Particles Relative to Water.................................35

C-2. Weighted Mass Attenuation and Absorption Coefficients for Magnetic Particles Exposed to ${ }^{60} \mathrm{Co} \gamma$-ray Energy of $1.25 \mathrm{MeV}$...

C-3. Weighted Mass Attenuation and Absorption Coefficients for Water Exposed to ${ }^{60} \mathrm{Co} \gamma$-ray Energy of $1.25 \mathrm{MeV}$

C-4. Multiplication Factors for Converting Water Equivalent Dose to Magnetic Particle Dose

C-5. Gamma Irradiation Dose Rates for Particles and Water..

D-1. Chemical Components of Particles Used for TRU Extraction.

D-2. Density of Magnetic Particles for Various Fractions of Polymer/Charcoal Absorption.

D-3. Total Moles of Particle Components per Gram of Components.

D-4. Elemental Composition of Magnetic Particles .40

D-5. Average Atomic Number of Magnetic Particles.

E-1. Suspension Solutions for Gamma Irradiations.

G-1. Data from Radiolysis and Hydrolysis Study 


\section{LIST OF TABLES (contd)}

$\underline{\text { No. }}$

Title

Page

G-2. Guide to Coating Parameters for Particles Used in Irradiations ..............................50

G-3. $\quad \mathrm{K}_{\mathrm{d}}(\mathrm{Am})$ Values from $2 \underline{\mathrm{M}} \mathrm{HNO}_{3}$ for Particle Coating MDZ-1089-58A with 1.2 $\mathrm{M} \mathrm{CMPO} / \mathrm{TBP}$. .65

G-4. $\quad \mathrm{K}_{\mathrm{d}}$ (Am) Values from $2 \mathrm{M} \mathrm{HNO}_{3}$ for MACS Particles MDZ-1089-65B Coated with $0.58 \underline{\mathrm{M}}$ CMPO/TBP. 


\title{
RADIOLYSIS AND HYDROLYSIS OF MAGNETICALLY ASSISTED \\ CHEMICAL SEPARATION PARTICLES
}

by

B. A. Buchhclz, L. Nuñez, and G. F. Vandegrift

\begin{abstract}
The magnetically assisted chemical separation (MACS) process is designed to separate transuranic (TRU) elements out of high-level waste (HLW) or TRU waste. Magnetic microparticles $(1-25 \mu \mathrm{m}$ ) were coated with octyl (phenyl)$\mathrm{N}, \mathrm{N}$-diisobutylcarbamoylmethylphosphine oxide (CMPO) dissolved in tributyl phosphate (TBP) and tested for removing TRU elements from acidic nitrate solutions. The particles were contacted with nitric acid solutions and Hanford plutonium finishing plant (PFP) simulant, irradiated with a high intensity ${ }^{60} \mathrm{Co}$ y-ray source, and evaluated for effectiveness in removing TRU elements from $2 \mathrm{M} \mathrm{HNO}_{3}$ solutions. The resistance of the coatings and magnetic cores to radiolytic damage and hydrolytic degradation was investigated by irradiating samples of particles suspended in a variety of solutions with doses of up to $5 \mathrm{Mrad}$. Transmission electron microscopy (TEM), magnetic susceptibility measurements, and physical observations of the particles and suspension solutions were used to assess physical changes to the particles. Processes that affect the surface of the particles dramatically alter the binding sites for TRU in solution. Hydrolysis played a larger role than radiolysis in the degradation of the extraction capacity of the particles.
\end{abstract}




\section{INTRODUCTION}

The magnetically assisted chemical separation (MACS) process removes transuranic (TRU) elements from aqueous nitric acid solutions. In this process, the TRU elements are extracted into a selective organic coating adsorbed onto a magnetic particle. Based upon the TRUEX (transuranic extraction) process, the organic coating consists of a neutral bifunctional organophosphorous extractant, octyl(phenyl)-N,N-diisobutylcarbamoylmethylphosphine oxide (CMPO), dissolved in tributyl phosphate (TBP). The particles consist of a cross-linked polyacrylamide ( $\mathrm{N}, \mathrm{N}$-methylenebisacrylamide), entrapping charcoal, and magnetite $\left(\mathrm{Fe}_{3} \mathrm{O}_{4}\right)$ in a 1:1:1 weight ratio.

The MACS process is designed to separate and concentrate TRU elements from high-level waste (HLW) or TRU waste. The TRU elements should be concentrated in a small volume so as not to produce a large secondary waste stream. The coated particles are added to the TRU waste solution in a processing tank or column, mixed thoroughly, and recovered with a magnet. The MACS system is potentially a multistage process in which the number of stages required is based upon the extraction efficiency of the system and the level of TRU activity in the feed solution. Reducing TRU activity below $3.7 \times 10^{6} \mathrm{~Bq} \mathrm{~kg}^{-1}(100 \mathrm{nCi} / \mathrm{g})$ in the waste solution should arlow its disposal as low-level waste ( $L L W)$, greatly reducing disposal costs. The organic coating containing the TRU elcments can be stripped from the particles using a small volume of organic solvent, or the loaded particles can be vitrified and disposed as HLW. The stripped particles can receive a fresh coating of CMPO/TBP and be recycled. A thorough discussion of the MACS process applied to the removal of TRU from nitric acid solutions is presented elsewhere [NUNEZ$1995]$.

Since CMPO extracts both actinides and lanthanides, the particles can quickly become saturated when in contact with solutions containıng high concentrations of lanthanides. The plutonium finishing plant (PFP) waste is an ideal waste matrix for the MACS process because it is practically free of lanthanides. A simulant of PFP dissolve sludge is used throughout this study to determine particle damage due to TRU activity and to monitor extraction efficiency. Its composition is given in Appendix A.

When the organic coating extracts TRU from the aqueous solution, the decay of extracted TRU will cause radiolytic damage to the coating and the particle core. Prolonged exposure to nitric acid produces hydrolytic damage to the coatings and dissolves exposed magnetite in the particles. The radiolysis and hydrolysis of the organic extractant coating converts some of the CMPO and TBP into other chemical species.

Descriptions of the structure (Fig. I-1) and chemistry of CMPO are in the literature [VANDEGRIFT, HORWITZ, LEONARD-1985, CHIARIZIA]. Although MACS is not a solvent extraction process, the behavior of CMPO should be similar to that in the TRUEX process solvent. The compositions of the various TRUEX solvents and the MACS coating are given in Table I-1. 


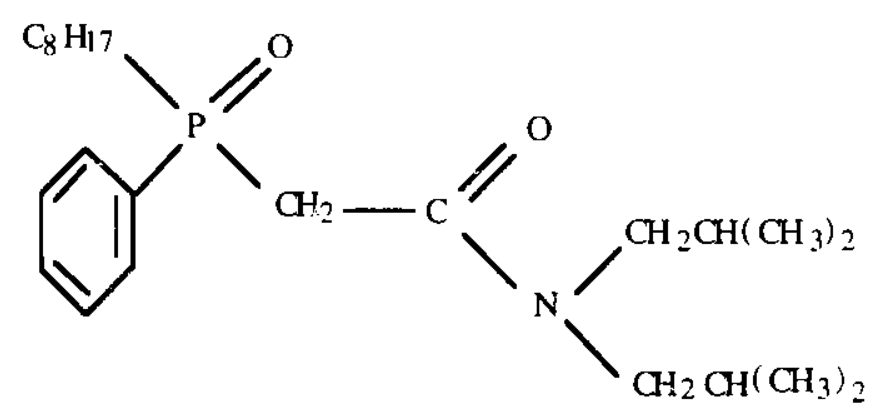

Fig. I-1. Octyl(phenyl)-N,N-diisobutylcarbamoylmethylphosphine Oxide (CMPO)

Table I-1. Components of TRUEX Solvents and MACS Coating

\begin{tabular}{cccc}
\hline Solvent & Diluent & $\begin{array}{c}\text { CMPO Concentration } \\
(\mathrm{mol} / \mathrm{L})\end{array}$ & $\begin{array}{c}\text { TBP' Concentration } \\
\text { (mol/L) }\end{array}$ \\
\hline TRUEX-CCl & $\mathrm{CCl}_{4}$ & 0.25 & 0.75 \\
TRUEX-TCE & TCE & 0.25 & 1.0 \\
TRUEX-NPH & NPH & 0.2 & 1.4 \\
MACS Coating & TBP & $0.58-1.5$ & diluent \\
\hline
\end{tabular}

The radioiycic degradation of TBP is well documented [DAVIS]. When the degradation products of TBP from the $\gamma$-radiolysis of TRUEX-TCE [NASH] were analyzed, only dibutyl phosphoric acid (HDBP) and small amounts of monobutyl phosphoric acid were found. A plethora of degradation products of CMPO from the $\gamma$-radiolysis of TRUEX-CCl 4 and TRUEX-TCE [CHIARIZIA, NASH] have been observed. The chemical bonds most often severed are those with the $\mathrm{N}$ atom, the $\mathrm{P}-\mathrm{CH}_{2}$ bond, and the $\mathrm{CH}_{2}$ - $\mathrm{CO}$ bond. The hydrocarbon chains, $\mathrm{P}=\mathrm{O}$ bond, and $\mathrm{C}=\mathrm{O}$ bond are least likely to suffer radiolytic damage. Models for calculating radiolytic and hydrolytic damage to the TRUEX-NPH solvent are reported [SIMONZADEH]. Supercritical gas chromatography was used to measure the purity of CMPO [TSE].

The radiolysis and hydrolysis of the extracting coatings are commonly referred to as degradation, and the resulting chemical species are degradation products. The degradation products from the coatings in turn degrade the CMPO, decreasing its concentration and producing several acidic degradation products. These products are strong extractants at low acid concentrations and, therefore, prevent stripping of actinides under normal stripping conditions. Radiation also induces cross-linking or polymerizing chemical reactions, which bond the CMPO to the charcoal and polymer and inhibit the dispersion of the particles.

The objectives of this study were to determine the following: (1) the effect of radiation exposure on the extraction capability of the MACS particles, (2) the effect of acid exposure on the extraction capability of the MACS particles, and (3) the robustness of the MACS particles under realistic process conditions.

Samples of MACS particles were subjected to radiolysis or hydrolysis, then tested for extraction performance. Extraction performance is measured with the partitioning coefficient $\mathrm{K}_{\mathrm{d}}$ using stock solutions of ${ }^{241} \mathrm{Am}$ in $2 \underline{\mathrm{M}} \mathrm{HNO}_{3}$ at $25^{\circ} \mathrm{C}$. The partitioning coefficient $\mathrm{K}_{\mathrm{d}}$ is derived from the mass balance ( $\mathrm{Eq}$. I-1) of the radiotracer ${ }^{241} \mathrm{Am}$. The $\mathrm{K}_{d}$ term is introduced in Eq. I-2 to describe the amount of $241 \mathrm{Am}$ on the particles in terms of its concentration in solution. This equation is rewritten as an expression of the $K_{d}$ value in Eq. I-3. 


$$
\begin{gathered}
\operatorname{Vol}_{\text {sol }}\left(C_{o}\right)=\operatorname{Vol}_{\text {sol }}\left(C_{f}\right)+m_{\text {part }}\left(C_{p}\right) \\
\operatorname{Vol}_{\text {sol }}\left(C_{o}\right)=\operatorname{Vol}_{\text {sol }}\left(C_{f}\right)+\left(m_{\text {part }}\right)\left(\mathrm{K}_{d}\right)\left(C_{f}\right) \\
K_{d}=\frac{\left(C_{0}-C_{f}\right)}{C_{f}} \frac{V_{\text {ol }}}{m_{\text {port }}}
\end{gathered}
$$

where

$$
\begin{aligned}
\mathrm{C}_{0} & =\text { initial concentration of }{ }^{241} \mathrm{Am} \text { in the stock solution, } \frac{\mathrm{cpm}}{\mathrm{mL}} \\
\mathrm{C}_{\mathrm{f}}= & \text { final concentration of }{ }^{241} \mathrm{Am} \text { in the contacted solution, } \frac{\mathrm{cpm}}{\mathrm{mL}} \\
\mathrm{C}_{\mathrm{p}}= & \text { final concentration of }{ }^{241} \mathrm{Am} \text { on the particles, } \frac{\mathrm{cpm}}{\mathrm{g}} \\
\mathrm{Vol}_{\text {sol }}= & \text { volume of solution in contact with the particles, } \mathrm{mL} \text { (assumed to not change due } \\
\mathrm{m}_{\mathrm{part}}= & \text { mass of particles in contact with the solution, } \mathrm{g} \\
\mathrm{K}_{\mathrm{d}} & =\text { partitioning coefficient, } \frac{\mathrm{mL}}{\mathrm{g}}=\frac{\mathrm{C}_{\mathrm{p}}}{\mathrm{C}_{\mathrm{f}}}
\end{aligned}
$$

Radiolytic and hydrolytic effects were noted. Macroscopic changes were observed during the experiments, and qualitative changes were described using electron microscopy. The physical changes observed include loss of coating during exposure, crystallization of the polymer, loss of dispersion when doing $K_{d}$ contacts, and dissolution of magnetite during exposure.

The radiation dose calculations for magnetic particles coated with ion-exchange resin materials designed to remove ${ }^{137} \mathrm{Cs}$ from alkaline aqueous solutions are also included. These particles are much larger than those designed for TRU removal. The ion-exchange materials are included to show how different particle size and content (i.e., different target) and a different radiation source affect the dose received by the particles. A detailed discussion of the particles prepared for ${ }^{137} \mathrm{Cs}$ removal is presented in another report [NUNEZ-94]. 


\section{SUMMARY}

The efficiency of the MACS particles at removing americium from an aqueous acidic solution decreases as the radiation dose to the particles increases. The decline in extraction capacity begins at doses much smaller than with the TRUEX solvent, $10^{4}$ rad versus $10^{6}$ rad. The early onset of loss in extraction capacity is not a severe problem, however, since the doses expected to be delivered in actual waste processing will be approximately $2000 \mathrm{rad}$ per cycle.

The decrease in separation efficiency varied with the particle coating and the contact solution. Nonhomogeneities in the particle coatings made modeling the changes in partitioning coefficient impractical. The changes in $\mathrm{K}_{\mathbf{d}}(\mathrm{Am})$ with dose do not consistently follow a linear, logarithmic, or exponential trend.

The MACS process exploits the high surface area of the particles to distribute a thin active layer of the TRU extractant (CMPO/TBP) on the particles and thus present abundant sites for the adsorption of TRU from solution. Processes which adversely affect the coating of the organic extractant cripple the MACS prccess. Prolonged contact with strong acid slowly dissolves the magnetite in the particles and appears to affect the bonding of the CMPO/TBP solvent to the particles. Few differences appear when examining hydrolysis and radiolysis data; however, hydrolysis, not radiolysis, appears to be primarily responsible for the changes observed in $\mathrm{K}_{\mathrm{d}}(\mathrm{Am})$.

The effects of the radiation in actual waste are probably greater than those observed in this study. Gamma-ray radiation did not appear to affect the particles, but the TRU wastes are primarily $\alpha$-particle emitters. Alpha-particles deposit their energy over very short ranges, often producing catastrophic damage. The actual resistance of the particles to high $\alpha$-particle radiation fields can be studied using a concentrated solution of ${ }^{241} \mathrm{Am}$ to load the particles.

The charcoal-polymer material in the particles experienced radiation damage for all doses. The transmission electron microscopy (TEM) micrographs showed that radiation-induced aggregations increased in size and density as the radiation dose increased. The organic core underwent additional polymerization, which inhibited the dispersion of the particles in solution. The available surface area of the particles decreased or was chemically modified, pulling $\mathrm{K}_{\mathrm{d}}(\mathrm{Am})$ values lower as binding sites for TRU were lost.

Improvements in coating procedures since the completion of the $\gamma$-ray irradiations of the particles produce more uniform particles with high $\mathrm{K}_{\mathrm{d}}(\mathrm{Am})$ values. The new particles will be used if additional radiolysis studies are done on MACS particles. Despite the adverse effects of hydrolysis and radiolysis on the partitioning coefficients, the short cycle time expected and probable coating regeneration make the MACS process an attractive alternative for separating TRU from waste streams with low lanthanide concentrations. 


\section{RADIATION DOSE CALCULATIONS}

The radiation doses delivered to the magnetic microparticles in the ${ }^{60} \mathrm{Co} \gamma$-ray irradiation facility were based upon estimates of the doses expected when processing waste solutions. The doses absorbed by the particles depend upon the concentration of specific isotopes adsorbed and the physical attributes such as density or average atomic number of the particles. Micrographs of the particles aided in developing assumptions about the relative concentrations of magnetite and polymer in the particles. The doses are also expressed in terms of contact cycles, where a cycle includes a complete extraction, separation, and strip process.

\section{A. Dose/Cycle Estimates for TRU Extraction}

Since the magnetic particles are most likely to be used in removing TRU from tanks with relatively low lanthanide concentrations, the concentrations of TRU in Plutonium Finishing Plant (PFP) wastes were used to calculate activity. Most of the radioactivity in PFP waste is from the decay of ${ }^{241} \mathrm{Am}$ and several plutonium isotopes [LEONARD-1985]. Table III-1 lists the radioisotopes used in calculating the doses to the magnetic particles.

Table III-1. Concentrations of TRU Contributing to Radiation Dose in PFP Waste

\begin{tabular}{lccc}
\hline Isotope & $\%$ of Isotope & $\begin{array}{c}\text { Concentration } \\
(\mathrm{mol} / \mathrm{L})\end{array}$ & $\begin{array}{c}\text { Specific Activity } \\
(\mathrm{dps} / \mathrm{L})\end{array}$ \\
\hline${ }^{241} \mathrm{Am}$ & 100 & $1.6 \times 10^{-5}$ & $4.90 \times 10^{8}$ \\
${ }^{239} \mathrm{Pu}$ & 94 & $1.5 \times 10^{-4}$ & $8.25 \times 10^{7}$ \\
$240 \mathrm{Pu}$ & 5.9 & $9.4 \times 10^{-6}$ & $1.91 \times 10^{7}$ \\
$241 \mathrm{Pu}$ & 0.1 & $1.6 \times 10^{-7}$ & $1.44 \times 10^{8}$ \\
\hline
\end{tabular}

Ionization is the prime mechanism of energy deposition by the emitted $\alpha$-particles. An expression for the energy deposition per unit path length for heavy charged ions such as $\alpha$-particles is given by Eq. III-1 [EVANS]:

$$
\left.\frac{\mathrm{dT}}{\mathrm{ds}}\right|_{\text {ion }}=\frac{4 \pi \mathrm{z}^{2} \mathrm{e}^{4}}{\mathrm{~m}_{\mathrm{o}} \mathrm{v}^{2}} \mathrm{NZ}\left(\ln \frac{2 \mathrm{~m}_{0} \mathrm{v}^{2}}{\mathrm{I}}-\ln \left(1-\beta^{2}\right)-\beta^{2}\right) \frac{\mathrm{erg}}{\mathrm{cm}}
$$

where

$$
\begin{aligned}
\mathrm{T} & =\text { kinetic energy of incident particle } \\
\mathrm{s} & =\text { path length of incident particle, } \mathrm{cm} \\
\mathrm{e} & =\text { electronic charge }=4.8 \times 10^{-10} \mathrm{stat} \mathrm{C} \\
\mathrm{m}_{0} & =\text { electron mass }=9.11 \times 10^{-28} \mathrm{~g} \\
\mathrm{z} & =\text { charge of incident particle }=2 \\
\mathrm{Z} & =\text { atomic number of target } \\
\mathrm{N} & =\text { atomic density of target, atoms } / \mathrm{cm}^{3}
\end{aligned}
$$


$\mathrm{NZ}=$ electron density of target, $\mathrm{cm}^{3}$

$$
\begin{aligned}
& A=\text { atomic mass of target } \\
& v=\text { velocity of } \alpha \text {-particle, } \mathrm{cm} / \mathrm{s} \\
& \mathrm{c}=\text { speed of light in vacuum }=3.00 \times 10^{10} \mathrm{~cm} / \mathrm{s} \\
& \beta=v / c \\
& I=\text { specific ionization }=\mathrm{kZ}=(11.5 \mathrm{eV}) \mathrm{Z}
\end{aligned}
$$

The atomic density of the target $(\mathrm{N})$ is calculated using

$$
\mathrm{N}=\frac{N_{\mathrm{A}}}{\mathrm{F} \cdot \mathrm{W}} \rho
$$

where

$$
\begin{aligned}
\mathrm{N}_{\mathrm{A}} & =6.023 \times 10^{23} \text { atoms } / \mathrm{mole} \\
\rho & =\text { density of target, } \mathrm{g} / \mathrm{cm}^{3} \\
\text { F.W. } & =\text { formula weight of the target, } \mathrm{g} / \mathrm{mol}
\end{aligned}
$$

The energy deposited in a target by $\beta$-particles is less concentrated than in the case of $\alpha$-particles. The loss in kinetic energy per unit path length for $\beta$-particles is given by [CEMBER]:

$$
\frac{\mathrm{dE}}{\mathrm{dx}}=\frac{2 \pi q^{4} \mathrm{NZ}\left(3 \times 10^{9}\right)^{4}}{\mathrm{E}_{\mathrm{m}} \beta^{2}\left(16 \times 10^{-6}\right)^{2}}\left[\ln \left(\frac{\mathrm{E}_{\mathrm{m}} \mathrm{E}_{\mathrm{k}} \beta^{2}}{\mathrm{I}^{2}\left(1-\beta^{2}\right)}\right)-\beta^{2}\right] \frac{\mathrm{MeV}}{\mathrm{cm}}
$$

where

$$
\begin{aligned}
\mathrm{q} & =\text { charge of an electron }=1.6 \times 10^{-19} \mathrm{C} \\
\mathrm{N} & =\text { number of absorber atoms per } \mathrm{cm}^{3} \\
\mathrm{Z} & =\text { atomic number of absorber } \\
\mathrm{NZ} & =\text { electron density of absorber, } \mathrm{cm}^{3} \\
\mathrm{E}_{\mathrm{m}} & =\text { rest energy of a } \beta \text {-particle }=0.511 \mathrm{MeV} \\
\mathrm{E}_{\mathrm{k}} & =\text { kinetic energy of the } \beta \text {-particle, eV } \\
v & =\text { velocity of the } \beta \text {-particle, } \mathrm{cm} / \mathrm{s} \\
\mathrm{c} & =\text { speed of light in vacuum }=3.00 \times 10^{10} \mathrm{~cm} / \mathrm{s} \\
\beta & =\text { v/c } \\
I & =\text { mean ionization and excitation potential of absorber }=\mathrm{Z} \cdot 13.5 \mathrm{eV}
\end{aligned}
$$


The numerical factors in Eq. III-3 are used to produce convenient "nits. The emitted $\beta$-particles from ${ }^{241} \mathrm{Pu}$ and a neutrino share $20.8 \mathrm{keV}$, producing an energy spectrum of emitted $\beta$-particles. The most probable kinetic and average energy of the $\beta$-particle is approximately $1 / 3 \mathrm{E}_{\max }$, or $7.0 \mathrm{keV}$. This energy is typically used when computing doses from $\beta$-particles. Ionization of target atoms is the principal mechanism for energy deposition. It is reasonable to assume that the contribution of $\gamma$-rays to the dose absorbed by the TRU extracting particles is insignificant.

The dose to the magnetic particles is calculated using Eqs. III-1 and III-3 and the following assumptions:

1. Half of the $\alpha$ - and $\beta$-particles are emitted into the solution, resulting in no dose to the magnetic particles.

2. Each $\alpha$ - and $\beta$-particle interacts with only one magnetic particle.

3. The $\gamma$-rays emitted by the TRU elements deposit an insignificant dose, compared to the $\alpha$ - and $\beta$-particles, and are thus dropped from calculations.

4. The rate of energy deposition for all isotopes is essentially the same, since the emitted $\alpha$-particles are all approximately $5 \mathrm{MeV}$.

5. All TRU atoms in solution are absorbed by the magnetic particles.

6. There are $10 \mathrm{~g}$ of magnetic particles per liter of solution.

7. Greater than $99.9 \%$ of ${ }^{241} \mathrm{Pu}$ decays by $\beta$-emission without an $\alpha$-emission.

8. Emitted $\alpha$-particles can be treated as classical particles (i.e., rest energy is much greater than kinetic energy).

The dose absorbed by the magnetic particles depends strongly upon the contact time per extraction, the number of extraction cycles used, the electron density of the magnetic particles. and the path length of the $\alpha$ - and $\beta$-particles as they traverse the absorber. Table III-2 contains dose approximations for a variety of path lengths, absorber properties, and contact times. Since the mass of the absorber is inversely proportional to the dose, decreasing the mass of particle: used will increase the dose to the particles.

\section{B. Dose/Cycle Estimates for Cesium Extraction}

The particles provided by Bradtec, Ltd. (UK) designed for cesium removal were larger than the TRU particles $(100-400 \mu \mathrm{m}$ vs. $10 \mu \mathrm{m})$. Since the kinetic energy of the emitted $\beta$-particles is deposited over a short range, the dose absorbed by large particles is significantly larger than that absorbed by smaller particles.

The doses anticipated to be absorbed by the Bradtec cesium-specific magnetic particles were calculated by considering the $\beta$-particle and $\gamma$-ray emitted by ${ }^{137} \mathrm{Cs}$ and its decay product ${ }^{137} \mathrm{Ba}$. The emitted $\beta$-particle and a neutrino share $514 \mathrm{keV}$, producing an energy spectrum of emitted $\beta$-particles. The most probable kinetic energy of the $\beta$-particle is $1 / 3 \mathrm{E}_{\mathrm{max}}$ or $171 \mathrm{keV}$. This energy is typically used when computing doses from $\beta$-particles. The principal mechanism for energy deposition is ionization of target atoms. 
Table III-2. TRU Dose Estimates for Magnetic Particles

\begin{tabular}{|c|c|c|c|c|c|c|c|c|}
\hline $\begin{array}{l}\text { Path } \\
(\mu \mathrm{m}) \\
\end{array}$ & $\begin{array}{l}\text { Density } \\
\left(\mathrm{g} / \mathrm{cm}^{3}\right)\end{array}$ & $\begin{array}{l}\text { Atomic } \\
\text { Number }\end{array}$ & $\begin{array}{c}\text { Atomic } \\
\text { Mass }\end{array}$ & $\begin{array}{c}\alpha \text { dose rate } \\
(\mathrm{rad} / \mathrm{h})\end{array}$ & $\begin{array}{c}\beta \text { dose rate } \\
(\mathrm{rad} / \mathrm{h})\end{array}$ & $\begin{array}{l}\text { Contact } \\
\text { Time (h) }\end{array}$ & $\begin{array}{c}10 \text { Cycle } \\
\text { Dose (rad) }\end{array}$ & $\begin{array}{l}100 \text { Cycle } \\
\text { Dose (rad) }\end{array}$ \\
\hline 5 & 1.82 & 6.03 & 12.0 & 1234 & 10 & 0.5 & $6.22 \mathrm{E}+03$ & $6.22 \mathrm{E}+04$ \\
\hline 5 & 1.82 & 6.03 & 12.0 & 1234 & 10 & 1 & $1.24 \mathrm{E}+04$ & $1.24 \mathrm{E}+05$ \\
\hline 5 & 1.82 & 6.03 & 12.0 & 1234 & 10 & 2 & $2.49 \mathrm{E}+04$ & $2.49 \mathrm{E}+05$ \\
\hline 8 & 1.82 & 6.03 & 12.0 & 1975 & 17 & 0.5 & $9.96 \mathrm{E}+03$ & $9.96 \mathrm{E}+04$ \\
\hline 8 & 1.82 & 6.03 & 12.0 & 1975 & 17 & 1 & $1.99 \mathrm{E}+04$ & $1.99 \mathrm{E}+05$ \\
\hline 8 & 1.82 & 6.03 & 12.0 & 1975 & 17 & 2 & $3.98 \mathrm{E}+04$ & $3.98 \mathrm{E}+05$ \\
\hline 11 & 1.82 & 6.03 & 12.0 & 2715 & 23 & 0.5 & $1.37 \mathrm{E}+04$ & $1.37 \mathrm{E}+05$ \\
\hline 11 & 1.82 & 6.03 & 12.0 & 2715 & 23 & 1 & $2.74 E+04$ & $2.74 \mathrm{E}+05$ \\
\hline 11 & 1.82 & 6.03 & 12.0 & 2715 & 23 & 2 & $5.48 E+04$ & $5.48 \mathrm{E}+05$ \\
\hline 5 & 2.0 & 6.03 & 12.0 & 1356 & 11 & 0.5 & $6.84 \mathrm{E}+03$ & $6.84 \mathrm{E}+04$ \\
\hline 5 & 2.0 & 6.03 & 12.0 & 1356 & 11 & 1 & $1.37 \mathrm{E}+04$ & $1.37 \mathrm{E}+05$ \\
\hline 5 & 2.0 & 6.03 & 12.0 & 1356 & 11 & 2 & $2.74 \mathrm{E}+04$ & $2.74 \mathrm{E}+05$ \\
\hline 8 & 2.0 & 6.03 & 12.0 & 2170 & 18 & 0.5 & $1.09 \mathrm{E}+04$ & $1.09 \mathrm{E}+05$ \\
\hline 8 & 2.0 & 6.03 & 12.0 & 2170 & 18 & 1 & $2.19 \mathrm{E}+04$ & $2.19 \mathrm{E}+05$ \\
\hline 8 & 2.0 & 6.03 & 12.0 & 2170 & 18 & 2 & $4.38 \mathrm{E}+04$ & $4.38 \mathrm{E}+05$ \\
\hline 11 & 2.0 & 6.03 & 12.0 & 2984 & 25 & 0.5 & $1.50 \mathrm{E}+04$ & $1.50 \mathrm{E}+05$ \\
\hline 11 & 2.0 & 6.03 & 12.0 & 2984 & 25 & 1 & $3.01 \mathrm{E}+04$ & $3.01 \mathrm{E}+05$ \\
\hline 11 & 2.0 & 6.03 & 12.0 & 2984 & 25 & 2 & $6.02 \mathrm{E}+04$ & $6.02 \mathrm{E}+05$ \\
\hline 5 & 2.2 & 6.03 & 12.0 & 1492 & 13 & 0.5 & $7.52 \mathrm{E}+03$ & $7.52 \mathrm{E}+04$ \\
\hline 5 & 2.2 & 6.03 & 12.0 & 1492 & 13 & 1 & $1.50 \mathrm{E}+04$ & $1.50 \mathrm{E}+05$ \\
\hline 5 & 2.2 & 6.03 & 12.0 & 1492 & 13 & 2 & $3.01 \mathrm{E}+04$ & $3.01 \mathrm{E}+05$ \\
\hline 8 & 2.2 & 6.03 & 12.0 & 2387 & 20 & 0.5 & $1.20 \mathrm{E}+04$ & $1.20 \mathrm{E}+05$ \\
\hline 8 & 2.2 & 6.03 & 12.0 & 2387 & 20 & 1 & $2.41 \mathrm{E}+04$ & $2.41 \mathrm{E}+05$ \\
\hline 8 & 2.2 & 6.03 & 12.0 & 2387 & 20 & 2 & $4.81 E+04$ & $4.81 E+05$ \\
\hline 11 & 2.2 & 6.03 & 12.0 & 3282 & 28 & 0.5 & $1.65 \mathrm{E}+04$ & $1.65 \mathrm{E}+05$ \\
\hline 11 & 2.2 & 6.03 & 12.0 & 3282 & 28 & 1 & $3.31 E+04$ & $3.31 E+05$ \\
\hline 11 & 2.2 & 6.03 & 12.0 & 3282 & 28 & 2 & $6.62 \mathrm{E}+04$ & $6.62 \mathrm{E}+05$ \\
\hline 5 & 2.2 & 9 & 18 & 1326 & 12 & 0.5 & $6.69 \mathrm{E}+03$ & $6.69 \mathrm{E}+04$ \\
\hline 5 & 2.2 & 9 & 18 & 1326 & 12 & 1 & $1.34 \mathrm{E}+04$ & $1.34 \mathrm{E}+05$ \\
\hline 5 & 2.2 & 9 & 18 & 1326 & 12 & 2 & $2.68 \mathrm{E}+04$ & $2.68 \mathrm{E}+05$ \\
\hline 8 & 2.2 & 9 & 18 & 2122 & 18 & 0.5 & $1.07 \mathrm{E}+04$ & $1.07 \mathrm{E}+05$ \\
\hline 8 & 2.2 & 9 & 18 & 2122 & 18 & 1 & $2.14 \mathrm{E}+04$ & $2.14 E+05$ \\
\hline 8 & 2.2 & 9 & 18 & 2122 & 18 & 2 & $4.28 \mathrm{E}+04$ & $4.28 \mathrm{E}+05$ \\
\hline 11 & 2.2 & 9 & 18 & 2918 & 25 & 0.5 & $1.47 \mathrm{E}+04$ & $1.47 \mathrm{E}+05$ \\
\hline 11 & 2.2 & 9 & 18 & 2918 & 25 & 1 & $2.94 \mathrm{E}+04$ & $2.94 \mathrm{E}+05$ \\
\hline 11 & 2.2 & 9 & 18 & 2918 & 25 & 2 & $5.89 \mathrm{E}+04$ & $5.89 \mathrm{E}+05$ \\
\hline
\end{tabular}


Table III-2. (contd)

\begin{tabular}{ccccccccc}
\hline $\begin{array}{c}\text { Path } \\
(\mu \mathrm{m})\end{array}$ & $\begin{array}{c}\text { Density } \\
\left(\mathrm{g} / \mathrm{cm}^{3}\right)\end{array}$ & $\begin{array}{c}\text { Atomic } \\
\text { Number }\end{array}$ & $\begin{array}{c}\text { Atomic } \\
\text { Mass }\end{array}$ & $\begin{array}{c}\alpha \text { dose rate } \\
(\mathrm{rad} / \mathrm{h})\end{array}$ & $\begin{array}{c}\beta \text { dose rate } \\
(\mathrm{rad} / \mathrm{h})\end{array}$ & $\begin{array}{c}\text { Contact } \\
\text { Time }(\mathrm{h})\end{array}$ & $\begin{array}{c}10 \text { Cycle } \\
\text { Dose }(\mathrm{rad})\end{array}$ & $\begin{array}{c}100 \text { Cycle } \\
\text { Dose (rad) }\end{array}$ \\
\hline & & & & & & & & \\
5 & 2.5 & 9 & 18 & 1507 & 13 & 0.5 & $7.60 \mathrm{E}+03$ & $7.60 \mathrm{E}+04$ \\
5 & 2.5 & 9 & 18 & 1507 & 13 & 1 & $1.52 \mathrm{E}+04$ & $1.52 \mathrm{E}+05$ \\
5 & 2.5 & 9 & 18 & 1507 & 13 & 2 & $3.04 \mathrm{E}+04$ & $3.04 \mathrm{E}+05$ \\
8 & 2.5 & 9 & 18 & 2411 & 21 & 0.5 & $1 . \hat{2} 2 \mathrm{E}+04$ & $1.22 \mathrm{E}+05$ \\
8 & 2.5 & 9 & 18 & 2411 & 21 & 1 & $2.43 \mathrm{E}+04$ & $2.43 \mathrm{E}+05$ \\
8 & 2.5 & 9 & 18 & 2411 & 21 & 2 & $4.86 \mathrm{E}+04$ & $4.86 \mathrm{E}+05$ \\
11 & 2.5 & 9 & 18 & 3315 & 29 & 0.5 & $1.67 \mathrm{E}+04$ & $1.67 \mathrm{E}+05$ \\
11 & 2.5 & 9 & 18 & 3315 & 29 & 1 & $3.34 \mathrm{E}+04$ & $3.34 \mathrm{E}+05$ \\
11 & 2.5 & 9 & 18 & 3315 & 29 & 2 & $6.69 \mathrm{E}+04$ & $6.69 \mathrm{E}+05$ \\
\hline 5 & 2.7 & 9 & 18 & 1628 & 14 & 0.5 & $8.21 \mathrm{E}+03$ & $8.21 \mathrm{E}+04$ \\
5 & 2.7 & 9 & 18 & 1628 & 14 & 1 & $1.64 \mathrm{E}+04$ & $1.64 \mathrm{E}+05$ \\
5 & 2.7 & 9 & 18 & 1628 & 14 & 2 & $3.28 \mathrm{E}+04$ & $3.28 \mathrm{E}+05$ \\
8 & 2.7 & 9 & 18 & 2604 & 23 & 0.5 & $1.31 \mathrm{E}+04$ & $1.31 \mathrm{E}+05$ \\
8 & 2.7 & 9 & 18 & 2604 & 23 & 1 & $2.63 \mathrm{E}+04$ & $2.63 \mathrm{E}+05$ \\
8 & 2.7 & 9 & 18 & 2604 & 23 & 2 & $5.25 \mathrm{E}+04$ & $5.25 \mathrm{E}+05$ \\
11 & 2.7 & 9 & 18 & 3581 & 31 & 0.5 & $1.81 \mathrm{E}+04$ & $1.81 \mathrm{E}+05$ \\
11 & 2.7 & 9 & 18 & 3581 & 31 & 1 & $3.61 \mathrm{E}+04$ & $3.61 \mathrm{E}+05$ \\
11 & 2.7 & 9 & 18 & 3581 & 31 & 2 & $7.22 \mathrm{E}+04$ & $7.22 \mathrm{E}+05$ \\
\hline & & & & & & & & \\
& & 9 & & & & &
\end{tabular}

The energy deposited in the magnetic particles was determined by using Eq. III-3 to calculate the loss in $\beta$-particle kinetic energy per unit path length and approximating the energy deposited by $\gamma$-rays using an attenuation coefficient (Eq. III-4). The absorption and attenuation coefficients for the magnetic particles are approximately equal. Equation III-4 is an expression for the intensity of $\gamma$-rays absorbed in a target compared to the initial intensity $I_{0}$.

where

$$
\mathrm{I}_{\mathrm{a}}=\mathrm{I}_{0}(1-(\exp (-\mu \mathrm{x}))
$$

$$
\begin{aligned}
I_{0} & =\text { initial intensity of } \gamma \text {-rays, photons } / \mathrm{cm}^{2} \\
I_{a} & =\text { intensity of } \gamma \text {-rays absorbed by the target, photons } / \mathrm{cm}^{2} \\
\mu & =\mu_{\mathrm{a}} \rho=\text { linear absorption coefficient of } 660-\mathrm{keV} \gamma \text {-rays, } \mathrm{cm}^{-1} \\
\mu_{\mathrm{a}} & =\text { absorption coefficient for } 660-\mathrm{keV} \gamma \text {-rays, } \mathrm{cm}^{2} / \mathrm{g} \\
\rho & =\text { density of target, } \mathrm{g} / \mathrm{cm}^{3} \\
\mathrm{x} & =\text { path length of } \gamma \text {-ray in target, } \mathrm{cm}
\end{aligned}
$$

The absorption coefficient $\mu_{\mathrm{a}}$ depends upon the atomic number of the target absorber and the energy of the incident $\gamma$-ray. The variation in $\mu_{a}$ for targets ranging from carbon to copper is 
minor for $660-\mathrm{keV} \gamma$-rays. The magnetic particles fall within this target range, in which $\mu_{\mathrm{a}}$ is $0.08 \mathrm{~cm}^{2} / \mathrm{g}$ [CEMBER].

The ratio $I_{a} / I_{0}$ gives the fraction of $\gamma$-rays absorbed when passing through the absorber. It was assumed that any $\gamma$-ray that interacts with the particles deposits all its energy. Since the magnetic particles are relatively transparent to $660-\mathrm{keV}$ photons, the $\gamma$-rays deposit much less energy than do the $\beta$-particles. The $\gamma$-ray dose rate $\left(\dot{D}_{\gamma}\right)$ was computed from the product of the fraction of $\gamma$-rays absorbed in the target, the specific activity of ${ }^{137} \mathrm{Cs}$, the energy of the absorbed $\gamma$-ray, the concentration of particles in solution, and numerical conversion factors (see Eq. III-5).

$$
\dot{\mathrm{D}}_{\gamma}\left(\frac{\mathrm{rad}}{\mathrm{h}}\right)=\frac{\mathrm{I}_{\mathrm{a}}}{\mathrm{I}_{0}}\left(\frac{1}{2}\right)\left(7.70 \times 10^{13} \frac{\mathrm{dis}}{\mathrm{h} \cdot \mathrm{L}}\right)\left(\frac{1 \mathrm{~L}}{1 \mathrm{~g}}\right)\left(\frac{0.662 \mathrm{MeV}}{\mathrm{dis}}\right)\left(\frac{1.602 \times 10^{-6} \mathrm{erg}}{\mathrm{MeV}}\right)\left(\frac{1 \mathrm{rad}}{100 \mathrm{erg} / \mathrm{g}}\right)
$$

The electron density of the target must be known to compute the absorbed dose. Since Bradtec was unable to provide detailed information regarding particle density, average atomic number, and average atomic mass, several values within a reasonable range were used to compute estimates. Since the dose absorbed depends on the path length of the ionizing radiation through the particle, large particles receive a larger dose than small particles. The assumptions used when calculating doses are as follows:

1. Half of the $\beta$-particles are emitted into solution, resulting in no energy deposition to the magnetic particles.

2. Each $\beta$-particle and $\gamma$-ray interacts with only one magnetic particle.

3. Only half of the $\gamma$-rays interact with magnetic particles.

4. The energy deposited by $\gamma$-rays depends solely on the absorption of the $662-\mathrm{keV}$ $\gamma$-ray from ${ }^{137} \mathrm{Ba}$.

5. All cesium in the supernatant solutior is absorbed onto particles.

6. One gram of particles is used per liter of solution.

7. The concentration of ${ }^{137} \mathrm{Cs}$ in the supernatant is $4.88 \times 10^{-5} \mathrm{~mol} / \mathrm{L}$.

Using these assumptions and the equations above for energy deposition as a function of path length, dose estimates to the magnetic particles are computed and presented in Table III-3.

The wide ranges of particle density, atomic number, and atomic weight are used due to the varying compositions of the particles. The particles composed of organic ion-exchange resin material (e.g., resorcinol, formaldehyde) possess attributes similar to the top of Table III-3 while an inorganic ion-exchange resin material (e.g., crystalline silicotitanate) resembles the particles described in the bottom of Table III-3. 
Table III-3. Dose Absorbed by Cesium Specific Magnetic Particles

\begin{tabular}{|c|c|c|c|c|c|c|c|c|}
\hline $\begin{array}{l}\text { Path } \\
\text { (um) }\end{array}$ & $\begin{array}{l}\text { Density } \\
\text { (g/cm3) }\end{array}$ & $\begin{array}{c}\text { Atomic } \\
\text { Number }\end{array}$ & $\begin{array}{c}\text { Atomic } \\
\text { Mass }\end{array}$ & $\begin{array}{c}\beta \text { dose rate } \\
(\mathrm{rad} / \mathrm{h})\end{array}$ & $\begin{array}{c}\gamma \text { dose rate } \\
(\mathrm{rad} / \mathrm{h})\end{array}$ & $\begin{array}{l}\text { Contact } \\
\text { Time (h) }\end{array}$ & $\begin{array}{c}10 \text { Cycle } \\
\text { Dose (rad) }\end{array}$ & $\begin{array}{l}100 \text { Cycle } \\
\text { Dose (rad) }\end{array}$ \\
\hline 10 & 1.8 & 6 & 12.3 & 3025 & 119 & 1 & $3.14 \mathrm{E}+04$ & $3.14 E+05$ \\
\hline 20 & 1.8 & 6 & 12.3 & 6049 & 238 & 1 & $6.29 \mathrm{E}+04$ & $6.29 \mathrm{E}+05$ \\
\hline 40 & 1.8 & 6 & 12.3 & 12099 & 476 & 1 & $1.26 \mathrm{E}+05$ & $1.26 \mathrm{E}+06$ \\
\hline 60 & 1.8 & 6 & 12.3 & 18148 & 713 & 1 & $1.89 E+05$ & $1.89 \mathrm{E}+06$ \\
\hline 100 & 1.8 & 6 & 12.3 & 30247 & 1188 & 1 & $3.14 E+05$ & $3.14 \mathrm{E}+06$ \\
\hline 10 & 2.0 & 7 & 14 & 3326 & 131 & $\overline{1}$ & $3.46 \mathrm{E}+04$ & $3.46 \mathrm{E}+05$ \\
\hline 20 & 2.0 & 7 & 14 & 6651 & 261 & 1 & $6.91 \mathrm{E}+04$ & $6.91 E+05$ \\
\hline 40 & 2.0 & 7 & 14 & 13302 & 523 & 1 & $1.38 \mathrm{E}+05$ & $1.38 \mathrm{E}+06$ \\
\hline 60 & 2.0 & 7 & 14 & 19953 & 784 & 1 & $2.07 \mathrm{E}+05$ & $2.07 \mathrm{E}+06$ \\
\hline 100 & 2.0 & 7 & 14 & 33256 & 1306 & 1 & $3.46 \mathrm{E}+05$ & $3.46 \mathrm{E}+06$ \\
\hline 10 & 2.2 & 8 & 16 & 3595 & 144 & 1 & $3.74 \mathrm{E}+04$ & $3.74 \mathrm{E}+05$ \\
\hline 20 & 2.2 & 8 & 16 & 7189 & 287 & 1 & $7.48 \mathrm{E}+04$ & $7.48 \mathrm{E}+05$ \\
\hline 40 & 2.2 & 8 & 16 & 14379 & 575 & 1 & $1.50 \mathrm{E}+05$ & $1.50 \mathrm{E}+06$ \\
\hline 60 & 2.2 & 8 & 16 & 21568 & 862 & 1 & $2.24 E+05$ & $2.24 \mathrm{E}+06$ \\
\hline 100 & 2.2 & 8 & 16 & 35947 & 1436 & 1 & $3.74 \mathrm{E}+05$ & $3.74 E+06$ \\
\hline 10 & 2.5 & 9 & 18 & 4021 & 163 & 1 & $4.18 \mathrm{E}+04$ & $4.18 \mathrm{E}+05$ \\
\hline 20 & 2.5 & 9 & 18 & 8043 & 327 & 1 & $8.37 \mathrm{E}+04$ & $8.37 E+05$ \\
\hline 40 & 2.5 & 9 & 18 & 16086 & 653 & 1 & $1.67 \mathrm{E}+05$ & $1.67 \mathrm{E}+06$ \\
\hline 60 & 2.5 & 9 & 18 & 24128 & 980 & 1 & $2.51 \mathrm{E}+05$ & $2.51 \mathrm{E}+06$ \\
\hline 100 & 2.5 & 9 & 18 & 40214 & 1632 & 1 & $4.18 \mathrm{E}+05$ & $4.18 \mathrm{E}+06$ \\
\hline 10 & 2.7 & 10 & 20 & 4282 & 176 & 1 & $4.46 \mathrm{E}+04$ & $4.46 \mathrm{E}+05$ \\
\hline 20 & 2.7 & 10 & 20 & 8563 & 353 & 1 & $8.92 \mathrm{E}+04$ & $8.92 E+05$ \\
\hline 40 & 2.7 & 10 & 20 & 17127 & 705 & 1 & $1.78 E+05$ & $1.78 \mathrm{E}+06$ \\
\hline 60 & 2.7 & 10 & 20 & 25690 & 1058 & 1 & $2.67 \mathrm{E}+05$ & $2.67 \mathrm{E}+06$ \\
\hline 100 & 2.7 & 10 & 20 & 42817 & 1762 & 1 & $4.46 \mathrm{E}+05$ & $4.46 \mathrm{E}+06$ \\
\hline 10 & 2.5 & 12 & 24 & 3866 & 163 & 1 & $4.03 \mathrm{E}+04$ & $4.03 \mathrm{E}+05$ \\
\hline 20 & 2.5 & 12 & 24 & 7732 & 327 & 1 & $8.06 E+04$ & $8.06 \mathrm{E}+05$ \\
\hline 40 & 2.5 & 12 & 24 & 15465 & 653 & 1 & $1.61 \mathrm{E}+05$ & $1.61 \mathrm{E}+06$ \\
\hline 60 & 2.5 & 12 & 24 & 23197 & 980 & 1 & $2.42 \mathrm{E}+05$ & $2.42 \mathrm{E}+06$ \\
\hline 100 & 2.5 & 12 & 24 & 38662 & 1632 & 1 & $4.03 E+05$ & $4.03 E+06$ \\
\hline 10 & 2.7 & 14 & 28 & 4086 & 176 & 1 & $4.26 \mathrm{E}+04$ & $4.26 \mathrm{E}+05$ \\
\hline 20 & 2.7 & 14 & 28 & 8171 & 353 & 1 & $8.52 E+04$ & $8.52 E+05$ \\
\hline 40 & 2.7 & 14 & 28 & 16343 & 705 & 1 & $1.70 \mathrm{E}+05$ & $1.70 \mathrm{E}+06$ \\
\hline 60 & 2.7 & 14 & 28 & 24514 & 1058 & 1 & $2.56 \mathrm{E}+05$ & $2.56 \mathrm{E}+06$ \\
\hline 100 & 2.7 & 14 & 28 & 40857 & 1762 & 1 & $4.26 \mathrm{E}+05$ & $4.26 \mathrm{E}+06$ \\
\hline
\end{tabular}




\section{RADIOLYSIS OF MACS PARTICLES}

Radiolysis pertains to physical or chemical changes induced by the deposition of highenergy radiation in a material. Although these changes are often referred to as damage or degradation, synthesis also occurs in many organic systems. In the radiolysis of MACS particles, chemical reactions in the particles, in the suspension solutions, and at the particle/solution interface combine to change their extraction behavior.

\section{A. Irradiation Conditions}

All sample irradiations for this study were conducted with the ${ }^{60} \mathrm{Co} \gamma$-ray source in Building 200 at ANL. Dose rates to the particles ranged from $1.1 \times 10^{5}$ to $2.3 \times 10^{5} \mathrm{rad} / \mathrm{h}$ to minimize acid contact time and consequently limit the effect of acid hydrolysis on the irradiated particles. Appendices $\mathrm{B}$ and $\mathrm{C}$ contain a description of the $\gamma$-ray irradiation facility and the experimental dosimetry techniques used.

The particles were suspended in solution and sealed in quartz tubes before irradiation. During irradiation, the tubes were rotated end over end at $5-10 \mathrm{rpm}$ to thoroughly mix the particles with the suspension solution. After irradiation, the samples were promptly opened, and the particles were separated from the suspension solutions. The procedure used to fill, seal, and open the samples is described in Appendix E. The irradiated particles were dried overnight on a watch glass, and samples were placed in culture tubes to complete measurement of the partitioning for americium, $\mathrm{K}_{\mathrm{d}}(\mathrm{Am})$. All partitioning experiments used $2 \mathrm{M} \mathrm{HNO}_{3}$ spiked with ${ }^{241} \mathrm{Am}$ at $25^{\circ} \mathrm{C}$. The procedure used to measure $\mathrm{K}_{\mathrm{d}}(\mathrm{Am})$ is discussed in Appendix $\mathrm{F}$.

\section{B. Relation between Dose and Cycles}

The relation between dose and the number of contact cycles is based upon the assumptions for loading the particles with TRU and the time required to complete a contact cycle. The assumptions used when computing theoretical dose rates are stated in the previous chapter. Assuming a one-hour cycle time during processing, the doses delivered to most of the particles correspond to 10,100 , and 2000 equivalent cycles of use.

The theoretical dose calculations in Chapter III consider a range of particle compositions. A more narrow array of dose rates is presented in Table IV-1. The dose rate calculations assume that the path length of the $\alpha$ - and $\beta$-particles is $8 \mu \mathrm{m}$ and the contact time for each cycle in the MACS process for TRU removal is one hour.

Table IV-1. Theoretical Dose Rates for Most Probable Particle Compositions $^{\mathrm{a}}$

\begin{tabular}{cccccc}
\hline $\begin{array}{c}\text { Density } \\
\left(\mathrm{g} / \mathrm{cm}^{3}\right)\end{array}$ & $\begin{array}{c}\text { Atomic } \\
\text { Number }\end{array}$ & $\begin{array}{c}\text { Atomic } \\
\text { Mass }\end{array}$ & $\begin{array}{c}\text { Dose Rate } \\
(\mathrm{rad} / \mathrm{h})\end{array}$ & $\begin{array}{c}10 \text { Cycle } \\
\text { Dose }(\mathrm{rad})\end{array}$ & $\begin{array}{c}\text { 100 Cycle } \\
\text { Dose }(\mathrm{rad})\end{array}$ \\
\hline 1.82 & 6.03 & 12.0 & 1991 & $1.99 \mathrm{E}+04$ & $1.99 \mathrm{E}+05$ \\
2.0 & 6.03 & 12.0 & 2188 & $2.19 \mathrm{E}+04$ & $2.19 \mathrm{E}+05$ \\
2.2 & 6.03 & 12.0 & 2407 & $2.41 \mathrm{E}+04$ & $2.41 \mathrm{E}+05$ \\
2.2 & 9 & 18 & 2140 & $2.14 \mathrm{E}+04$ & $2.14 \mathrm{E}+05$ \\
2.5 & 9 & 18 & 2432 & $2.43 \mathrm{E}+04$ & $2.43 \mathrm{E}+05$ \\
2.7 & 9 & 18 & 2627 & $2.63 \mathrm{E}+04$ & $2.63 \mathrm{E}+05$ \\
\hline
\end{tabular}

assumptions include an $8-\mu \mathrm{m}$ path length and contact cycle time of one hour for TRU removal. 
The doses delivered to the particles can be expressed in terms of equivalent extraction. cycles (Table IV-2). A realistic dose rate when processing PFP waste would be from 2100 to $2400 \mathrm{rad} / \mathrm{h}$.

\section{C. $\quad \underline{\text { Results }}$}

The radiolysis effects on the MACS particles were documented by monitoring changes in $\mathrm{K}_{\mathrm{d}}(\mathrm{Am})$ with variations in radiation dose and suspension solution, noting changes in the physical appearances of the particles and suspension solutions, visually inspecting changes in electron micrographs of the particles, and observing the crystallization of charcoal-polymer particle cores. Changes in particle coating techniques prevent a reliable comparison of different coatings. Since the coating procedure improved during the course of the irradiations, particles used in the later irradiations generally had higher initial partitioning coefficients, making changes easier to observe. The procedures for collecting the particles and completing the $K_{d}(\mathrm{Am})$ measurements are found in Appendices $\mathrm{E}$ and F, respectively.

\section{Change in $\mathbf{K}_{\mathrm{d}}(\mathrm{Am})$ with Radiation Dose and Suspension Solution}

The partitioning coefficient for americium decreased as the radiation dose increased. The rate of decline varied with the suspension solution and the particie coating. In general, the particles that received low $\left(1.1 \times 10^{4}-2.3 \times 10^{4} \mathrm{rad}\right)$ and medium $\left(1.1 \times 10^{5}\right.$. $2.3 \times 10^{5} \mathrm{rad}$ ) doses retained greater extraction capability than those that received the highest dose (2.4-5 Mrad). Nonhomogeneous particle coatings complicate the comparison of partition coefficients for different doses of the same particle coating as well as between different coatings. Based upon the scatter in $K_{d}(A m)$ values measured for unirradiated particles of the same coating batches, it is reasonable to assume an uncertainty on the order of $10-20 \%$ for the $K_{d}(A m)$ values of the irradiated particles.

With such large uncertainties in $K_{d}(A m)$ values, an accurate graphical representation should depict bands of data rather than points and lines. Although accurate, the graph would be unreadable. Figures IV-1, IV-2, and IV-3 depict the decrease in $\mathrm{K}_{\mathrm{d}}(\mathrm{Am})$ with the increase in dose for coatings with $1.2 \mathrm{M}$ CMPO/TBP, 1.2M CMPO/TBP, and 1.36M CMPO/TBP, respectively. The rate of decline is different for different suspension solutions, but the fuzzy nature of the data limits distinctions between suspension solutions. No clear trend between the concentration of $\mathrm{HNO}_{3}$ in the suspension solutions and the rate of decline in $\mathrm{K}_{\mathrm{d}}(\mathrm{Am})$ was established. The data could not be fit consistently with a linear, logarithmic, or exponential curve.

Table IV-2. Relation between Experimental Doses and Equivalent Contact Cycles for TRU Removal

\begin{tabular}{ccccccc}
\hline $\begin{array}{c}\text { Theoretical } \\
\text { Dose } \\
\text { Rate }\end{array}$ & $\begin{array}{c}\text { Equivalent } \\
\text { Cycles } \\
\text { for Dose }\end{array}$ & $\begin{array}{c}\text { Equivalent } \\
\text { Cycles } \\
\text { for Dose }\end{array}$ & $\begin{array}{c}\text { Equivalent } \\
\text { Cycles } \\
\text { for Dose }\end{array}$ & $\begin{array}{c}\text { Equivalent } \\
\text { Cycles } \\
\text { for Dose }\end{array}$ & $\begin{array}{c}\text { Equivalent } \\
\text { Cycles } \\
\text { for Dose }\end{array}$ & $\begin{array}{c}\text { Equivalent } \\
\text { Cycles } \\
\text { for Dose }\end{array}$ \\
\hline 1991 & 6 & 12 & 55 & $\mathrm{rad}$ & $2.3 \times 10^{4} \mathrm{rad}$ & $1.1 \times 10^{5} \mathrm{rad}$ \\
$2.3 \times 10^{5} \mathrm{rad}$ & $2.5 \times 10^{6} \mathrm{rad}$ & $5.0 \times 10^{6} \mathrm{rad}$ \\
2188 & 5 & 11 & 50 & 116 & 1255 & 2511 \\
2407 & 5 & 10 & 46 & 96 & 1142 & 2285 \\
2140 & 5 & 11 & 51 & 107 & 1168 & 2336 \\
2432 & 5 & 9 & 45 & 95 & 1028 & 2056 \\
2627 & 4 & 9 & 42 & 88 & 952 & 1904 \\
\hline
\end{tabular}




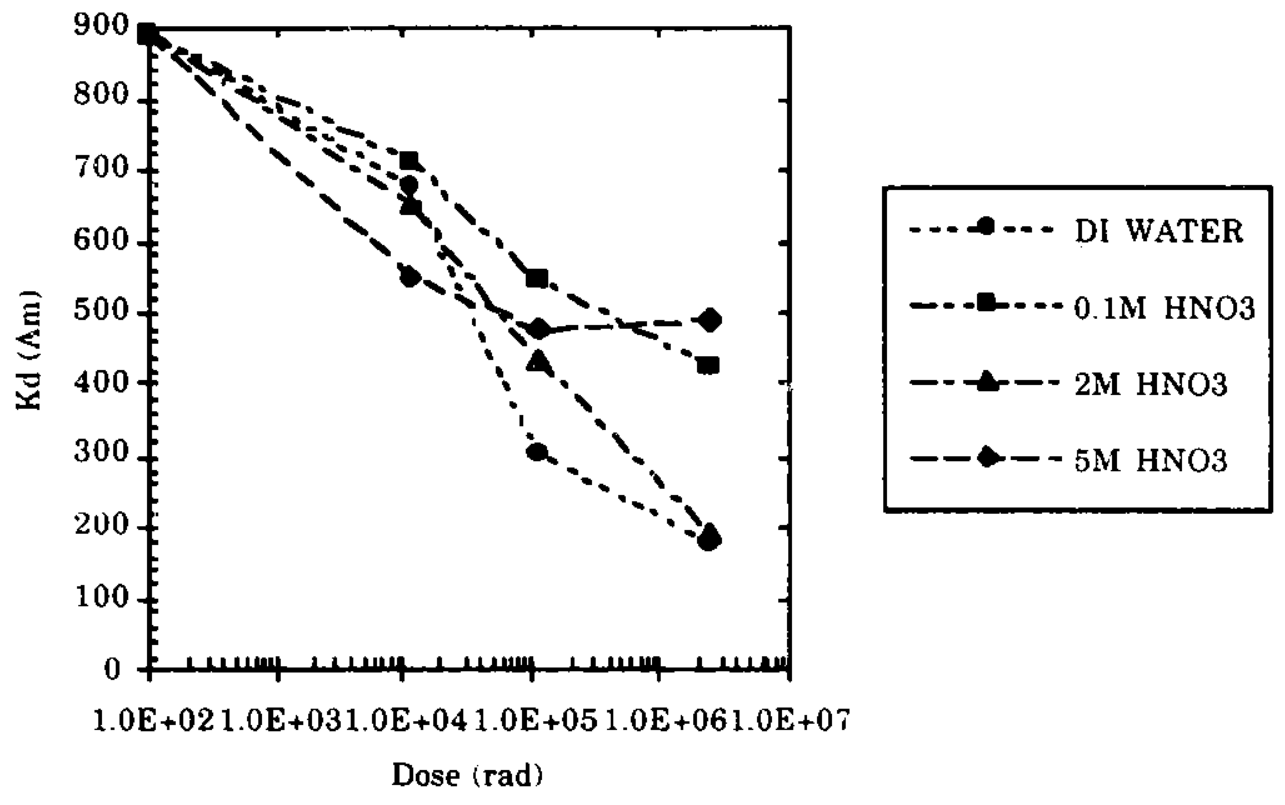

Fig. IV-1. $\quad \mathrm{K}_{\mathrm{d}}(\mathrm{Am})$ vs. Radiation Dose for MDZ-1089-22A Particles Coated with 1.2M CMPO/TBP. The zero dose partitioning coefficient is actually plotted at $100 \mathrm{rad}$ due to the $\log$ scale. The series labels refer to suspension solution during irradiation.

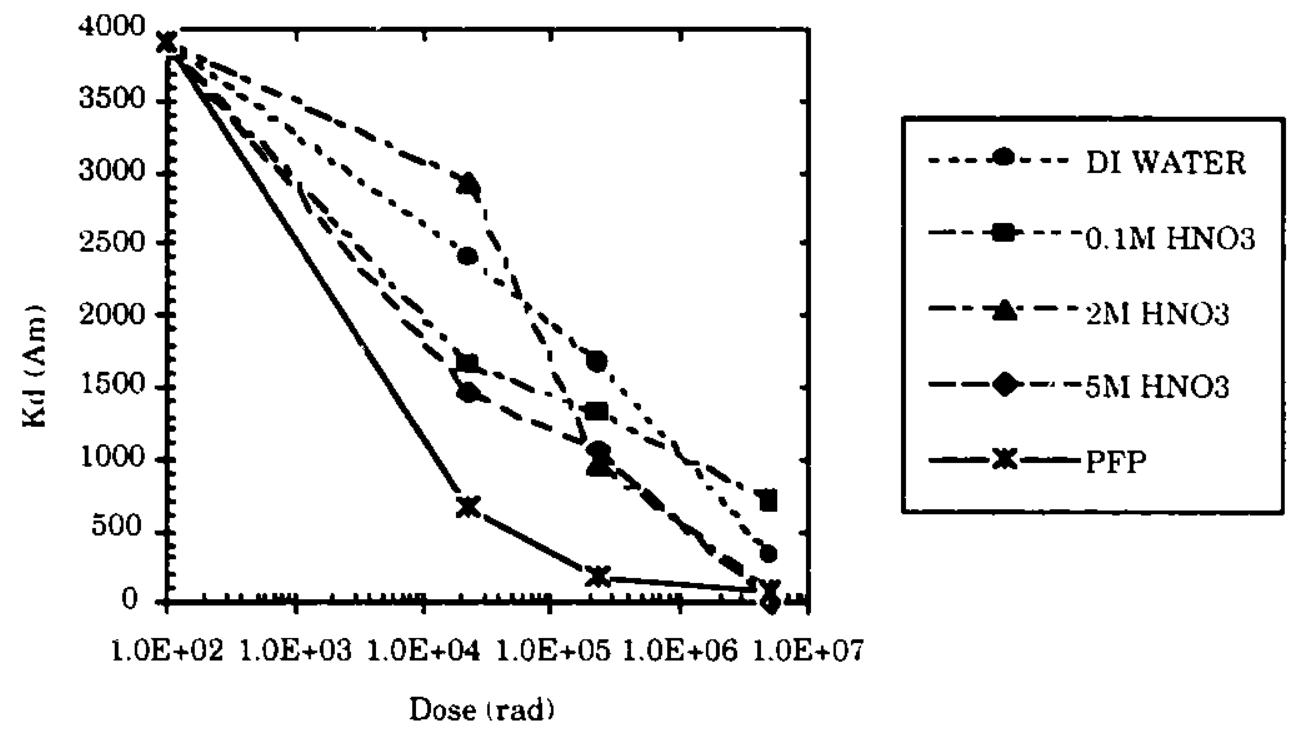

Fig. IV-2. $\quad K_{d}(\mathrm{Am})$ vs. Radiation Dose for MDZ-1089-58A Particles Coated with 1.2M CMPO/TBP. The zero dose partitioning coefficient is actually plotted at 100 rad due to the log scale. The series labels refer to suspension solution during irradiation. 


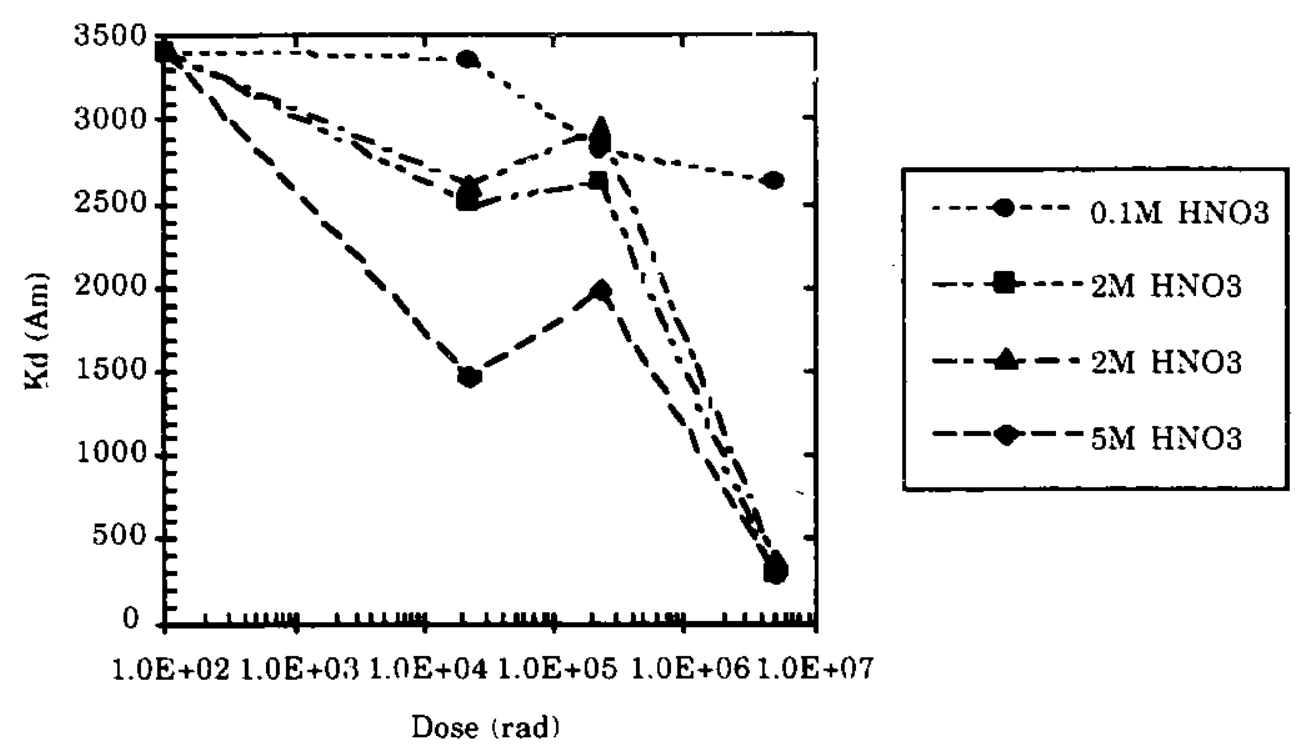

Fig. IV-3. $\quad K_{d}(A m)$ vs. Radiation Dose for MDZ-1089-60A Particles Coated with $1.36 \underline{\mathrm{M}}$ CMPO/TBP. The zero dose partitioning coefficient is actually plotted at 100 rad due to the $\log$ scale. The series labels refer to suspension solution during irradiation.

The strongest acid contact solutions had the largest initial drop in partitioning coefficient for all the samples irradiated. Figures IV-1 through IV-3 show that the particles irradiated in $5 \mathrm{M} \mathrm{HNO}_{3}$ suffered the largest initial drop in $\mathrm{K}_{\mathrm{d}}(\mathrm{Am})$ for simple acid contact solutions. The PFP waste simulant is also strongly acidic (1.4M $\mathrm{HNO}_{3}$ and $\left.0.1 \mathrm{M} \mathrm{HF}\right)$ in addition to containing cations such as $\mathrm{Fe}^{3+}$ and $\mathrm{Cr}^{3+}$ which compete with $\mathrm{Am}^{3+}$ for binding sites on the CMPO. After the initial drop in $\mathrm{K}_{\mathrm{d}}(\mathrm{Am})$ for the particles coated with $1.2 \mathrm{M}$ CMPO/TBP and suspended in $5 \underline{\mathrm{M}} \mathrm{HNO}_{3}$ (MDZ-1089-22A), the partitioning coefficient was nearly constant for the remaining doses (Fig. IV-2).

The particles suspended in $0.1 \mathrm{M} \mathrm{HNO}_{3}$ appeared to retain greater extraction capability for the highest radiation doses than those suspended in other solutions (Figs. IV-1 through IV-3). The particles irradiated in deionized water demonstrated losses in separation efficiency similar to those of the stronger acids (Fig. IV-2).

The radiolysis of the suspension solutions produces radicals that can recombine in solution or attack the particles and their coatings. The nitrate anion scavenges some of the free $\mathrm{H}^{+}$produced during irradiation. When the $\mathrm{HNO}_{3}$ concentration was low, radiolytically produced radicals were scavenged, suppressing their attack on the particles. The stronger $\mathrm{HNO}_{3}$ concentrations may have improved radical reduction, but damage from the high $\mathrm{H}^{+}$concentration may have outweighed any advantage.

\section{Variation in $\mathrm{K}_{\mathrm{d}}(\mathrm{Am})$ with CMPO/TBP Concentration}

Inconsistent particle coatings made a comparison of partition coefficient with dose and CMPO/TBP concentration difficult. Since no relation between CMPO/TBP concentration and $\mathrm{K}_{\mathrm{d}}(\mathrm{Am})$ was observed for unirradiated particles, none was expected after irradiation. Figures IV-4 through IV-6 plot the change in $\mathrm{K}_{d}(\mathrm{Am})$ versus dose for specific suspension solutions and several series of particle coatings. 


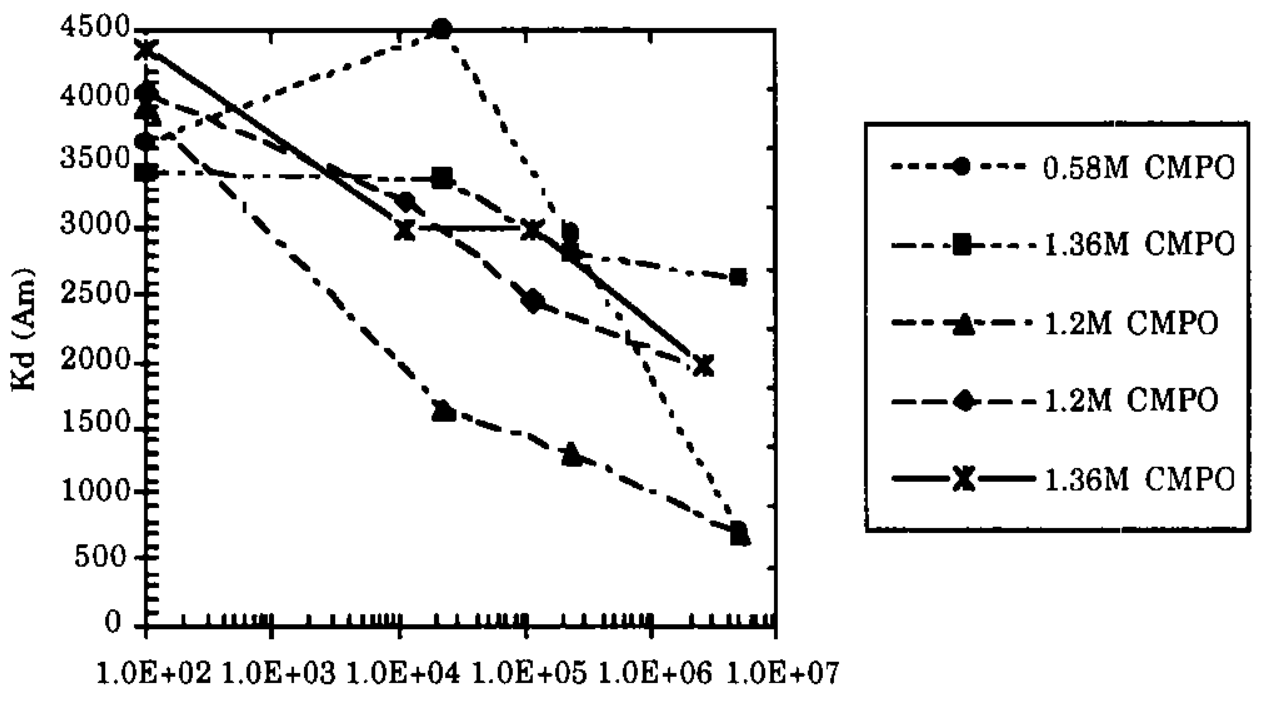

Dose (rad)

Fig. IV-4. $\quad \mathrm{K}_{\mathrm{d}}(\mathrm{Am})$ vs. Radiation Dose for Particles Suspended in $0.1 \underline{\mathrm{M}} \mathrm{HNO}_{3}$ during Irradiation. The zero dose partitioning coefficient is actually plotted at $100 \mathrm{rad}$ due to the log scale. The series labels refer to the concentration of CMPO/TBP in the coatings.

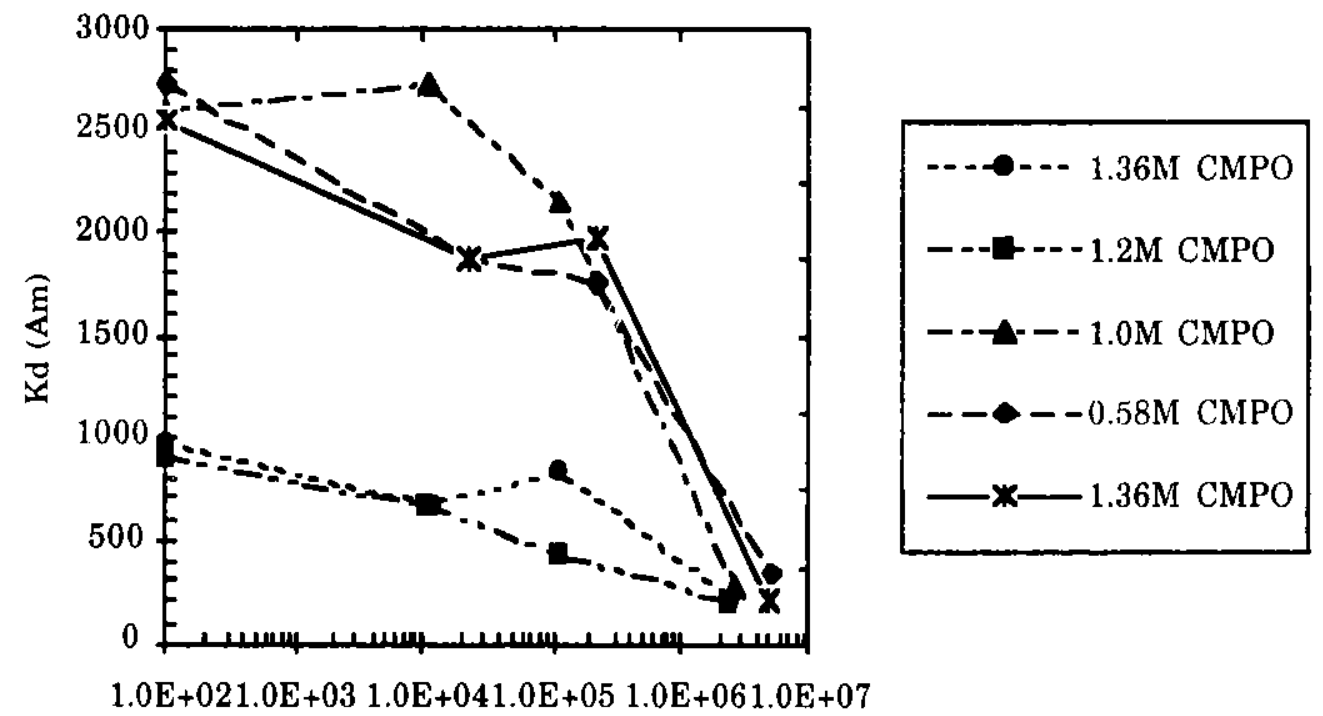

Dose (rad)

Fig. IV-5. $\quad K_{d}(A m)$ vs. Radiation Dose for Particles Suspended in $2 \mathrm{M} \mathrm{HNO}_{3}$ during Irradiation. The zero dose partitioning coefficient is actually plotted at $100 \mathrm{rad}$ due to the log scale. The series labels refer to the concentration of CMPO/TBP in the coatings. 


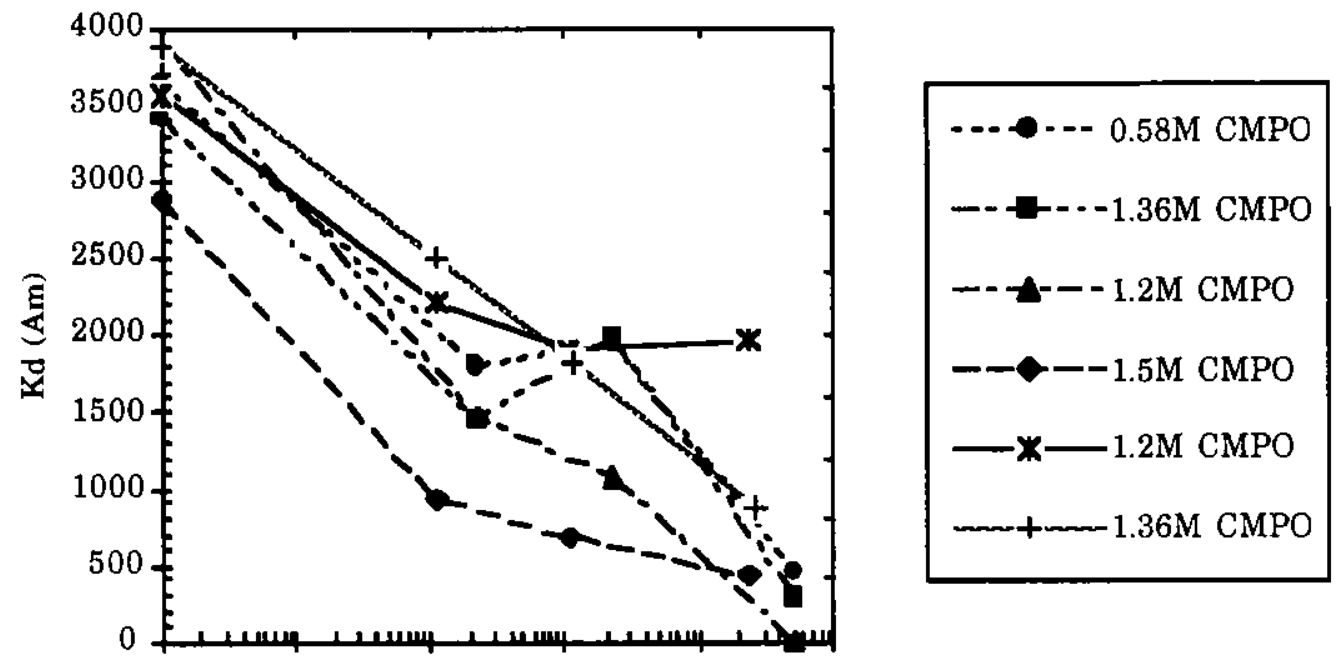

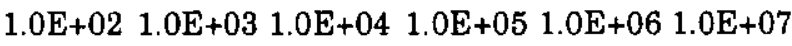

Dose (rad)

Fig. IV-6. $\quad \mathrm{K}_{\mathrm{d}}(\mathrm{Am})$ vs. Radiation Dose for Particles Suspended in $5 \underline{\mathrm{M}} \mathrm{HNO}_{3}$ during Irradiation. The zero dose partitioning coefficient is actually plotted at $100 \mathrm{rad}$ due to the log scale. The series labels refer to the concentration of CMPO/TBP in the coatings.

\section{Physical Changes in Suspension Solutions}

The physical appearance of the suspension solutions varied with dose. The irradiated acid solutions became yellowish. The intensity of the color increased with dose and $\mathrm{HNO}_{3}$ concentration. The stronger acids turned a deeper yellow color. The deionized water solutions did not turn yellow: They became opaque and turned white to light gray to medium gray as dose increased. The opaque solutions separated from the particles eventually cleared after several weeks, and a fine black precipitate formed on the bottom of the shell vials. The precipitate appeared to be nonmagnetized charcoal fragments.

\section{Physical Changes in Particles}

The particles appeared to embrittle and to disperse less as the dose increased. Increasing the sonication time from 15 minutes to 30 minutes did not improve dispersion of the particles.

The quartz irradiation vials acquired a fine coating of particles during all irradiations. The thickness of the coating increased as dose and $\mathrm{HNO}_{3}$ concentration increased. The quartz vials also acquired deposits of a viscous, yellow aqueous-immiscible liquid. The thickest deposits occurred in rings at the top of the suspension when the major axis of the was vertical. The position of the deposits suggests that the water-immiscible phase produced during irradiation is less dense than water.

\section{Electron Micrographs of Particles Irradiated in PFP Waste Simul.nnt}

Electron micrograghs of irradiated and unirradiated particles suspended in PFP waste simulant were produced by C. Bradley and N. Brown of the Nuclear Waste Technology 
Section in the Chemical Technology Division at ANL. The samples were prepared for transmission electron microscopy (TEM) by ultramicrotomy to a nominal thickness of approximately $1000 \mathrm{~nm}$. Semiquantitative elemental compositions were obtained by electron diffraction spectroscopy (EDS). Quantitative elemental analysis is impossible at this scale due to nonhomogeneous standard reference materials.

An uncoated sample of a MACS particle core is shown in Fig. IV-7a. The charcoal-polymer material appears light gray in the TEM micrograph. The small dark regions were identified as magnetite using EDS. The magnetite was not encapsulated in the charcoal-polymer material. Electron diffraction patterns indicated that the magnetite was a crystalline material, but that the charcoal-polymer possessed only short-range order.

Figures IV-7b, IV-7c, and IV-7d are TEM micrographs of MACS particles that were irradiated with $\gamma$-ray doses of $1.2 \times 10^{4}, 1.2 \times 10^{5}$, and $2.6 \times 10^{6} \mathrm{rad}$, respectively. The particles were coated with 1.36 $\mathrm{M}$ CMPO/TBP and suspended in PFP waste simulant during irradiation. These samples all exhibit some radiation damage. The damage appears as aggregations of increased contrast in the micrographs. As the dose increases, the density and size of the aggregations increases. The damaged charcoal-polymer material also exhibited shortrange order. The crystallinity of the material does not appear to vary significantly with the various radiation doses.

The EDS spectra of the coatings provided little useful information. The concentrations of cations in the waste simulant were not distributed evenly in the coatings. The relative concentration of silicon was fairly constant in all the EDS spectra. Unfortunately, the PFP simulant did not contain silicon. The $\mathrm{HF} / \mathrm{HNO}_{3}$ matrix is believed to have dissolved the silicon in the quartz irradiation vials. The relative concentration of phosphorous in the coatings appeared to decrease as radiation dose increased, suggesting that the phosphorous-rich coating materials CMPO/TBP were lost from the particles.

\section{6. $\quad$ Crystallization of Polymer}

The electron diffraction patterns obtained with the electron microscope indicated that the polymer crystallized during irradiation, but could not be quantified as a furction of radiation dose. Only the samples receiving doses in the 2-5 Mrad range showed evidence of short-range order.

\section{Magnetic Properties}

The magnetic properties of the particles were not adversely affected by a radiation

dose. The magnetization was measured using a SQUID magnetometer. Figure IV-8 shows magnetization versus applied magnetic field for three different particles. The field at which magnetic saturation occurs is identical for all the particle3, indicating that radiation did not effect the magnetic properties of the particles. The magnitude of the magnetization depends on the relative concentration of magnetite in the samples.

\section{Conclusion}

The effect of radiolysis on a typical MACS extraction cycle is minimal. The decline in $\mathrm{K}_{\mathrm{d}}(\mathrm{Am})$ was insignificant for low doses to the later particle coatings. Improvements in coating procedures since the irradiation study have yielded more homogeneous coatings with consistent partitioning coefficients in the $3000-$ to $4000-\mathrm{mL} / \mathrm{g}$ range from $2 \underline{\mathrm{M}} \mathrm{HNO}_{3}$. The radiation dose received during a one-hour contact cycle will have little effect on the extraction capacity of the particles. 


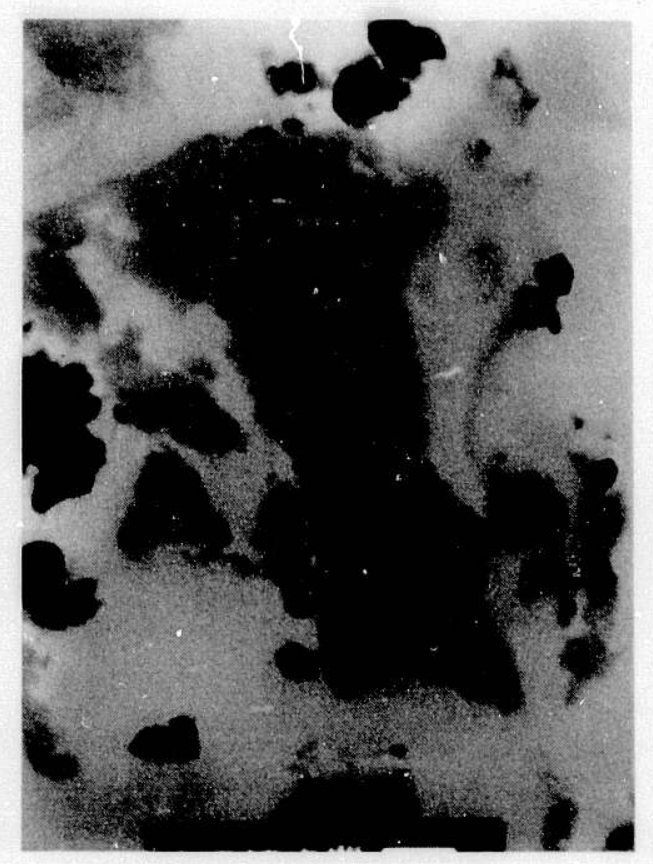

(a)

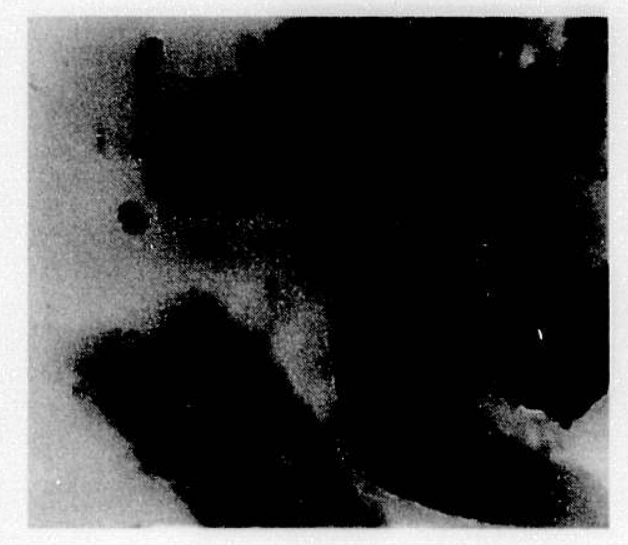

(c)

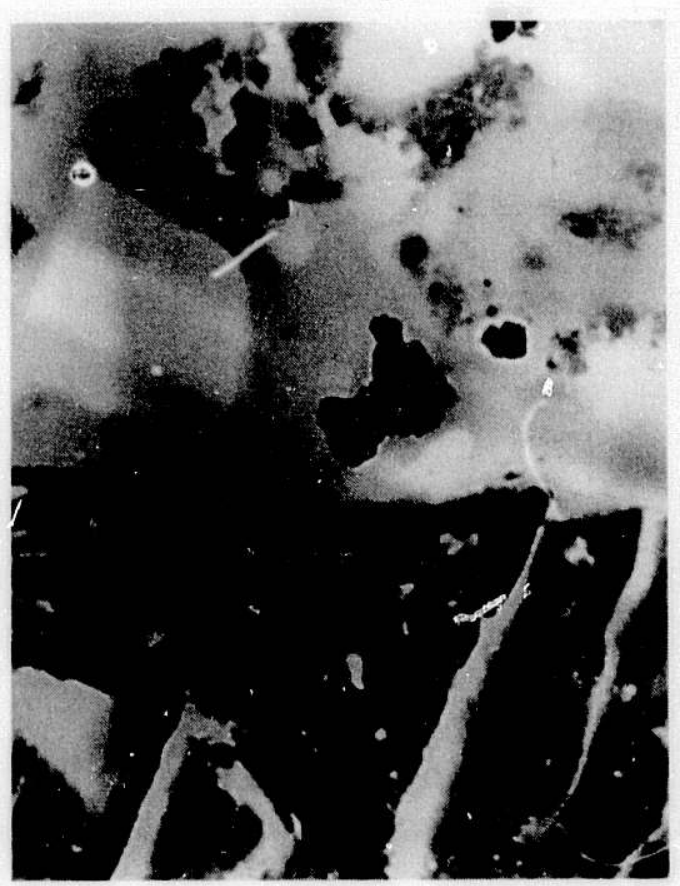

(b)

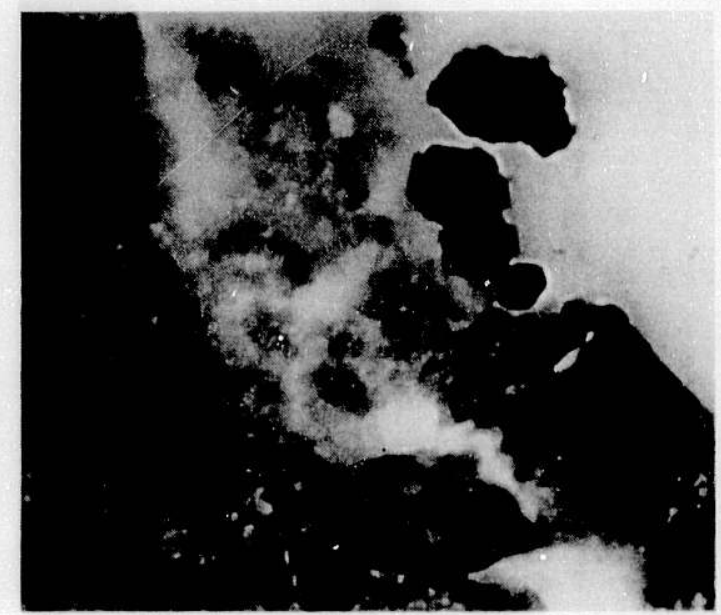

(i)

Fig. IV-7. TEM Micrographs of Charcoal-Polymer-Magnetite Particles. The irradiated particles were coated with $1.36 \mathrm{M}$ CMPO/TBP and suspended in PFP waste simulant during $\gamma$-ray exposure. (a) Unirradiated particle. (b) Radiation dose $=$

$1.2 \times 10^{4} \mathrm{rad}$. (c) Radiation dose $=1.2 \times 10^{5} \mathrm{rad}$. (d) Radiation dose $=2.6 \times 10^{6}$. 


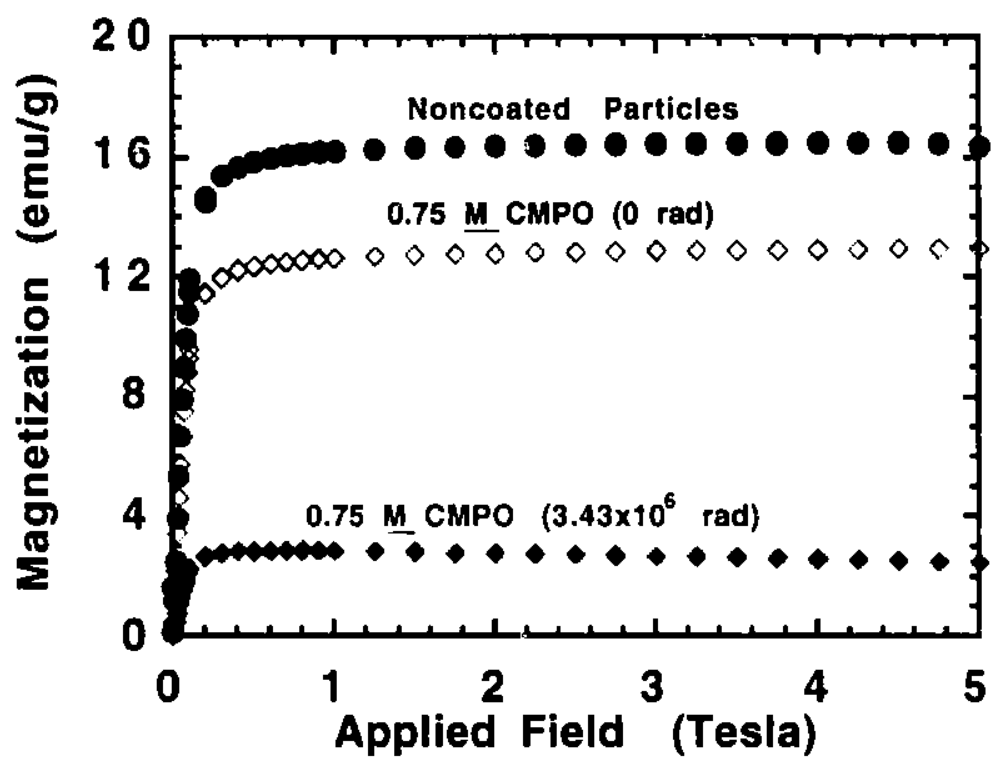

Fig. IV-8. Effect of Radiation on the Magnetization of MACS Particles

Much of the decline in $\mathrm{K}_{\mathrm{d}}(\mathrm{Am})$ is associated with a loss in the CMPO/TBP coating. The loss appears to depend more strongly on the solution in contact with the particles than on the radiation dose received. If the MACS process ultimately strips the organic coating loaded with TRU from the particles at the completion of a cycle and recoats them: with fresh CMPO/TBP, any radiation damage will probably be negligible. 


\section{HYDROLYSIS OF MACS PARTICLES}

The effects of radiolysis cannot be easily separated from those of hydrolysis in the system used for the irradiations. The particles were suspended in aqueous solutions at all times during irradiation. The concentration of $\mathrm{HNO}_{3}$ in the suspension solutions did not appear to greatly affect the changes in partitioning coefficient with radiation dose. But since the contact time of the particles and acid suspension solutions was greater for the highest doses, the decline in $\mathrm{K}_{\mathrm{d}}(\mathrm{Am})$ with increasing contact time was also investigated. Finally, the effect of thermal cycling during sealing and opening the vials was considered.

\section{A. Acid Dissolution of Magnetite}

The magnetite in the MACS particles is susceptible to dissolution by the $\mathrm{HNO}_{3}$ in solution. Particles coated with 1.5 M CMPO/TBP were placed in a variety of acid solutions ranging form 0.02 to $8 \mathrm{M} \mathrm{HNO} 3$ for two weeks. Upon completion of the contact, the supernatant was removed and analyzed for iron concentration using inductively coupled plasma atomic emission spectroscopy (ICP/AES). The experiment also included a water blank that was used as the background iron concentration.

The change in concentration of iron dissolved from the MACS particles in solution versus the concentration of $\mathrm{HNO}_{3}$ is plotted in Fig. V-1. The background concentration of iron was $20 \mathrm{ppm}$. The concentration of iron in solution appears to reach a plateau for high acid concentrations. A shorter exposure time would probably dissolve less iron from the particles; nevertheless, the position of the magnetite in the particles, on the surface rather than encapsulated, encourages dissolution in acidic environments.

The concentration of iron in solution can be used to determine the total fraction of iron in the particles that dissolves during contact with $\mathrm{HNO}_{3}$. We know that the magnetic particles consist of a 1:1:1 ratio by weight of charcoal, polymer, and magnetite and that iron accounts for approximately $72 \%$ of the weight of magnetite $\left(\mathrm{Fe}_{3} \mathrm{O}_{4}\right)$. Hence, iron represents only $24 \%$ of the mass of the particles. The fraction of total iron dissolved in the $2.00 \mathrm{~mL}$ of $\mathrm{HNO}_{3}\left(\mathrm{~F}_{\mathrm{Fe}}\right)$ is given by

$$
\mathrm{F}_{\mathrm{Fe}}=\frac{\mathrm{C}_{\mathrm{Fe}} \cdot \mathrm{V}}{\mathrm{m}} \cdot \frac{1 \mathrm{~g}}{10^{6} \mu \mathrm{g}} \cdot \frac{0.24 \mathrm{~g} \mathrm{Fe}}{1 \mathrm{~g} \text { particle }}
$$

where

$$
\begin{aligned}
\mathrm{F}_{\mathrm{Fe}} & =\text { total fraction of iron dissolved from particles } \\
\mathrm{C}_{\mathrm{Fe}} & =\text { concentration of iron in solution, } \mu \mathrm{g} / \mathrm{mL} \\
\mathrm{V} & =\text { volume of nitric acid in contact with particles, } \mathrm{mL} \\
\mathrm{m} & =\text { mass of contacted particles, } \mathrm{g}
\end{aligned}
$$

The fraction of iron dissolved form the particles in each $\mathrm{HNO}_{3}$ concentration is presented in Table V-1. 


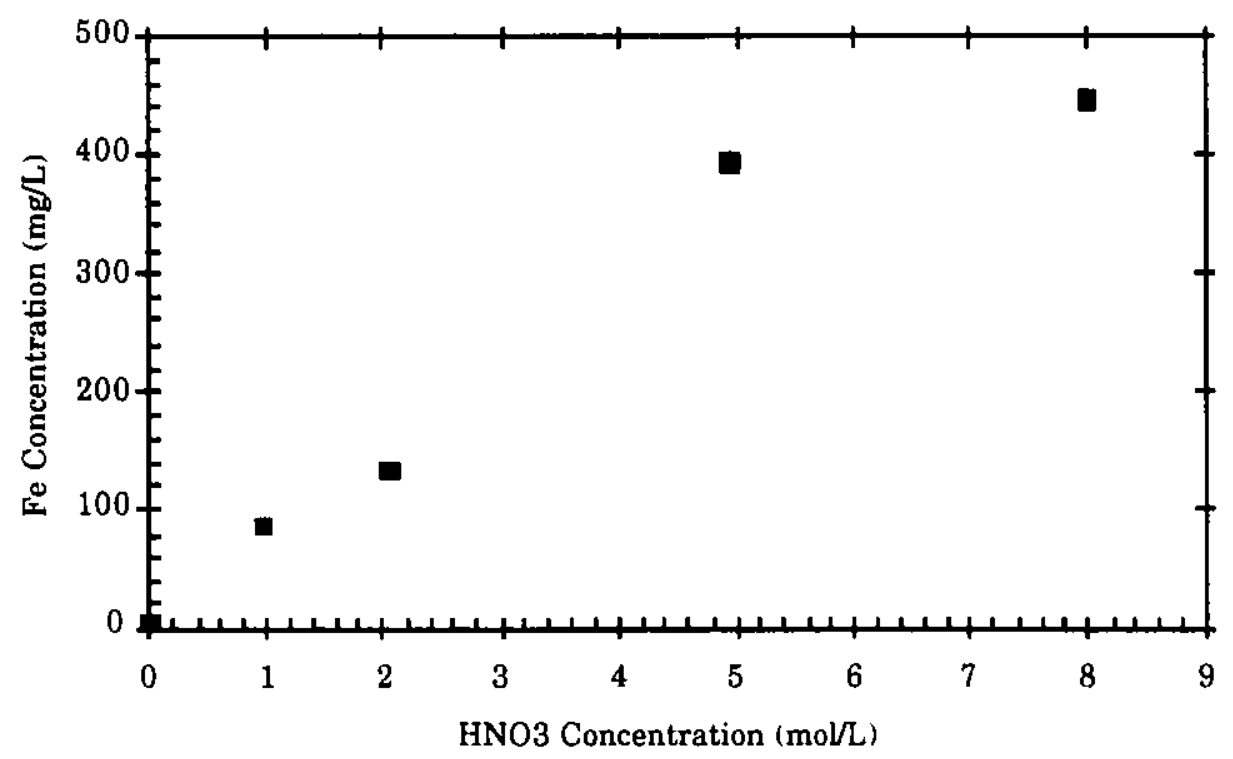

Fig. V-1. Concentration of Dissolved Iron in Solution vs. $\mathrm{HNO}_{3}$ Concentration. The particles were coated with 1.5ㅆ $\mathrm{CMPO} /$ TBP and contacted with $\mathrm{HNO}_{3}$ concentrations for 2 weeks.

Table V-1. Percentage of Iron Dissolved from Particles Coated with $1.5 \underline{\mathrm{M}}$ CMPO/TBP during Two-Week Contact with 2-mL Portions of Various $\mathrm{HNO}_{3}$ Concentrations

\begin{tabular}{ccccc}
\hline $\begin{array}{c}\mathrm{HNO}_{3} \\
(\mathrm{~mol} / \mathrm{L})\end{array}$ & $\begin{array}{c}\text { Mass } \\
(\mathrm{g})\end{array}$ & $\begin{array}{c}\text { Net Iron Dissolved } \\
(\mu \mathrm{g} / \mathrm{mL})\end{array}$ & $\begin{array}{c}\text { Dissolved Iron/Particle } \\
(\mu \mathrm{g} / \mathrm{g})\end{array}$ & $\begin{array}{c}\text { Iron Dissolved } \\
(\%)\end{array}$ \\
\hline 0.02 & 0.0224 & 3 & $2.68 \mathrm{E}+02$ & $0.1 \%$ \\
0.98 & 0.0141 & 85 & $1.21 \mathrm{E}+04$ & $5.0 \%$ \\
2.08 & 0.0093 & 131 & $2.82 \mathrm{E}+04$ & $11.7 \%$ \\
4.97 & 0.0204 & 390 & $3.82 \mathrm{E}+04$ & $15.9 \%$ \\
8.01 & 0.0167 & 443 & $5.31 \mathrm{E}+04$ & $22.0 \%$ \\
\hline
\end{tabular}

The iron dissolved from the magnetite is probably in the $\mathrm{Fe}^{3+}$ state. Iron (III) is extracted by CMPO, so in addition to attacking the magnetic properties of the particles, the dissolved iron competes with TRU for extraction sites. The contact time of the particles in high acid solutions should be limited to prevent these adverse effects.

\section{B. Thermal Cycling}

The procedure used to seal and open the quartz irradiation vials required the particles and suspension solutions to be frozen and thawed twice (Appendix E). The ex Jansion of the aqueous solutions during freezing subjected the particles to high pressures. Slowly freezing the quartz tubes from the hemispherical end allowed a slow expansion of the solutions during freezing. Nevertheless, several tubes containing deionized water burst during freezing. The effect of thermal cycling on $\mathrm{K}_{\mathrm{d}}(\mathrm{Am})$ at $2 \underline{\mathrm{M}} \mathrm{HNO}_{3}$ was investigated using unirradiated particles coated with 1.2 and $1.36 \underline{\mathrm{M}}$ CMPO/TBP in contact with a series of aqueous phase solutions. 
In most cases, no difference in $\mathrm{K}_{\mathrm{d}}(\mathrm{Am})$ was apparent between particles put through thermal cycles and those contacted with the same solution for the same duration (4 hours). Nonhomogeneity in the particle coating is probably responsible for the low $K_{d}(A m)$ obtained for the contact with $0.1 \underline{\mathrm{M}} \mathrm{HNO}_{3}$. In Fig. V-2 the partitioning coefficients are compared for the particles put through two thermal cycles and those only maintained in solution.

\section{Hydrolysis Experimental Conditions}

The general procedure for sealing and opening the hydrolysis vials is outlined in Appendix E. The solution contact times mirrored those experienced by the particles during the radiolysis experiments. The particles that received low and medium doses were in the solutions for 4-5 hours; those that received the high doses were exposed for 25 hours. The vials were rotated end-over-end at $8 \mathrm{rpm}$ for 1 hour or 24 hours. After showing that thermal cycling did not affect the partitioning coefficients, the freezing and thawing of the particles in solution was omitted from the procedure. The particles were promptly removed from the solutions and dried. Partitioning coefficients were measured following the procedure given in Appendix F.

\section{Results}

The hydrolysis effects on the MACS particles were measured by monitoring changes in $\mathrm{K}_{\mathrm{d}}(\mathrm{Am})$ with solution contact time and noting changes in the physical appearances of the particles and solutions. Changes in particle coating techniques and nonhomogeneities in the coating of each sample limit the significance of sets of acid exposures. The procedures used to collect the particles and complete the $K_{d}(A m)$ measurements are found in Appendices $E$ and $F$, respectively.

\section{Change in $\mathrm{K}_{\mathrm{d}}(\mathrm{Am})$ with Acid Contact Time}

The partitioning coefficient for americium from $2 \mathrm{M} \mathrm{HNO}_{3}$ decreased as acid contact time increased. The rate of decline varied with contact solution and between the different coatings. The particles in contact with the solutions for 24 hours lost much of their extraction capacity for americium. Although the nonhomogeneous particle coatings blurred the differences between the effects of different contact solutions, the partitioning coefficient suffered greater

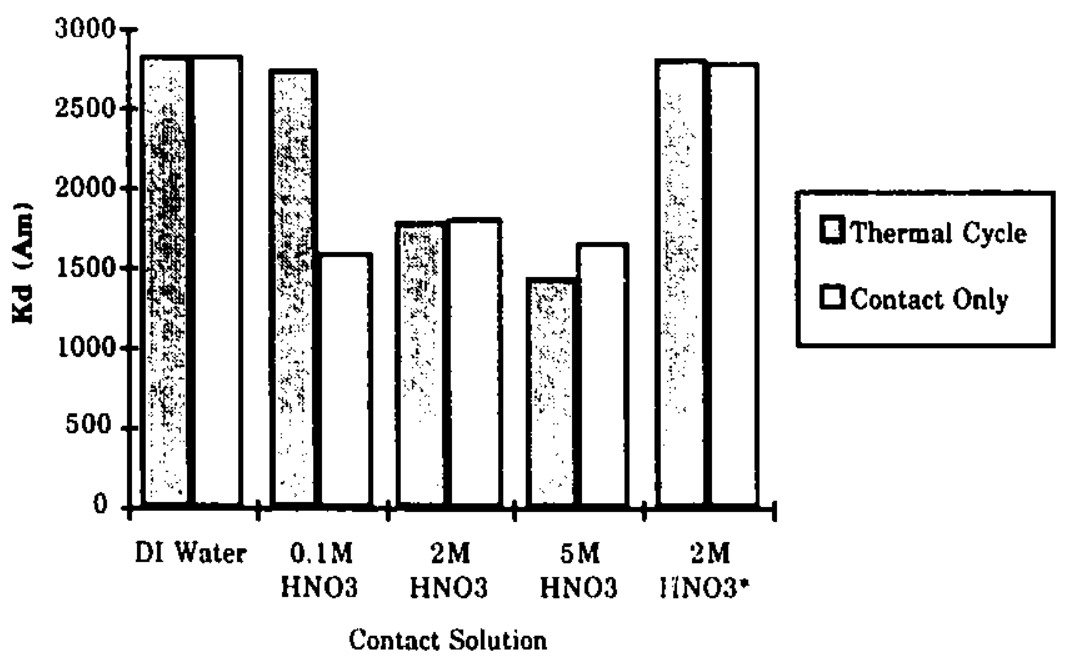

Fig. V-2. Effect of Thermal Cycling on $K_{d}(A m)$. The particle coatings were $1.2 \mathrm{M}$ and $1.36 \mathrm{M}^{*} \mathrm{CMPO} / \mathrm{TBP}$ 
decreases in capacity for stronger acid concentrations. The change in partitioning coefficient with contact time is plotted for particles coated with $1.2,1.36$, and $0.58 \mathrm{M}$ CMPO/TBP in Figs. V-3, V-4, and V-5, respectively.

The extraction capacity of the particles coated with 1.2M CMPO/TBP showed no dependence on the concentration of $\mathrm{HNO}_{3}$ in solution (Fig. V-3). The 50 and $90 \%$ losses in $\mathrm{K}_{\mathrm{d}}(\mathrm{Am}$ ) for the contact times used for the irradiations suggests that hydrolysis damage was a major factor in the decline in partitioning coefficients.

Figures V-4 and V-5 show some solution dependence in the decline in $\mathrm{K}_{\mathrm{d}}(\mathrm{Am})$ with increased contact time for particles coated with 1.36 and $0.58 \underline{\mathrm{M}} \mathrm{CMPO}$, respectively. The strong acids appear to dissolve the coatings from the particles and dissolve the exposed magnetite on the surface of the charcoal/polymer cores. The loss in extraction capability is significant for all the long exposures except for the $1.36 \underline{\mathrm{M}} \mathrm{CMPO} / \mathrm{TBP}$-coated particles contacted with $0.1 \underline{\mathrm{M}} \mathrm{HNO}_{3}$.

\section{Physical Changes in Suspension Solutions}

The physical appearance of the suspension solutions changed with time. The strong acid solutions turned pale yellow. Deposits of a viscous yellow water-immiscible liquid coated the contact vials after long exposures to the 2 and $5 \underline{\mathrm{M}} \mathrm{HNO}_{3}$. As in the case with the irradiation vials, the thickest deposits occurred in rings at the top of the suspension solutions when the axis of the tube was vertical. The position of the rings suggests that the immiscible phase was less dense than the aqueous solution.

\section{Physical Changes in the Particles}

The particles did not embrittle or lose dispersive ability when contacted with the acid solutions. As in the radiolysis experiments, a fine coating of particles covered the inside of the contact vials. The surface of the particles appears to be attacked by the acidic contact solutions. The yellow color in some suspension solutions and in the water-immiscible deposits to the vials is probably due to iron.

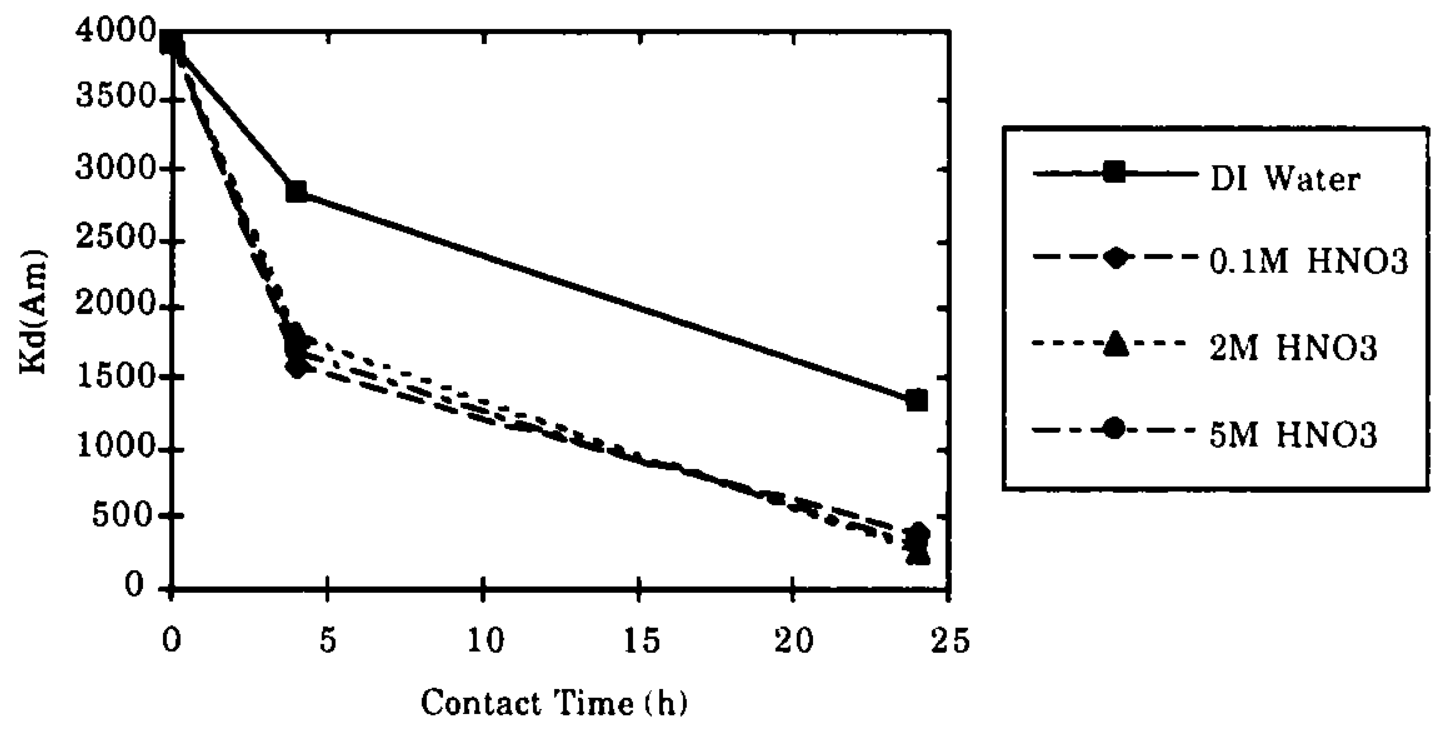

Fig. V-3. $\quad \mathrm{K}_{\mathrm{d}}(\mathrm{Am})$ from $2 \underline{\mathrm{M}} \mathrm{HNO}_{3}$ vs. Solution Contact Time for Particles Coated with 1.2M CMPO/TBP. The series refer to the suspension solution during contact. 


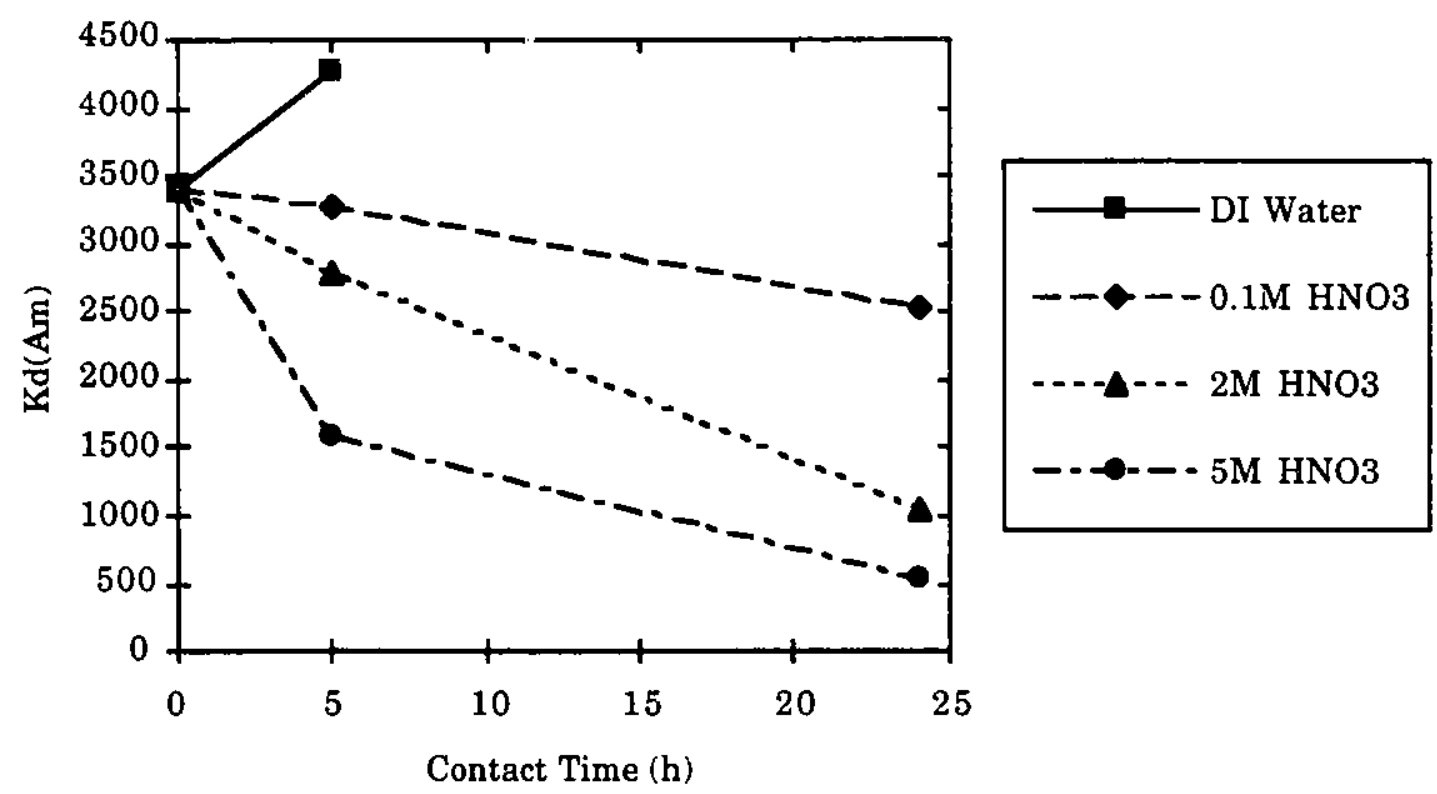

Fig. V-4. $\quad \mathrm{K}_{\mathrm{d}}(\mathrm{Am})$ from $2 \mathrm{M} \mathrm{HNO}_{3}$ vs. Solution Contact Time and Aqueous Phase Composition for Particles Coated with 1.36M CMPO/TBP. The series refer to the suspension solution during contact.

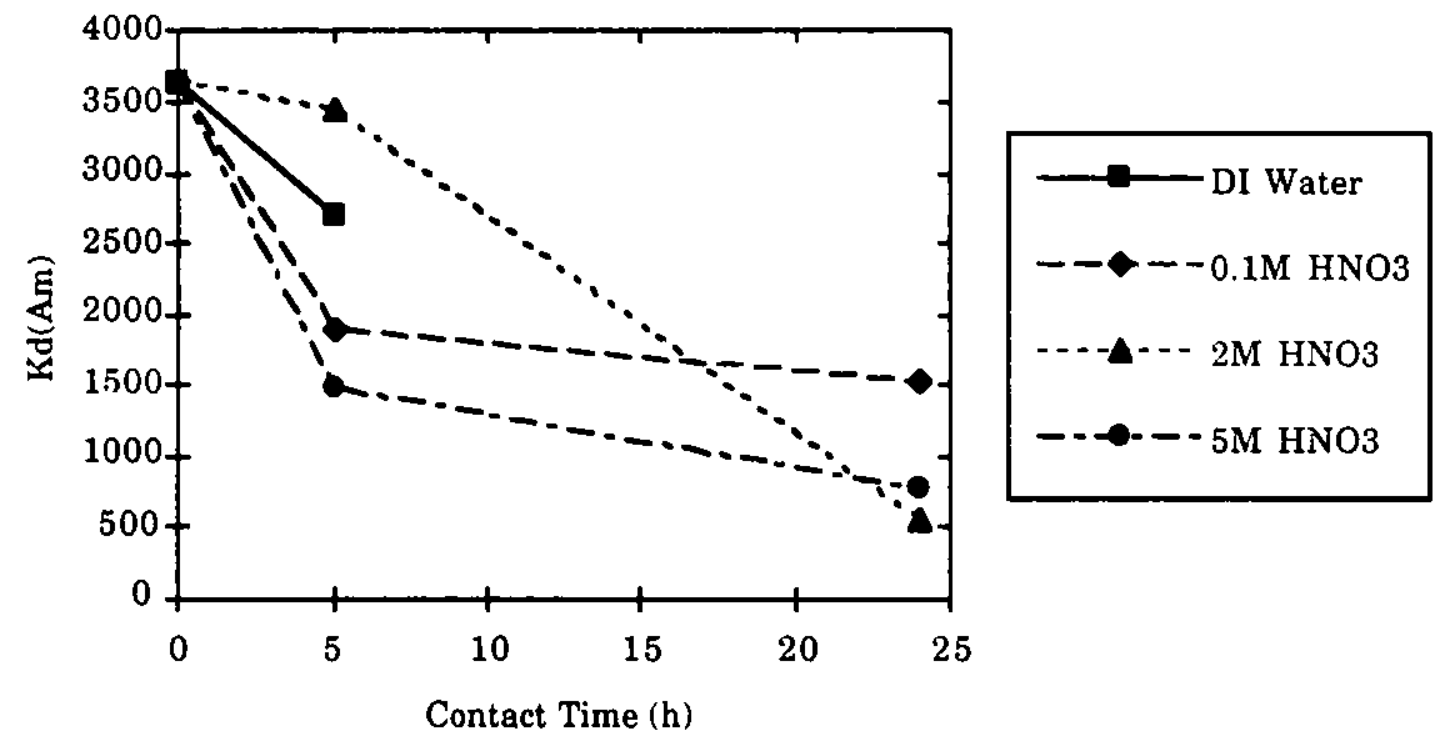

Fig. V-5. $\quad \mathrm{K}_{\mathrm{d}}(\mathrm{Am})$ from $2 \underline{\mathrm{M}} \mathrm{HNO}_{3}$ vs. Solution Contact Time for Particles Coated with $0.58 \mathrm{M}$ CMPO/TBP. The series refer to the suspension solution during contact. 


\section{E. Hydrolysis and Radiolysis}

Radiolysis of the suspension solutions creates free radicals and products that can attack the coatings and surface-exposed magnetite on the particles. The radiation products produce hydrolytic effects, enhancing the behavior of the original solutions. References on the radiation chemistry of aqueous solutions report numerous intermediate and final products formed during radiolysis [DRAGONIC, WOODS]. Strong oxidizers like hydrogen peroxide may strongly influence the desorption of the coatings from the particles and the dissolution of iron in the magnetite.

The changes in $\mathrm{K}_{\mathbf{d}}(\mathrm{Am})$ with radiation dose and contact time were plotted together in an effort to directly compare the effects of radiolysis and hydrolysis on the MACS particles. The particles coated with 1.36 M CMPO/TBP (MDZ-1089-60A) were exposed to three radiation doses in three different contact solutions. The $\mathrm{K}_{\mathrm{d}}(\mathrm{Am})$ value corresponding to zero contact time and the $1.0 \times 10^{2} \mathrm{rad}$ dose is an average of a few measurements. The individual $\mathrm{K}_{\mathrm{d}}$ measurements were distributed from 3300 to 3500 and the average was $3410 \pm 60$. This particle coating was the most homogeneous of those used in irradiations.

Figures V-6 through V-8 plot both radiolysis and hydrolysis data. The particles that received low $\left(10^{4} \mathrm{rad}\right)$ and medium $\left(10^{5} \mathrm{rad}\right)$ radiation doses were in contact with the suspension solutions for 4-5 hours. Those that received highest radiation doses $\left(10^{6} \mathrm{rad}\right)$ were in the solutions for 24 hours.

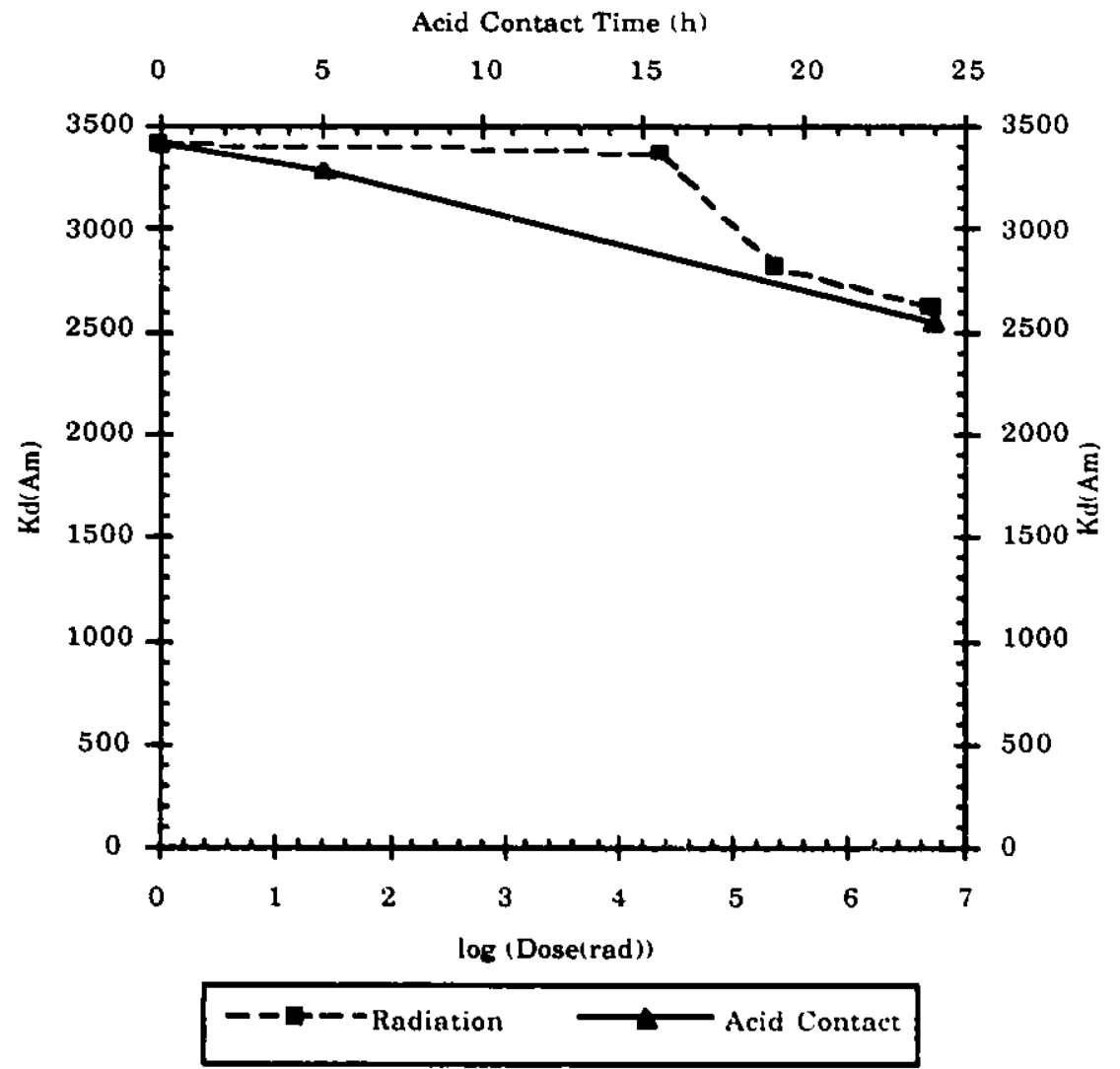

Fig. V-6. $\quad \mathrm{K}_{\mathrm{d}}(\mathrm{Am})$ from $2 \mathrm{M} \mathrm{HNO}_{3}$ vs. Solution Contact Time and Radiation Dose for MDZ-1089-60A Particles Coated with $1.36 \underline{\mathrm{M}} \mathrm{CMPO} / \mathrm{TBP}$ in Contact with $0.1 \underline{\mathrm{M}} \mathrm{HNO}_{3}$ 

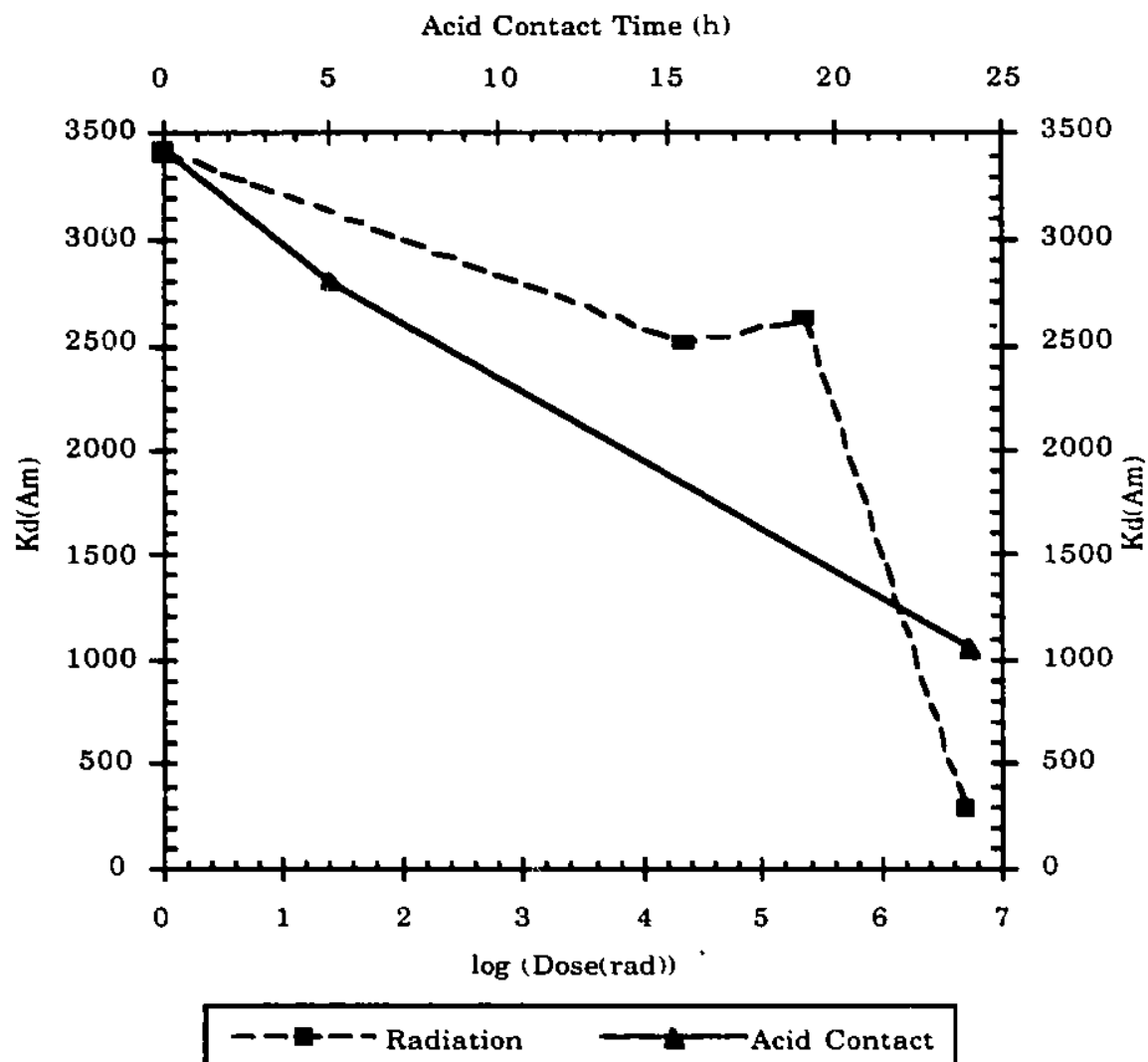

Fig. V-7. $\mathrm{K}_{\mathrm{d}}(\mathrm{Am})$ from $2 \mathrm{M} \mathrm{HNO}_{3}$ vs. Solution Contact Time and Radiation Dose for MDZ-1089-60A Particles Coated with 1.36M CMPO/TBP in Contact with $2 \underline{\mathrm{M}} \mathrm{HNO}_{3}$

Figure V-6 plots radiolysis and hydrolysis data for particles coated with $1.36 \underline{\mathrm{M}}$ CMPO/TBP and suspended in $0.1 \mathrm{M} \mathrm{HNO}_{3}$. The partitioning coefficient for 5 -h acid exposure (3284) fell between the values for the low and medium radiation doses, 3370 and 2821 respectively. The partitioning coefficient for $24-\mathrm{h}$ acid exposure (2542) fell just below the value for the high radiation dose (2621). These $K_{d}(A m)$ values are essentially indistinguishable. The decline in $\mathrm{K}_{\mathrm{d}}(\mathrm{Am})$ appears to be a consequence of hydrolysis rather than radiolysis. Similar comparisons can be made for the 2 and $5 \mathrm{M} \mathrm{HNO}_{3}$ contact solutions (Figs. V-7 and V-8). The hydrolysis data mirrors the radiolysis data, indicating hydrolysis is probably responsible for the observed loss in extraction capacity of the particles. 


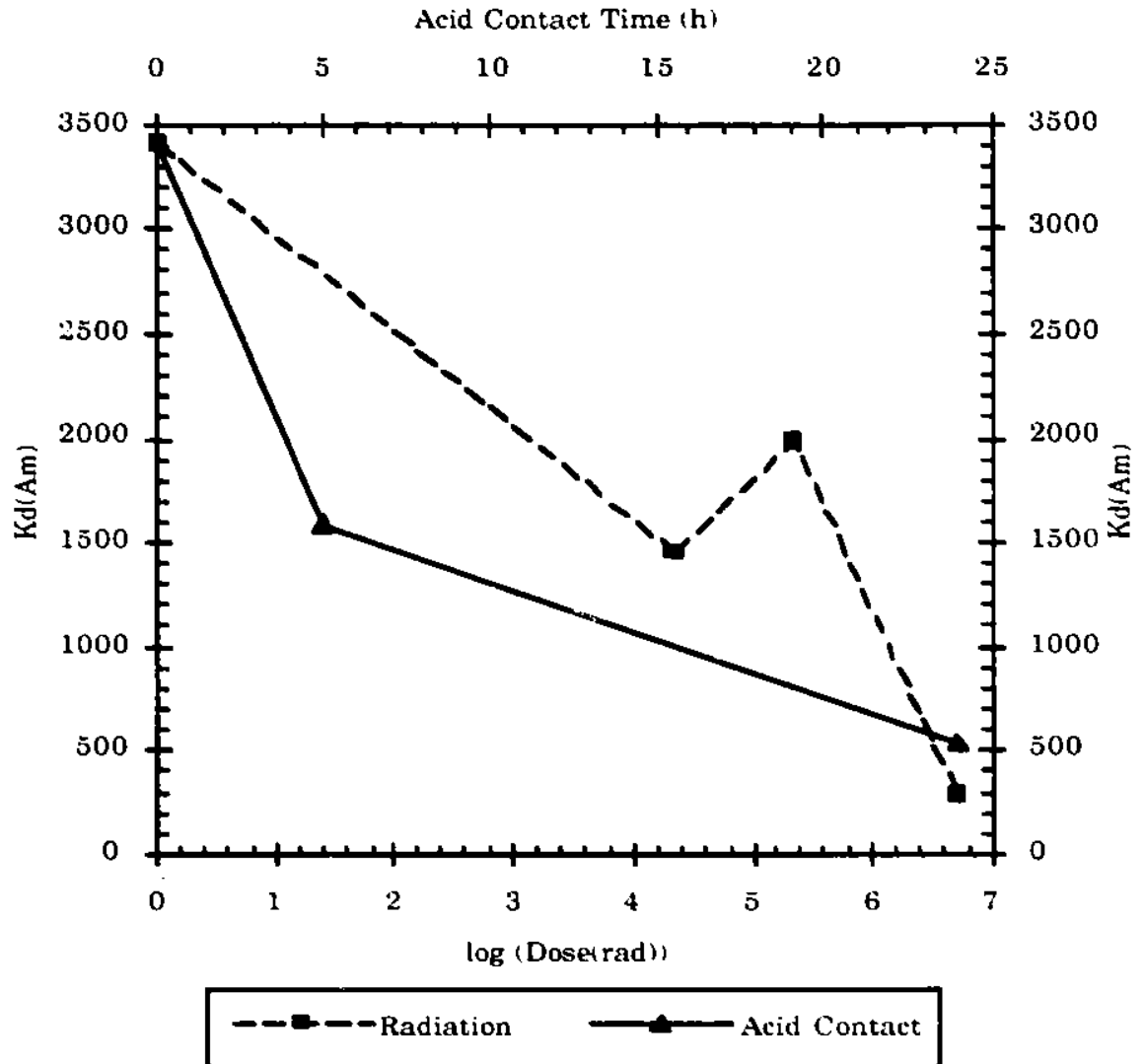

Fig. V-8. $\quad \mathrm{K}_{\mathrm{d}}(\mathrm{Am})$ from $2 \mathrm{M} \mathrm{HNO}_{3}$ vs. Solution Contact Time and Radiation Dose for MDZ-1089-60A Particles Coated with 1.36M CMPO/TBP in Contact with $5 \underline{\mathrm{M}} \mathrm{HNO}_{3}$ 


\section{ACKNOWLEDGMENTS}

We appreciate the cooperation we received when coordinating activities with the Glass Shop and the Gamma Irradiation Facility in the Chemistry Division at ANL. All the quartz vials were blown and sealed by Joe Gregar in the Chemistry Division Glass Shop. The assistance provided by Joe Hoh in using the ${ }^{60} \mathrm{Co} \gamma$-ray source is gratefully acknowledged.

The electron microscopy work was completed by C. Bradley and Neil Brown in the Chemical Technology Division at ANL.

Finally, we acknowledge the people who prepared the coatings on the magnetic particles used in this study: L. M. Castello, DEP participant from the Chicago Public Schools; M. D. Kaminski, undergraduate student from the University of Illinois at Urbana-Champaign; and M. D. Ziemer, SERS participant from Brigham Young University. 


\section{APPENDIX A}

\section{WASTE_SIMULANT COMPOSITION}

Some particles designed for TRU extraction were irradiated in simulated plutonium finishing plant (PFP) dissolved sludge. The particles supplied by Bradtec, Inc., for cesium extraction were irradiated in alkaline simulated single shell tank (SST) supernatant. Neither simulant contained any radioactive isotopes.

\section{1. $\quad$ PFP Simulant}

The PFP simulant is a blue-green acidic solution. The composition, given in Table A-1, is based on process knowledge of operations in the plutonium finishing plant.

\section{SST Supernatant Simulant}

The SST supernatant simulant is a dense, viscous alkaline solution. The formulation used in these experiments (Table A-2) is based upon charge balance of the prominent aniors and cations. Except for cesium, components with concentrations below $1 \times 10^{-4} \underline{\underline{M}}$ in the actual waste supernatant were not included in the simulant.

Table A-1. Composition of PFP Dissolved Sludge Simulant

\begin{tabular}{cccc}
\hline Component & $\begin{array}{c}\text { Molarity } \\
(\mathrm{mol} / \mathrm{L})\end{array}$ & $\begin{array}{c}\mathrm{F} . \mathrm{W} . \\
(\mathrm{g} / \mathrm{mol})\end{array}$ & \% Weight \\
\hline $\mathrm{H}^{+}$ & $1.50 \mathrm{E}+00$ & 1 & $0.1250 \%$ \\
$\mathrm{Al}^{3+}$ & $4.30 \mathrm{E}-01$ & 26.98 & $0.9668 \%$ \\
$\mathrm{Ca}^{2+}$ & $6.00 \mathrm{E}-02$ & 40 & $0.2000 \%$ \\
$\mathrm{Mg}^{2+}$ & $6.00 \mathrm{E}-02$ & 24.3 & $0.1215 \%$ \\
$\mathrm{Na}^{+}$ & $4.00 \mathrm{E}-02$ & 23 & $0.0767 \%$ \\
$\mathrm{Fe}^{3+}$ & $3.00 \mathrm{E}-02$ & 55.85 & $0.1496 \%$ \\
$\mathrm{~K}^{+}$ & $3.00 \mathrm{E}-03$ & 39 & $0.0098 \%$ \\
$\mathrm{Mn}^{2+}$ & $3.00 \mathrm{E}-03$ & 54.9 & $0.0137 \%$ \\
$\mathrm{Zn}^{2+}$ & $6.00 \mathrm{E}-04$ & 65.38 & $0.0033 \%$ \\
$\mathrm{~Pb}^{2+}$ & $5.00 \mathrm{E}-04$ & 207.2 & $0.0086 \%$ \\
$\mathrm{Cr}^{3+}$ & $4.00 \mathrm{E}-04$ & 51.996 & $0.0017 \%$ \\
$\mathrm{Ni}^{2+}$ & $4.00 \mathrm{E}-04$ & 58.7 & $0.0020 \%$ \\
$\mathrm{Cu}^{2+}$ & $3.00 \mathrm{E}-04$ & 63.546 & $0.0016 \%$ \\
$\mathrm{Be}^{3+}$ & $7.00 \mathrm{E}-05$ & 9.012 & $0.0001 \%$ \\
$\mathrm{SO}_{4}^{2-}$ & $1.00 \mathrm{E}-02$ & 96.06 & $0.0801 \%$ \\
$\mathrm{NO}_{3}{ }^{-}$ & $3.06 \mathrm{E}+00$ & 62 & $15.8307 \%$ \\
$\mathrm{~F}^{-}$ & $9.00 \mathrm{E}-02$ & 19 & $0.1425 \%$ \\
$\mathrm{H}_{2} \mathrm{O}$ & & 18 & $82.2663 \%$ \\
& & & $100.0000 \%$ \\
\hline & & &
\end{tabular}


Table A-2. Composition of SST Supernatant Simulant

\begin{tabular}{cccr}
\hline Component & $\begin{array}{c}\text { Molarity } \\
(\mathrm{mol} / \mathrm{L})\end{array}$ & $\begin{array}{c}\text { F.W. } \\
(\mathrm{g} / \mathrm{mol})\end{array}$ & \% Weight \\
\hline $\mathrm{Na}^{+}$ & $8.82 \mathrm{E}+00$ & 23 & $16.9050 \%$ \\
$\mathrm{~K}^{+}$ & $9.35 \mathrm{E}-02$ & 39 & $0.3039 \%$ \\
$\mathrm{Cs}^{+}$ & $4.48 \mathrm{E}-05$ & 132.9 & $0.0005 \%$ \\
$\mathrm{OH}^{-}$ & $6.54 \mathrm{E}+00$ & 17 & $9.2693 \%$ \\
$\mathrm{NO}_{3}^{-}$ & $1.09 \mathrm{E}+00$ & 62 & $5.6441 \%$ \\
$\mathrm{NO}_{2}{ }^{-}$ & $8.09 \mathrm{E}-01$ & 46 & $3.1030 \%$ \\
$\mathrm{Al}^{-}\left(\mathrm{OH}_{4}\right)^{-}$ & $2.07 \mathrm{E}-02$ & 94.98 & $0.1634 \%$ \\
$\mathrm{CO}_{3}^{2-}$ & $2.22 \mathrm{E}-01$ & 60.01 & $1.1090 \%$ \\
$\mathrm{CrO}_{4}{ }^{2-}$ & $4.37 \mathrm{E}-03$ & 116.0 & $0.0422 \%$ \\
$\mathrm{PO}_{4}^{3-}$ & $8.00 \mathrm{E}-04$ & 94.97 & $0.0063 \%$ \\
$\mathrm{H}_{2} \mathrm{O}^{-}$ & & 18 & $63.4533 \%$ \\
& & & $100.0000 \%$ \\
\hline
\end{tabular}




\section{APPENDIX B}

\section{GAMMA IRRADIATION FACILITY}

\section{Facility Description}

The ${ }^{60} \mathrm{Co}$ irradiation source is located on the Mega Curie level (basement) in the ANL Hot Cell Facility in Building 200. The gamma cell is approximately $12 \mathrm{ft} \times 16 \mathrm{ft} \times 12.5 \mathrm{ft}$ high $(365.76 \mathrm{~cm} \times 487.68 \mathrm{~cm} \times 381.00 \mathrm{~cm}$ high) ceiling. The atmosphere is once-through air, with a total of $1200 \mathrm{cfm}$ being exhausted. This flow rate produces an air change about every two minutes.

The cobalt source is stored under the floor of the cell when not in use. It is elevated by means of an A-frame mechanism to expose items placed in the cell. The shielding walls are 4-ft(121.92-cm-) thick magnetite concrete and should shield against $1 \mathrm{MCi}$ of $1 \mathrm{MeV} \gamma$-rays. Viewing into the cell is provided by two functional zinc bromide windows, which are normally covered with 6 -in. $(15.24-\mathrm{cm})$ shielding shutters. The shutters can be raised to observe irradiations.

\section{Cobalt Source}

The source array is comprised of six rods 1 in. $(2.54 \mathrm{~cm})$ in diameter by $8 \mathrm{in} .(20.32 \mathrm{~cm})$ long. Four of the rods are located on a $2.5-\mathrm{in} .(6.35-\mathrm{cm})$ radius from the center of the array. The other two rods are located on a 3.75 -in. $(9.525-\mathrm{cm})$ radius from the center on opposing corners of the array (see Fig. B-1). When raised into the cell, the centers of the rods are $16 \mathrm{in} .(40.64 \mathrm{~cm})$ from the floor. The source strength is approximately $50 \mathrm{kCi}$ of ${ }^{60} \mathrm{Co}$. 


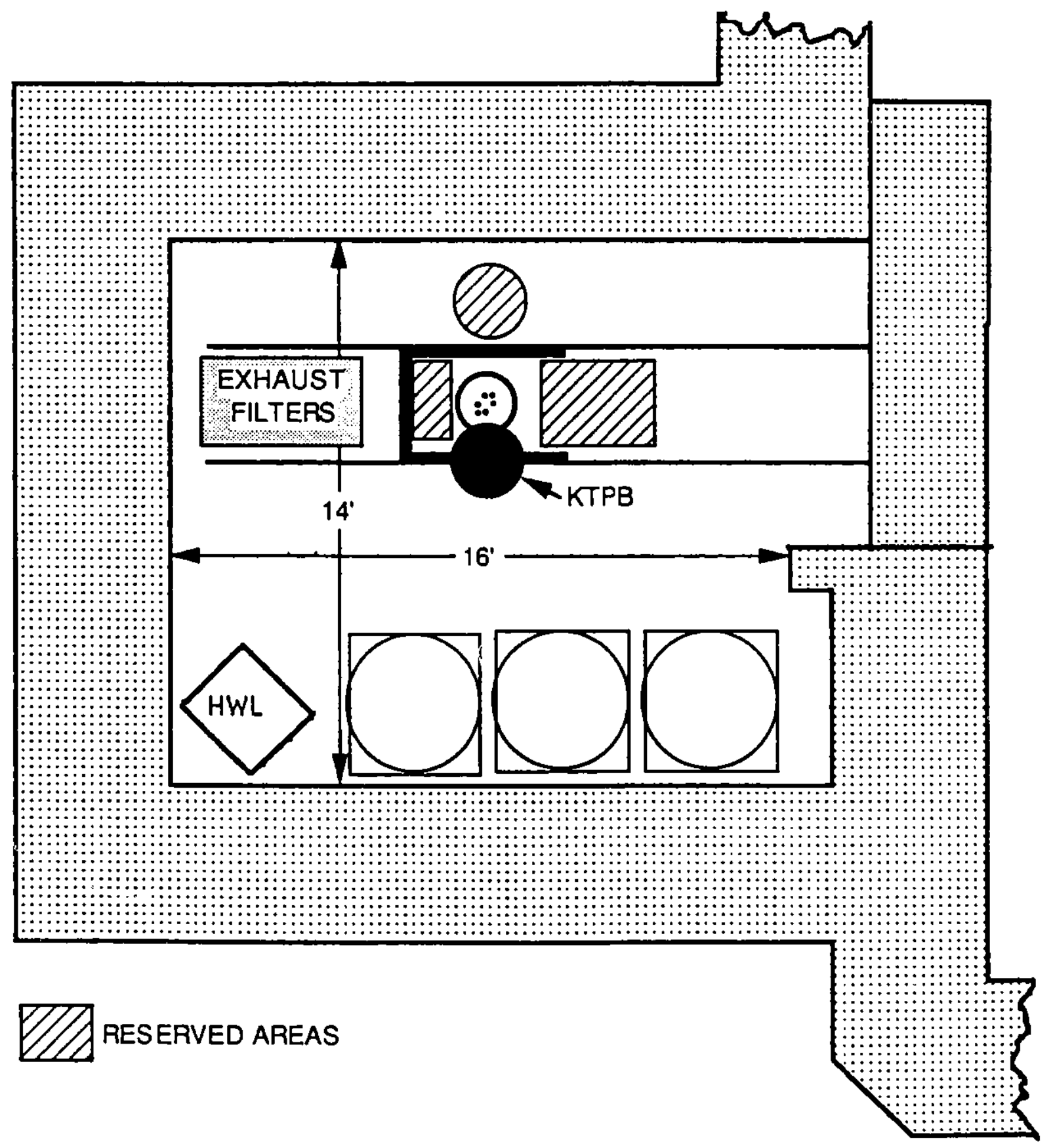

Fig. B-1. Layout of Gamma Irradiation Facility 


\section{APPENDIX C}

\section{${ }^{60}$ Co DOSIMETRY}

The dose rates to the samples irradiated in the ${ }^{60} \mathrm{Co}$ hot cell were measured using cobalt glass. The dose over a specified time (e.g., 60 or 70 minutes in these cases) is calculated from measurements of the change in optical density of the small glass plates. Cobalt glass dosimetry works well for doses up to $1 \mathrm{Mrad}$.

When exposed to $\gamma$-ray irradiation, the glass accumulates aggregations of imperfections that increase the optical density of the glass, changing it from a deep medium blue to dark blue. The optical density is measured with a Bausch and Lomb Spectronic 20 using liont of wavelength $450 \mathrm{~nm}$. The change in optical density can be used to calculate the dose to within $\pm 10 \%$ using in-house software [SCHMITZ]. The doses calculated with this software assume water is the absorber.

Since ionization is the dominant mechanism for energy deposition of $\gamma$-rays, the electron density of a target strongly affects its absorbed dose. The electron density of a material is given by

$$
\mathrm{NZ}=\frac{\mathrm{N}_{\mathrm{A}}}{\mathrm{A}} \rho \cdot \mathrm{Z}
$$

where

$$
\begin{aligned}
\mathrm{NZ} & =\text { electron density, } \mathrm{cm}^{3} \\
\mathrm{~N}_{\mathrm{A}} & =\text { Avogadro's Number }=6.023 \times 10^{23} \text { atoms/mole } \\
\mathrm{A} & =\text { average atomic mass, } \mathrm{g} / \mathrm{mol} \\
\rho & =\text { density, } \mathrm{g} / \mathrm{cm}^{3} \\
\mathrm{Z} & =\text { average atomic number, electrons/atom }
\end{aligned}
$$

The dose to an arbitrary absorber can be calculated from the ratio of its electron density to that of water. The electron density relative to water for a series of possible magnetic particles is given in Table C-1. The relative electron density is the ratio of that calculated for a set of physical parameters to the electron density of water $\left(3.346 \times 10^{23}\right.$ electrons per cubic centimeter).

Table C-1. Electron Density of Magnetic Particles Relative to Water

\begin{tabular}{ccccc}
\hline $\begin{array}{c}\text { Density } \\
\left(\mathrm{g} / \mathrm{cm}^{3}\right)\end{array}$ & $\begin{array}{c}\text { Atomic } \\
\text { Number }\end{array}$ & $\begin{array}{c}\text { Atomic } \\
\text { Mass }\end{array}$ & $\begin{array}{c}\text { Electron Density } \\
\left(\mathrm{cm}^{3}\right)\end{array}$ & $\begin{array}{c}\text { Relative } \\
\text { Electron Density }\end{array}$ \\
\hline 1.82 & 6.03 & 12.3 & $5.37 \mathrm{E}+23$ & 1.61 \\
2.0 & 7 & 14 & $6.02 \mathrm{E}+23$ & 1.80 \\
2.2 & 8 & 16 & $6.62 \mathrm{E}+23$ & 1.98 \\
2.5 & 9 & 18 & $7.53 \mathrm{E}+23$ & 2.25 \\
2.7 & 10 & 20 & $8.13 \mathrm{E}+23$ & 2.43 \\
2.5 & 12 & 25 & $7.23 \mathrm{E}+23$ & 2.16 \\
2.7 & 14 & 29 & $7.85 \mathrm{E}+23$ & 2.35 \\
\hline
\end{tabular}


If two fairly similar absorbers receiving $\gamma$-ray irradiation are thin, an equation that relates the dose between two can be written [WOODS]. The dose relation equation (Eq. C-3) is based upon the approximation $\left(1-\mathrm{e}^{-\mu l}\right) \approx \mu l$, a consequence of the series expansion of $\mathrm{e}^{-\mu l}$ for small $\mu \mathrm{l}$ as follows:

$$
1-\mathrm{e}^{-\mu \mathrm{l}}=1-1-(-\mu \mathrm{l})-\frac{(-\mu \mathrm{l})^{2}}{2 !}-\frac{(-\mu \mathrm{l})^{3}}{3 !}-\ldots=\mu \mathrm{l}
$$

The approximate dose relation between two materials, $A$ and $B$, irradiated under the same conditions is given by

$$
\frac{D_{A}}{D_{B}}=\frac{(\mu / \rho)_{A}}{(\mu / \rho)_{B}}
$$

where

$$
\begin{aligned}
& D \quad=\text { radiation dose of material } \mathrm{A} \text { or } \mathrm{B}, \mathrm{rad} \\
& \mu \quad=\text { total linear absorption coefficient of material } \mathrm{A} \text { or } \mathrm{B}, \mathrm{cm}^{-1} \\
& \rho \quad=\text { density of material } \mathrm{A} \text { or } \mathrm{B}, \mathrm{g} / \mathrm{cm}^{3} \\
& \mu / \rho \quad=\text { total mass absorption coefficient of material } \mathrm{A} \text { or } \mathrm{B}, \mathrm{cm}^{2} / \mathrm{g}
\end{aligned}
$$

The attenuation coefficient gives the fraction of energy scattered out of a beam of radiation while the absorption coefficient gives the fraction actually absorbed by the target in the radiation beam. The mass attenuation and absorption coefficients for the particles and water are calculated in Tables C-2 and C-3. The coefficients for individual elements were obtained from published tables [TEMPLIN]. The weighted coefficients in Tables C-2 and C-3 are the product of the elemental mass fraction and the coefficient for the particular element for the average ${ }^{60} \mathrm{Co} \gamma$-ray energy of $1.25 \mathrm{MeV}$.

A table of dose multiplication factors is generated (Table C-4) by applying Eq. C-3 to the computed total absorption coefficients. The dose multiplication factors computed in Table C- 4 are almost identical to the relative electron densities for comparable particles computed in Table C-1.

Table C-2. Weighted Mass Attenuation and Absorption Coefficients for Magnetic Particles Exposed to ${ }^{60} \mathrm{Co} \gamma$-ray Energy of $1.25 \mathrm{MeV}$

\begin{tabular}{lccccc}
\hline \multicolumn{1}{c}{ Element } & $\begin{array}{c}\text { Mass } \\
\text { Mass }\end{array}$ & $\begin{array}{c}\text { Attenuation } \\
\text { Coefficient } \\
\left(\mathrm{cm}^{2} / \mathrm{g}\right)\end{array}$ & $\begin{array}{c}\text { Weighted } \\
\text { Mass } \\
\text { Att. Coef. } \\
\left(\mathrm{cm}^{2} / \mathrm{g}\right)\end{array}$ & $\begin{array}{c}\text { Mass } \\
\text { Absorption } \\
\text { Coefficient } \\
\left(\mathrm{cm}^{2} / \mathrm{g}\right)\end{array}$ & $\begin{array}{c}\text { Weighted } \\
\text { Mass } \\
\text { Abs. Coef. } \\
\left(\mathrm{cm}^{2} / \mathrm{g}\right)\end{array}$ \\
\hline Carbon & 0.52 & $0.0568^{\mathrm{a}}$ & 0.0293 & $0.0268^{\mathrm{a}}$ & 0.0138 \\
Hydrogen & 0.02 & $0.113^{\mathrm{a}}$ & 0.0024 & $0.0533^{\mathrm{a}}$ & 0.0012 \\
Iron & 0.24 & $0.0531^{\mathrm{a}}$ & 0.0128 & $0.0250^{\mathrm{a}}$ & 0.0060 \\
Nitrogen & 0.06 & $0.0568^{\mathrm{a}}$ & 0.0034 & $0.0268^{\mathrm{a}}$ & 0.0016 \\
Oxygen & 0.16 & $0.0568^{\mathrm{a}}$ & 0.0091 & $0.0268^{\mathrm{a}}$ & 0.0043 \\
TOTAL & & & $\mathbf{0 . 0 5 7 1}$ & & $\mathbf{0 . 0 2 6 9}$ \\
\hline
\end{tabular}

aFrom Ref. [TEMPLIN]. 
Table C-3. Weighted Mass Attenuation and Absorption Coefficients for Water Exposed to ${ }^{60} \mathrm{Co} \gamma$-ray Energy of $1.25 \mathrm{MeV}$

\begin{tabular}{lccccc}
\hline \multicolumn{1}{c}{ Element } & $\begin{array}{c}\text { Mass } \\
\text { Mass } \\
\text { Fraction }\end{array}$ & $\begin{array}{c}\text { Weighted } \\
\text { Coefficient } \\
\left(\mathrm{cm}^{2} / \mathrm{g}\right)\end{array}$ & $\begin{array}{c}\text { Mass } \\
\text { Att. Coef. } \\
\left(\mathrm{cm}^{2} / \mathrm{g}\right)\end{array}$ & $\begin{array}{c}\text { Mass } \\
\text { Absorption } \\
\text { Coefficient } \\
\left(\mathrm{cm}^{2} / \mathrm{g}\right)\end{array}$ & $\begin{array}{c}\text { Weighted } \\
\text { Mass } \\
\text { Abs. Coef. } \\
\left(\mathrm{cm}^{2} / \mathrm{g}\right)\end{array}$ \\
\hline $\begin{array}{l}\text { Hydrogen } \\
\text { Oxygen }\end{array}$ & 0.11 & $0.113^{\mathrm{a}}$ & 0.0126 & $0.0533^{\mathrm{a}}$ & 0.0059 \\
TOTAL & 0.89 & $0.0568^{\mathrm{a}}$ & 0.0505 & $0.0268^{\mathrm{a}}$ & 0.0238 \\
\hline
\end{tabular}

aFrom Ref. [TEMPLIN].

Table C-4. Multiplication Factors for Converting Water Equivalent Dose to Magnetic Particle Dose

\begin{tabular}{cc}
\hline $\begin{array}{c}\text { Particle } \\
\text { Density } \\
\left(\mathrm{g} / \mathrm{cm}^{3}\right)\end{array}$ & $\begin{array}{c}\text { Dose Multiplication } \\
\text { Factor } \\
(\times \text { Water Dose })\end{array}$ \\
\hline 1.82 & 1.65 \\
1.9 & 1.72 \\
2.0 & 1.81 \\
2.1 & 1.90 \\
2.2 & 1.99 \\
2.3 & 2.08 \\
2.4 & 2.17 \\
2.5 & 2.26 \\
2.7 & 2.44 \\
\hline
\end{tabular}

The agreement of these two approaches is encouraging reinforcement for the factors used to convert water equivalent dose to particle dose.

Each rotor used during irradiations had two cobalt glass plates affixed to it. The average of the change in optical density was used to calculate the dose for the initial 60 or 70 minute irradiation and to compute a dose rate. Table C-5 contains information on the dose rate of the irradiation configurations used throughout these experiments. It was assumed that the dose multiplication factor is 2.0 .

Table C-5. Gamma Irradiation Dose Rates for Particles and Water

\begin{tabular}{lcccc}
\hline \multicolumn{1}{c}{ Configuration } & 1 & 2 & 3 & 4 \\
\hline Change in Optical Density & 0.110 & 0.116 & 0.114 & 0.181 \\
Dose to Water (rad) & $6.35 \times 10^{4}$ & $6.75 \times 10^{4}$ & $6.60 \times 10^{4}$ & $1.13 \times 10^{5}$ \\
Dose Rate to Water $(\mathrm{rad} / \mathrm{h})$ & $5.44 \times 10^{4}$ & $5.79 \times 10^{4}$ & $5.66 \times 10^{4}$ & $1.13 \times 10^{5}$ \\
Dose Rate to Particles $(\mathrm{rad} / \mathrm{h})$ & $1.09 \times 10^{5}$ & $1.16 \times 10^{5}$ & $1.13 \times 10^{5}$ & $2.26 \times 10^{5}$ \\
\hline
\end{tabular}

aThe various configurations refer to different rotator positions used during the irradiations. 


\section{APPENDIX D}

\section{PARTICLE COMPOSITION}

The particle composition is needed to accurately estimate doses expected to be encountered when processing real waste solutions and when converting experimental dosimetry information from water targets to magnetic particle targets. Particle manufacturers were unwilling or unable to provide physical data on the density, average atomic number, and average atomic mass. Two approaches were applied to obtain the physical parameters needed to perform dosimetry calculations. The parameters were calculated from gross composition information supplied by manufacturers and approximated by inspection of electron and optical micrographs.

\section{Calculation of Physical Parameters}

The density, average atomic number, and average atomic mass of the particles used in the TRU extractions were calculated based on information from their manufacturer, Cortex Biochem, Inc. (San Leandro, CA). The particles consist of a cross-linked polyacrylamide ( $\mathrm{N}, \mathrm{N}$-methylene bis-acrylamide), entrapping charcoal (Norit SX-Ultra), and magnetite $\left(\mathrm{Fe}_{3} \mathrm{O}_{4}\right)$ in a 1:1:1 w/w ratio. The chemical formula and density of the components are presented in Table D-1.

There is no way to accurately estimate the size of the acrylamide polymer from the available information. The following calculations use only one $\mathrm{N}, \mathrm{N}$-methylene bis-acrylamide because repeating units have the same ratio of elements and information is given only in terms of mass ratios.

\section{Density}

The density of the Cortex particles can be calculated from the densities and the weight ratios of the constituent materials. The volumes of $1 \mathrm{~g}$ of each particle constituent are added together to obtain the volume of a 1:1:1 weight ratio as follows:

$$
\mathrm{V}=\frac{1 \mathrm{~g}}{2.2 \mathrm{~g} / \mathrm{cm}^{3}}+\frac{1 \mathrm{~g}}{5.18 \mathrm{~g} / \mathrm{cm}^{3}}+\frac{1 \mathrm{~g}}{1 \mathrm{~g} / \mathrm{cm}^{3}}=165 \mathrm{~cm}^{3}
$$

above.

The density is determined by dividing the $3 \mathrm{~g}$ of material by the volume calculated

$$
\rho=\frac{3.0 \mathrm{~g}}{165 \mathrm{~cm}^{3}}=182 \frac{\mathrm{g}}{\mathrm{cm}^{3}}
$$

This method assumes that none of the polymer is absorbed in the charcoal. If the polymer is partially absorbed by the charcoal, the density would be higher. Equation D-1 can be

Table D-1. Chemical Components of Particles Used for TRU Extraction

\begin{tabular}{lcc}
\hline \multicolumn{1}{c}{ Chemical Name } & $\begin{array}{c}\text { Chemical } \\
\text { Formula }\end{array}$ & $\begin{array}{c}\text { Density } \\
\left(\mathrm{g} / \mathrm{cm}^{3}\right)\end{array}$ \\
\hline Acrylamide & $\mathrm{CH}_{2}=\mathrm{CHCONH}_{2}$ & $\sim 1$ \\
N,N-methylene bis acrylamide & $\mathrm{C}_{7} \mathrm{O}_{2} \mathrm{~N}_{2} \mathrm{H}_{10}$ & $\sim 1$ \\
Charcoal & $\mathrm{C}$ & 2.2 \\
Magnetite & $\mathrm{Fe}_{3} \mathrm{O}_{4}$ & 5.18 \\
\hline
\end{tabular}


modified to account for the reduction in total volume due to the mutual absorption of polymer and charcoal. The absorbed fraction $\left(F_{a}\right)$ is the fractional decrease in the volume of the charcoal and polymer components:

$$
\mathrm{V}=\frac{1 \mathrm{~g}}{5.18 \mathrm{~g} / \mathrm{cm}^{3}}+\left(1-\mathrm{F}_{\mathrm{a}}\right)\left[\frac{1 \mathrm{~g}}{2.2 \mathrm{~g} / \mathrm{cm}^{3}}+\frac{1 \mathrm{~g}}{1 \mathrm{~g} / \mathrm{cm}^{3}}\right]
$$

Table D-2 gives the density of particles for various fractions of polymer/charcoal absorption.

\section{Average Atomic Mass and Number}

The average atomic mass and number of the particles is calculated from the number of moles of each constituent component. The total moles of each constituent are given in Table D-3.

The moles of each element in the charcoal, magnetite, and acrylamide polymer are calculated by multiplying the moles of material by the number of atoms of the element in the material. Table D-4 reports for each element the moles per gram of particles, the mole fraction, and the mass fraction. The mole fraction is the ratio of the moles of a particular element to the total moles of atoms. The mass fraction is the product of the moles of an element per gram of particles and the atomic weight of the element. The total moles of an element in the particles is merely the sum of component parts, (e.g., $1.00 \mathrm{~g}$ of particles is composed of $0.33 \mathrm{~g}$ charcoal,

Table D-2. Density of Magnetic Particles for Various Fractions of Polymer/Charcoal Absorption

\begin{tabular}{ccc}
\hline $\begin{array}{c}\text { Polymer/Charcoal } \\
\text { Absorption Fraction } \\
\left(\mathrm{F}_{\mathrm{a}}\right)\end{array}$ & $\begin{array}{c}\text { Volume } \\
\left(\mathrm{cm}^{3}\right)\end{array}$ & $\begin{array}{c}\text { Density } \\
\left(\mathrm{g} / \mathrm{cm}^{3}\right)\end{array}$ \\
\hline 0.00 & 1.65 & 1.82 \\
0.05 & 1.57 & 1.90 \\
0.10 & 1.50 & 2.00 \\
0.15 & 1.43 & 2.10 \\
0.20 & 1.36 & 2.21 \\
0.25 & 1.28 & 2.34 \\
0.30 & 1.21 & 2.48 \\
0.40 & 1.07 & 2.81 \\
0.50 & 0.92 & 3.26 \\
\hline
\end{tabular}

Table D-3. Total Moles of Particle Components per Gram of Components

\begin{tabular}{lcc}
\hline Component & $\begin{array}{c}\text { Formula Weight } \\
(\mathrm{g} / \mathrm{mol})\end{array}$ & $\begin{array}{c}\text { Material } \\
(\mathrm{mol} / \mathrm{g})\end{array}$ \\
\hline Charcoal & 12 & $8.33 \mathrm{E}-02$ \\
Magnetite & 232 & $4.31 \mathrm{E}-03$ \\
Polymer & 154 & $6.49 \mathrm{E}-03$ \\
\hline
\end{tabular}

${ }^{a}$ Chem:cal formula for methylene bis-acrylamide polymer is $\mathrm{C}_{7} \mathrm{O}_{2} \mathrm{~N}_{2} \mathrm{H}_{10}$. 
Table D-4. Elemental Composition of Magnetic Particles

\begin{tabular}{|c|c|c|c|}
\hline Element & $\begin{array}{c}\text { Moles/Mass } \\
\text { (mol/g particles) }\end{array}$ & $\begin{array}{l}\text { Mole Fraction } \\
\text { (mol/total mol) }\end{array}$ & $\begin{array}{l}\text { Mass Fraction } \\
\text { (g/g particles) }\end{array}$ \\
\hline Carbon & $4.29 \mathrm{E}-02$ & 0.52 & 0.52 \\
\hline Iron & 4.30E-03 & 0.05 & 0.24 \\
\hline Oxygen & $1.01 \mathrm{E}-02$ & 0.12 & 0.16 \\
\hline Hydrogen & 2.16E-02 & 0.26 & 0.02 \\
\hline Nitrogen & 4.33E-03 & 0.05 & 0.06 \\
\hline Total & 8.33E-02 & 1.00 & 1.00 \\
\hline
\end{tabular}

$0.33 \mathrm{~g}$ magnetite, and $0.33 \mathrm{~g}$ polymer. The total moles of carbon in the particles $\left(\mathrm{M}_{\mathrm{C}}\right)$ is given by Eq. D-4. Similar calculations are performed for the other elements listed in Table D-4.

$$
M_{C}=0.33 \times 8.33 \times 10^{-2}+0.33 \times 0 \times 4.31 \times 10^{-3}+0.33 \times 7 \times 6.49 \times 10^{-3}=4.29 \times 10^{-2}
$$

Carbon dominates both the mole and mass fraction of elements in the particles. Iron and hydrogen exchange roles in the mole and mass fractions. The relatively small number of iron atoms make a major contribution to the mass of the particles. Although more than a quarter of atoms are hydrogen, the contribution to the mass is relatively small. The elemental concentrations of the particles are used because their molecular form is unimportant for radiation interactions. The average atomic mass (A) of the particles is obtained from the reciprocal of the total moles-to-mass ratio.

The average atomic number is calculated by multiplying the atomic number and the mole fraction of each element and summing the contributions of each element (Table D-5).

The iron in the magnetite tends to increase $Z$ and $A$ while the hydrogen in the polymer tends to decrease boih values. The composition of the Cortex magnetic particles balances these effects and yields an average atomic number $(Z=6.02)$ and atomic mass $(A=12.0)$ similar to charcoal.

\section{TEM Micrographs of Particles}

Electron micrographs of unirradiated particles were produced by C. Bradley of the Nuclear Waste Technology Section of the Chemical Technology Division at ANL. The samples were prepared for transmission electron microscopy (TEM) by ultramicrotomy to a nominal thickness of approximately $1000 \mathrm{~nm}$. Semi-quantitative elemental compositions were obtained electron diffraction spectroscopy (EDS). Quantitative elemental analysis is impossible at this scale due to nonhomogeneous standard reference materials.

An uncoated sample of a MACS particle core is shown in Fig. D-1. The charcoal-polymer material appears light gray in the TEM micrograph. The small dark regions were identified as magnetite using EDS. The magnetite was not encapsulated in the charcoal-polymer material. Electron diffraction patterns indicated that the magnetite was a crystalline material while the unirradiated charcoal-polymer was amorphous. 
Table D-5. Average Atomic Number of Magnetic Particles

\begin{tabular}{lcc}
\hline & $\begin{array}{c}\text { Atomic } \\
\text { Number } \\
(\mathrm{Z})\end{array}$ & $\begin{array}{c}\text { Average Z } \\
\text { Contribution }\end{array}$ \\
\hline Carbon & 6 & 3.09 \\
Iron & 26 & 1.34 \\
Oxygen & 8 & 0.97 \\
Hydrogen & 1 & 0.26 \\
Nitrogen & 7 & 0.36 \\
Total & & $\mathbf{6 . 0 2}$ \\
\hline
\end{tabular}




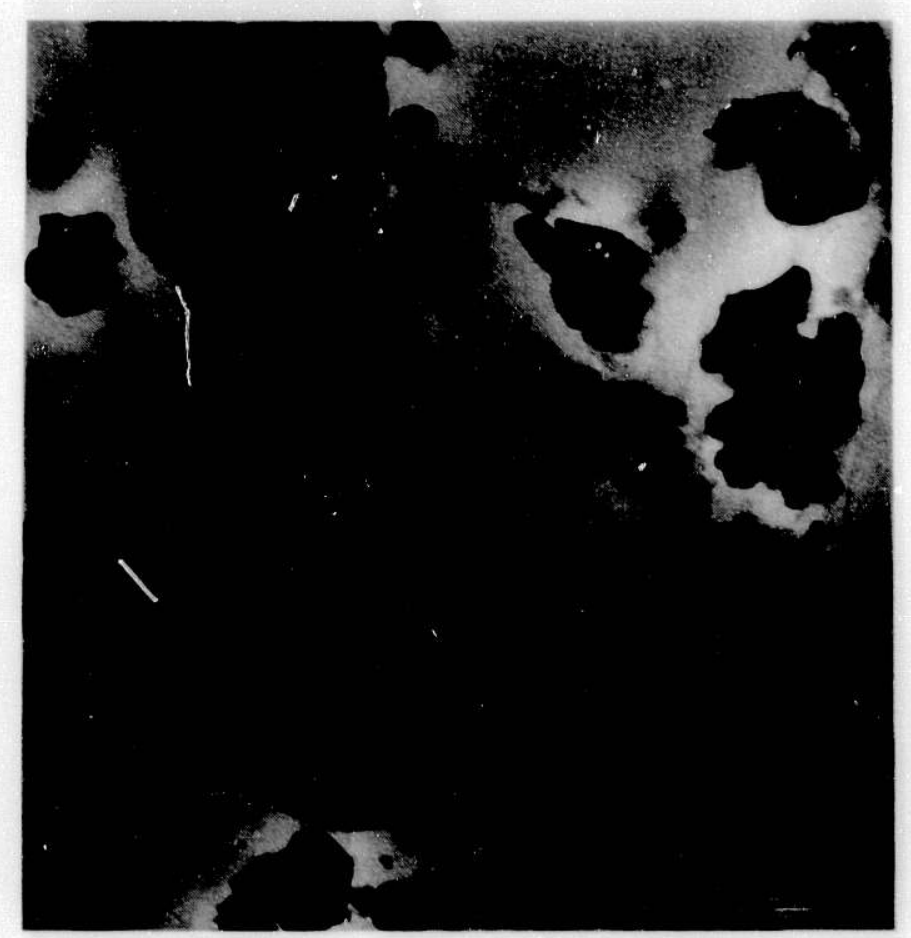

Fig. D-1. TEM Micrograph of Unirradiated Charcoal-Polymer-Magnetite Particles 


\section{APPENDIX E \\ PROCEDURES FOR SEALING AND OPENING VIALS}

The particles were suspended in aqueous solutions during irradiations to simulate process conditions. The vials used for all irradiations were blown from quartz tubing. The vials had a $10-\mathrm{mm}$ outer diameter with $1-\mathrm{mm}$-thick walls and were $11-13 \mathrm{~cm}$ long.

\section{Sealing Vials before Irradiations}

The Building 200 Glass Shop at ANL delivered the quartz vials with one end sealed in a convex hemisphere and a constriction $12 \mathrm{~cm}$ from the sealed end. The constriction expedited final sealing but did not impede filling the vials. The vials were filled and sealed in the Glass Shop because it adjoins the Gamma Irradiation facility.

Magnetic particles were placed in the vials using a spatula. The mass of particles per vial was $30-60 \mathrm{mg}$ for the TRU extraction particles and $0.5 \mathrm{~g}$ for the cesium extraction particles. The TRU extraction particles were suspended in $2.0 \mathrm{~mL}$ of one of several aqueous acid solutions (Table E-1). The cesium extraction particles were wetted with 1.5 or $2.0 \mathrm{~mL}$ of alkaline SST supernatant simulant solution. The constrictions were then cleaned with dry cotton swabs to remove any liquid or particle residue from the sealing region of the vials.

The filled vials were then placed in crushed dry ice to freeze the solutions before sealing. The solutions were slowly cooled from the bottom to allow the freezing aqueous solutions to expand upward and limit stress on the vials. The vials were evacuated with a roughing pump while their bottoms were kept in a Dewar of crushed dry ice and sealed at the constriction.

The vials were placed in crushed ice after sealing so that the solutions would slowly melt. When the solutions melted, the vial exteriors were dried, and the samples were allowed to reach room temperature. The samples were then placed in a small sonic cleaning bath for two minutes to disperse the particles before irradiation.

\section{Qpening Vials after Irradiations}

The vials were promptly opened after irradiation. The quartz vials were again placed in crushed dry ice and frozen slowly as described above. After the solutions were frozen, the vials were placed in holes drilled into a heavy block of wood 4-in. $\times 4$-in. $\times 15$-in. $(10.16-\mathrm{cm} \times$

Table E-1. Suspension Solutions for Gamma Irradiations

\begin{tabular}{ll}
\hline \multicolumn{1}{c}{ Particle Type } & \multicolumn{1}{c}{ Irradiation Solution } \\
\hline TRU Extraction & Deionized Water \\
& $0.01 \mathrm{M} \mathrm{HNO} \mathrm{HNO}_{3}$ \\
& $0.1 \mathrm{M} \mathrm{HNO}_{3}$ \\
& $2 \underline{\mathrm{M}} \mathrm{HNO}_{3}$ \\
& $5 \mathrm{M} \mathrm{HNO}_{3}$ \\
& $\mathrm{PFP}$ Dissolved Sluige Simulantid \\
& SST Supernatant Simulant \\
\hline
\end{tabular}

a See Table A-1 for composition.

b See Table A-2 for composition. 
$10.16-\mathrm{cm} \times 38.1-\mathrm{cm})$. The holes were slightly wider than the vials $(10.5-11.0 \mathrm{~mm}$ vs. $10 \mathrm{~mm})$ and about 8.5-10 cm deep, so that about a quarter of the vial remained visible above the wood. The quartz vials were scored with a file around the circumference about $5-9 \mathrm{~mm}$ above the surface of the wood. The top of the vial was covered wiih a paper towel and the top of the vial was snapped off from the bottom. The bottom part of the vial was then placed in a rack at room temperature while the soiution malted.

After melting, the solutions in the quartz vials were poured into 0.5-dram borosilicate glass vials which were then placed on a magnetic plate. The loose particles remaining in each quartz vial were washed onto individual watch glasses using deionized water. After allowing the suspended particles in the shell vial to settle out of solution, the supernatant was removed to a new 0.5-dram shell vial and stoppered. The residue at the bottom of the first shell vial was washed onto the appropriate $\mathrm{u}$ atch glass using deionized water. The watch glasses were placed in a hood overnight to allow the particles to dry. The following morning the particle samples were placed in individual glass shell vials which were then stoppered. Small samples of these stored irradiated particles were then used in $K_{d}$ measurements as needed.

\section{Solution Only Contact Vials}

The series of experiments in which the particles were exposed to the contact solutions but not irradiated were done in borosilicate culture tubes with screv tops. The culture tubes were used instead of quartz vials to reduce costs and avoid time delays from waiting for radiation surveys and fitting into the schedule at the glass shop.

Each sample of particles was placed in a tube, then $2 \mathrm{~mL}$ of the appropriate solution was added. The tubes were rotated end-over-end at $8 \mathrm{rpm}$ for 5 or $24 \mathrm{~h}$. The particles were separated from the contact solutions similarly to the irradiated samples. 


\section{APPENDIX F}

\section{PROCEDURE FOR MEASURING $\mathrm{K}_{\mathrm{d}}(\mathrm{Am})$}

The partitioning coefficient $\left(\mathrm{K}_{\mathrm{d}}\right)$ measurements used contact solutions of ${ }^{241} \mathrm{Am}$ in $2 \mathrm{M} \mathrm{HNO}_{3}$. These solutions were prepared by spiking $125-\mathrm{mL}$ samples of $2 \mathrm{M} \mathrm{HNO}_{3}$ with concentrated ${ }^{241} \mathrm{Am}$ stock to achieve a specific activity of approximately $2 \times 10^{5} \mathrm{dpm} / \mathrm{mL}$. The concentration of ${ }^{241} \mathrm{Am}$ in the solutions before and after contact was measured using the $59.5-\mathrm{keV}$ $\gamma$-ray emitted when ${ }^{241} \mathrm{Am}$ decays to ${ }^{237} \mathrm{~Np}$.

The procedure followed when completing the contacts to determine the $K_{d}$ values is outlined below:

1. Measure $1.0-5.0 \mathrm{mg}$ of particles exposed to radiation or acid solutions into disposable glass screw-top culture tube $(13 \times 100 \mathrm{~mm})$. Record mass.

2. Add $2 \mathrm{~mL}$ of $2 \underline{\mathrm{M}} \mathrm{HNO}_{3}$ spiked with ${ }^{24}{ }^{1} \mathrm{Am}$ to each culture tube.

3. Place culture tubes in sonic cleaning bath for 10 minutes.

4. Place culture tubes in a $25^{\circ} \mathrm{C}$ temperature bath for 10 minutes.

5. Return culture tubes to sonic cleaning bath for 5 minutes.

6. Return culture tubes to temperature bath for 5 minutes.

7. Blend on vortex mixer for 2 minutes. Pause briefly every 30 seconds to tip tubes back and forth and rinse particles clinging to sides back into solution.

8. Place culture tubes in the $25^{\circ} \mathrm{C}$ temperature bath for 2 minutes.

9. Repeat steps 7 and 8 twice.

10. Centrifuge tubes at high setting for $\mathbf{7 5}$ seconds.

11. Remove tubes from centrifuge and place on magnetic rack for 40-70 minutes. Loosen caps of culture tubes when placing them in the magnetic rack.

12. Remove supernatant from culture tubes with disposable transfer pipet and place liquid in 0.5-dram flat-bottomed glass shell vials resting on a magnetic plate. Wait 10-30 minutes to allow any particles to settle out of solution.

13. Remove duplicate $100-\mu \mathrm{L}$ aliquots of contacted solution for $\gamma$-ray counting.

14. Count each sample aliquot for 30 minutes. Aiso count duplicate $100-\mu \mathrm{L}$ aliquots of noncontacted, spiked $2 \mathrm{M} \mathrm{HNO}_{3}$ and duplicate blank tips in $\gamma$-ray counting tubes (background).

The samples were counted with a United Technologies Packard Minaxi 5000 Series gamma counter. The detector system uses a 3-in. $\times 3$-in. $(7.62-\mathrm{cm} \times 7.62-\mathrm{cm}) \mathrm{NaI}$ crystal coupled to a photomultiplier tube. Although $\mathrm{NaI}$ crystals have poor resolution, they work well when the sample contains only one $\gamma$-ray emitting radioisotope. The counter was programmed to collect data in two regions of interest, $15-80 \mathrm{keV}$ and $15-2000 \mathrm{keV}$. The difference in counts between the two regions was insignificant. 


\section{APPENDIX G}

\section{DATA}

The data collected during the course of this study are presented in several formats in this appendix. Samples 25-160 are listed in Table G-1. Their data are graphed in Figs. G-1 to G-27. The first irradiation samples (1-24) were sealed and stored for about two weeks before irradiation. However, attempts to determine values for the partition coefficient for americium, $\mathrm{K}_{\mathrm{d}}(\mathrm{Am})$, were unsuccessful. The coatings were dissolved off the particles and the samples were fused so that the particles would not disperse.

Table G-1. Data from Radiolysis and Hydrolysis Study

\begin{tabular}{|c|c|c|c|c|c|c|}
\hline $\begin{array}{l}\text { Date } \\
\text { Irrad. }\end{array}$ & $\begin{array}{c}\text { Bead } \\
\text { Sample }\end{array}$ & $\begin{array}{c}\text { Coated } \\
\text { Particle ID }\end{array}$ & $\begin{array}{l}\text { Contact } \\
\text { Solution }\end{array}$ & $\begin{array}{c}\text { Solution } \\
\text { Contact Time }\end{array}$ & $\begin{array}{l}\text { Dose } \\
(\mathrm{rad})\end{array}$ & $\begin{array}{c}\mathrm{K}_{\mathrm{d}}{ }^{\mathrm{a}} \\
(\mathrm{mL} / \mathrm{g})\end{array}$ \\
\hline $9 / 22 / 93$ & 25 & MDK-1064-113 & $0.01 \underline{\mathrm{M}} \mathrm{HNO}_{3}$ & $5 \mathrm{~h}$ & $1.15 \mathrm{E}+04$ & 664 \\
\hline $9 / 22 / 93$ & 26 & MDK-1064-113 & $2 \mathrm{M} \mathrm{HNO}_{3}$ & $5 \mathrm{~h}$ & $1.15 \mathrm{E}+04$ & 667 \\
\hline $9 / 22 / 93$ & 27 & MDK-1064-113 & $5 \underline{\mathrm{M}} \mathrm{HNO}_{3}$ & $5 \mathrm{~h}$ & $1.15 \mathrm{E}+04$ & 626 \\
\hline $9 / 22 / 93$ & 28 & MDK-1064-113 & PFP & $5 \mathrm{~h}$ & $1.15 E+04$ & 90 \\
\hline $9 / 22 / 93$ & 29 & MDK-1064-113 & $0.01 \underline{\mathrm{M}} \mathrm{HNO}_{3}$ & $5 \mathrm{~h}$ & $1.12 \mathrm{E}+05$ & 668 \\
\hline $9 / 22 / 93$ & 30 & MDK-1064-113 & $2 \underline{\mathrm{M}} \mathrm{HNO}_{3}$ & $5 \mathrm{~h}$ & $1.12 \mathrm{E}+05$ & 827 \\
\hline $9 / 22 / 93$ & 31 & MDK-1064-119 & $2 \mathrm{M} \mathrm{HNO}_{3}$ & $5 \mathrm{~h}$ & $1.12 \mathrm{E}+04$ & 375 \\
\hline $9 / 22 / 93$ & 32 & MDK-1064-119 & $5 \mathrm{M} \mathrm{HNO} 3$ & $5 \mathrm{~h}$ & $1.12 \mathrm{E}+04$ & 248 \\
\hline $9 / 22 / 93$ & 33 & MDK-1064-119 & PFP & $5 \mathrm{~h}$ & $1.12 \mathrm{E}+04$ & 57 \\
\hline $9 / 22 / 93$ & 34 & MDK-1064-119 & $0.01 \underline{\mathrm{M}} \mathrm{HNO}_{3}$ & $5 \mathrm{~h}$ & $1.15 \mathrm{E}+05$ & 870 \\
\hline $9 / 22 / 93$ & 35 & MDK-1064-119 & $2 \underline{\mathrm{M}} \mathrm{HNO}_{3}$ & $5 \mathrm{~h}$ & $1.15 \mathrm{E}+05$ & 331 \\
\hline $9 / 22 / 93$ & 36 & MDK-1064-119 & $5 \underline{\mathrm{M}} \mathrm{HNO}_{3}$ & $5 \mathrm{~h}$ & $1.15 \mathrm{E}+05$ & 199 \\
\hline $9 / 22 / 93$ & 37 & MDK-1064-113 & $5 \mathrm{M} \mathrm{HNO}_{3}$ & $25 \mathrm{~h}$ & $1.12 \mathrm{E}+05$ & 456 \\
\hline $9 / 22 / 93$ & 38 & MDK-1064-113 & PFP & $25 \mathrm{~h}$ & $1.12 \mathrm{E}+05$ & 113 \\
\hline $9 / 22 / 93$ & 39 & MDK-1064-113 & $0.01 \underline{\mathrm{M}} \mathrm{HNO}_{3}$ & $25 \mathrm{~h}$ & $2.60 \mathrm{E}+06$ & 438 \\
\hline $9 / 22 / 93$ & 40 & MDK-1064-113 & $2 \mathrm{M} \mathrm{HNO}_{3}$ & $25 \mathrm{~h}$ & $2.60 \mathrm{E}+06$ & 213 \\
\hline $9 / 22 / 93$ & 41 & MDK-1064-113 & $5 \mathrm{M} \mathrm{HNO}_{3}$ & $25 \mathrm{~h}$ & $2.60 \mathrm{E}+06$ & 218 \\
\hline $9 / 22 / 93$ & 42 & MDK-1064-113 & PFP & $25 \mathrm{~h}$ & $2.60 \mathrm{E}+06$ & 40 \\
\hline $9 / 22 / 93$ & 43 & MDK-1064-119 & PFP & $25 \mathrm{~h}$ & $1.15 \mathrm{E}+05$ & 126 \\
\hline $9 / 22 / 93$ & 44 & MDK-1064-119 & $2 \underline{\mathrm{M}} \mathrm{HNO}_{3}$ & $25 \mathrm{~h}$ & $2.55 \mathrm{E}+06$ & 235 \\
\hline $9 / 22 / 93$ & 45 & MDK-1064-119 & $5 \underline{\mathrm{M}} \mathrm{HNO}_{3}$ & $25 \mathrm{~h}$ & $2.55 \mathrm{E}+06$ & 127 \\
\hline $9 / 22 / 93$ & 46 & MDK-1064-119 & PFP & $25 \mathrm{~h}$ & $2.55 \mathrm{E}+06$ & 46 \\
\hline $10 / 6 / 93$ & 47 & MDZ-1089-22A & DI WATER & $5 \mathrm{~h}$ & $1.11 \mathrm{E}+04$ & 679 \\
\hline $10 / 6 / 93$ & 48 & MDZ-1089-22A & DI WATER & $5 \mathrm{~h}$ & $1.11 \mathrm{E}+05$ & 305 \\
\hline $10 / 6 / 93$ & 49 & MDZ-1089-22A & DI WATER & $25 \mathrm{~h}$ & $2.37 \mathrm{E}+06$ & 178 \\
\hline $10 / 6 / 93$ & 50 & MDZ-1089-22A & $0.01 \mathrm{M} \mathrm{HNO}_{3}$ & $5 \mathrm{~h}$ & $1.11 \mathrm{E}+04$ & 715 \\
\hline $10 / 6 / 93$ & 51 & MDZ-1089-22A & $0.01 \mathrm{MNO}$ & $5 \mathrm{~h}$ & $1.11 \mathrm{E}+05$ & 545 \\
\hline $10 / 6 / 93$ & 52 & MDZ-1089-22A & $0.01 \underline{\mathrm{M}} \mathrm{HNO}_{3}$ & $25 \mathrm{~h}$ & $2.37 \mathrm{E}+06$ & 429 \\
\hline $10 / 6 / 93$ & 53 & MDZ-1089-22A & $2 \underline{\mathrm{M}} \mathrm{HNO}_{3}$ & $5 \mathrm{~h}$ & $1.11 \mathrm{E}+04$ & 653 \\
\hline $10 / 6 / 93$ & 54 & MDZ-1089-22A & $2 \underline{\mathrm{M}} \mathrm{HNO}_{3}$ & $5 \mathrm{~h}$ & $1.11 \mathrm{E}+05$ & 437 \\
\hline $10 / 6 / 93$ & 55 & MDZ-1089-22A & $2 \underline{\mathrm{M}} \mathrm{HNO}_{3}$ & $25 \mathrm{~h}$ & $2.37 E+06$ & 194 \\
\hline
\end{tabular}


Table G-1. (contd)

\begin{tabular}{|c|c|c|c|c|c|c|}
\hline $\begin{array}{l}\text { Date } \\
\text { Irrad. }\end{array}$ & $\begin{array}{c}\text { Bead } \\
\text { Sample }\end{array}$ & $\begin{array}{c}\text { Coated } \\
\text { Particle ID }\end{array}$ & $\begin{array}{l}\text { Contact } \\
\text { Solution }\end{array}$ & $\begin{array}{c}\text { Solution } \\
\text { Contact Time }\end{array}$ & $\begin{array}{l}\text { Dose } \\
\text { (rad) }\end{array}$ & $\begin{array}{c}\mathrm{K}_{\mathrm{d}}^{\mathrm{a}} \\
(\mathrm{mL} / \mathrm{g})\end{array}$ \\
\hline $10 / 6 / 93$ & 56 & MDZ-1089-22A & $5 \underline{\mathrm{M}} \mathrm{HNO}_{3}$ & $5 \mathrm{~h}$ & $1.11 \mathrm{E}+04$ & 552 \\
\hline $10 / 6 / 93$ & 57 & MDZ-1089-22A & $5 \underline{\mathrm{M}} \mathrm{HNO}_{3}$ & $5 \mathrm{~h}$ & $1.11 \mathrm{E}+05$ & 478 \\
\hline $10 / 6 / 93$ & 58 & MDZ-1089-22A & $5 \underline{\mathrm{M}} \mathrm{HNO}_{3}$ & $25 \mathrm{~h}$ & $2.37 \mathrm{E}+06$ & 491 \\
\hline $10 / 6 / 93$ & 59 & MDZ-1089-46A & DI WATER & $5 \mathrm{~h}$ & $1.11 \mathrm{E}+04$ & 205 \\
\hline n.a. ${ }^{b}$ & 60 & MDZ-1089-46A & DI WATER & $5 \mathrm{~h}$ & none & 266 \\
\hline $10 / 6 / 93$ & 61 & MDZ-1089-46A & DI WATER & $5 \mathrm{~h}$ & $1.11 \mathrm{E}+05$ & 138 \\
\hline $10 / 6 / 93$ & 62 & MDZ-1089-46A & $0.01 \underline{\mathrm{MNO}} \mathrm{HN}_{3}$ & $5 \mathrm{~h}$ & $1.11 \mathrm{E}+04$ & 295 \\
\hline $10 / 6 / 93$ & 63 & MDZ-1089-46A & $0.01 \underline{\mathrm{MNO}} \mathrm{HN}_{3}$ & $5 \mathrm{~h}$ & $1.11 \mathrm{E}+05$ & 207 \\
\hline $10 / 6 / 93$ & 64 & MDZ-1089-46A & $0.01 \mathrm{M} \mathrm{HNO} 3$ & $25 \mathrm{~h}$ & $2.37 \mathrm{E}+06$ & 28 \\
\hline $10 / 6 / 93$ & 65 & MDZ-1089-46A & $2 \underline{\mathrm{M}} \mathrm{HNO}_{3}$ & $5 \mathrm{~h}$ & $1.11 E+04$ & 369 \\
\hline $10 / 6 / 93$ & 66 & MDZ-1089-46A & $2 \underline{\mathrm{M}} \mathrm{HNO}_{3}$ & $5 \mathrm{~h}$ & $1.11 \mathrm{E}+05$ & 154 \\
\hline $10 / 6 / 93$ & 67 & MDZ-1089-46A & $2 \underline{\mathrm{M}} \mathrm{HNO}_{3}$ & $25 \mathrm{~h}$ & $2.37 \mathrm{E}+06$ & 18 \\
\hline $10 / 6 / 93$ & 68 & MDZ-1089-46A & $5 \mathrm{M} \mathrm{HNO} 3$ & $5 \mathrm{~h}$ & $1.11 \mathrm{E}+04$ & 231 \\
\hline $10 / 6 / 93$ & 69 & MDZ-1089-46A & $5 \underline{\mathrm{M}} \mathrm{HNO}_{3}$ & $5 \mathrm{~h}$ & $1.11 \mathrm{E}+05$ & 172 \\
\hline $10 / 6 / 93$ & 70 & MDZ-1089-46A & $5 \underline{\mathrm{M}} \mathrm{HNO}_{3}$ & $25 \mathrm{~h}$ & $2.37 \mathrm{E}+06$ & 105 \\
\hline $10 / 14 / 93$ & 71 & MDZ-1089-53A & DI WATER & $5 \mathrm{~h}$ & $1.11 \mathrm{E}+04$ & 510 \\
\hline $10 / 14 / 93$ & 72 & MDZ-1089-53A & DI WATER & $5 \mathrm{~h}$ & $1.11 \mathrm{E}+05$ & 314 \\
\hline $10 / 14 / 93$ & 73 & MDZ-1089-53A & DI WATER & $25 \mathrm{~h}$ & $2.67 \mathrm{E}+06$ & 20 \\
\hline $10 / 14 / 93$ & 74 & MDZ-1089-53A & $0.01 \underline{\mathrm{M}} \mathrm{HNO}_{3}$ & $5 \mathrm{~h}$ & $1.11 \mathrm{E}+04$ & 342 \\
\hline $10 / 14 / 93$ & 75 & MDZ-1089-53A & $0.01 \underline{\mathrm{M}} \mathrm{HNO}_{3}$ & $5 \mathrm{~h}$ & $1.11 \mathrm{E}+05$ & 193 \\
\hline $10 / 14 / 93$ & 76 & MDZ-1089-53A & $0.01 \underline{\mathrm{M}} \mathrm{HNO}_{3}$ & $25 \mathrm{~h}$ & $2.67 \mathrm{E}+06$ & 12 \\
\hline $10 / 14 / 93$ & 77 & MDZ-1089-53A & $2 \mathrm{M} \mathrm{HNO} 3$ & $5 \mathrm{~h}$ & $1.11 \mathrm{E}+04$ & 399 \\
\hline $10 / 14 / 93$ & 78 & MDZ-1089-53A & $2 \underline{\mathrm{M}} \mathrm{HNO}_{3}$ & $5 \mathrm{~h}$ & $1.11 \mathrm{E}+05$ & 315 \\
\hline $10 / 14 / 93$ & 79 & MDZ-1089-53A & $2 \underline{\mathrm{M}} \mathrm{HNO}_{3}$ & $25 \mathrm{~h}$ & $2.67 \mathrm{E}+06$ & 37 \\
\hline $10 / 14 / 93$ & 80 & LMC-1064-30A & $2 \underline{\mathrm{M}} \mathrm{HNO}_{3}$ & $5 \mathrm{~h}$ & $1.11 \mathrm{E}+04$ & 2735 \\
\hline $10 / 14 / 93$ & 81 & LMC-1064-30A & $2 \mathrm{M} \mathrm{HNO} 3$ & $5 \mathrm{~h}$ & $1.11 \mathrm{E}+05$ & 2156 \\
\hline $10 / 14 / 93$ & 82 & LMC-1064-30A & $2 \mathrm{M} \mathrm{HNO}_{3}$ & $25 \mathrm{~h}$ & $2.67 \mathrm{E}+06$ & 278 \\
\hline $10 / 14 / 93$ & 83 & LMC-1064-55 & DI WATER & $5 \mathrm{~h}$ & $1.11 \mathrm{E}+04$ & 1174 \\
\hline $10 / 14 / 93$ & 84 & LMC-1064-55 & DI WATER & $5 \mathrm{~h}$ & $1.11 \mathrm{E}+05$ & 1277 \\
\hline $10 / 14 / 93$ & 85 & LMC-1064-55 & DI WATER & $25 \mathrm{~h}$ & $2.67 \mathrm{E}+06$ & 171 \\
\hline $10 / 14 / 93$ & 86 & LMC-1064-55 & $2 \mathrm{M} \mathrm{HNO}_{3}$ & $5 \mathrm{~h}$ & $1.11 \mathrm{E}+04$ & 850 \\
\hline $10 / 14 / 93$ & 87 & LMC-1064-55 & $2 \underline{\mathrm{M}} \mathrm{HNO}_{3}$ & $5 \mathrm{~h}$ & $1.11 \mathrm{E}+05$ & 1006 \\
\hline $10 / 14 / 93$ & 88 & LMC-1064-55 & $2 \underline{\mathrm{M}} \mathrm{HNO}_{3}$ & $25 \mathrm{~h}$ & $2.67 \mathrm{E}+06$ & 814 \\
\hline $10 / 14 / 93$ & 89 & LMC-1064-53 & $2 \underline{\mathrm{M}} \mathrm{HNO}_{3}$ & $5 \mathrm{~h}$ & $1.11 E+04$ & 17 \\
\hline $10 / 14 / 93$ & 90 & LMC-1064-53 & $2 \mathrm{M} \mathrm{HNO}_{3}$ & $5 \mathrm{~h}$ & $1.11 \mathrm{E}+05$ & 23 \\
\hline $10 / 14 / 93$ & 91 & LMC-1064 -53 & $2 \mathrm{M} \mathrm{HNO}_{3}$ & $25 \mathrm{~h}$ & $2.67 \mathrm{E}+06$ & 12 \\
\hline $10 / 14 / 93$ & 92 & MDZ-1089-49A & $2 \underline{\mathrm{M}} \mathrm{HNO}_{3}$ & $5 \mathrm{~h}$ & $1.11 \mathrm{E}+04$ & 402 \\
\hline $10 / 14 / 93$ & 93 & MDZ-1089-49A & $2 \underline{\mathrm{M}} \mathrm{HNO}_{3}$ & $5 \mathrm{~h}$ & $1.11 \mathrm{E}+05$ & 297 \\
\hline $10 / 14 / 93$ & 94 & MDZ-1089-49A & $2 \underline{\mathrm{M}} \mathrm{HNO}_{3}$ & $25 \mathrm{~h}$ & $2.67 \mathrm{E}+06$ & 50 \\
\hline $12 / 1 / 93$ & 95 & MDZ-1089-58A & DI WATER & $5 \mathrm{~h}$ & $2.26 \mathrm{E}+05$ & 1677 \\
\hline
\end{tabular}


Table G-1. (contd)

\begin{tabular}{|c|c|c|c|c|c|c|}
\hline $\begin{array}{l}\text { Date } \\
\text { Irrad. }\end{array}$ & $\begin{array}{c}\text { Bead } \\
\text { Sample }\end{array}$ & $\begin{array}{c}\text { Coated } \\
\text { Particle ID }\end{array}$ & $\begin{array}{l}\text { Contact } \\
\text { Solution }\end{array}$ & $\begin{array}{c}\text { Solution } \\
\text { Contact Time }\end{array}$ & $\begin{array}{l}\text { Dose } \\
\text { (rad) }\end{array}$ & $\begin{array}{c}\mathrm{K}_{\mathrm{d}}^{\mathrm{a}} \\
\left(\mathrm{mL} \mathrm{L}^{\prime} \mathrm{g}\right)\end{array}$ \\
\hline $12 / 1 / 93$ & 96 & MDZ-1089-58A & DI WATER & $5 \mathrm{~h}$ & $2.26 \mathrm{E}+04$ & 2396 \\
\hline $12 / 1 / 93$ & 97 & MDZ-1089-58A & DI WATER & $25 \mathrm{~h}$ & $4.99 \mathrm{E}+06$ & 332 \\
\hline $12 / 1 / 93$ & 98 & MDZ-1089-58A & $0.01 \underline{\mathrm{MNO}} \mathrm{HN}_{3}$ & $5 \mathrm{~h}$ & $2.26 \mathrm{E}+05$ & 1317 \\
\hline $12 / 1 / 93$ & 99 & MDZ-1089-58A & $0.01 \overline{\mathrm{M}} \mathrm{HNO}_{3}$ & $5 \mathrm{~h}$ & $2.26 \mathrm{E}+04$ & 1640 \\
\hline $12 / 1 / 93$ & 100 & MDZ-1089-58A & $0.01 \underline{\mathrm{M}} \mathrm{HNO}_{3}$ & $25 \mathrm{~h}$ & $4.99 E+06$ & 708 \\
\hline $12 / 1 / 93$ & 101 & MDZ-1089-58A & $2 \underline{\mathrm{M} \mathrm{HNO}} 3$ & $5 \mathrm{~h}$ & $2.26 \mathrm{E}+05$ & 949 \\
\hline $12 / 1 / 93$ & 102 & MDZ-1089-58A & $2 \underline{\mathrm{M}} \mathrm{HNO}_{3}$ & $5 \mathrm{~h}$ & $2.26 \mathrm{E}+04$ & 2920 \\
\hline $12 / 1 / 93$ & 103 & MDZ-1089-58A & $2 \overline{\mathrm{M}} \mathrm{HNO}_{3}$ & $25 \mathrm{~h}$ & $4.99 \mathrm{E}+06$ & 91 \\
\hline $12 / 1 / 93$ & 104 & MDZ-1089-58A & $5 \mathrm{M} \mathrm{HNO}_{3}$ & $5 \mathrm{~h}$ & $2.26 \mathrm{E}+05$ & 1065 \\
\hline $12 / 1 / 93$ & 105 & MDZ-1089-58A & $5 \underline{\bar{M}} \mathrm{HNO}_{3}$ & $5 \mathrm{~h}$ & $2.26 \mathrm{E}+04$ & 1461 \\
\hline $12 / 1 / 93$ & 106 & MDZ-1089-58A & $5 \underline{\bar{M}} \mathrm{HNO}_{3}$ & $25 \mathrm{~h}$ & $4.99 \mathrm{E}+06$ & 0.1 \\
\hline $12 / 1 / 93$ & 107 & MDZ-1089-58A & PFP & $5 \mathrm{~h}$ & $2.26 \mathrm{E}+05$ & 186 \\
\hline $12 / 1 / 93$ & 108 & MDZ-1089-58A & PFP & $5 \mathrm{~h}$ & $2.26 \mathrm{E}+04$ & 657 \\
\hline $12 / 1 / 93$ & 109 & MDZ-1089-58A & PFP & $25 \mathrm{~h}$ & $4.99 E+06$ & 79 \\
\hline $12 / 1 / 93$ & 110 & MDZ-1089-60A & $2 \underline{\mathrm{M}} \mathrm{HNO}_{3}$ & $5 \mathrm{~h}$ & $2.26 \mathrm{E}+05$ & 2625 \\
\hline $12 / 1 / 93$ & 111 & MDZ-1089-60A & $2 \underline{\mathrm{M}} \mathrm{HNO}_{3}$ & $5 \mathrm{~h}$ & $2.26 \mathrm{E}+04$ & 2503 \\
\hline $12 / 1 / 93$ & 112 & MDZ-1089-60A & $2 \mathrm{M} \mathrm{HNO}_{3}$ & $25 \mathrm{~h}$ & $4.99 \mathrm{E}_{+} .06$ & 282 \\
\hline n.a. ${ }^{b}$ & 113 & MDZ-1089-58A & DI WATER & $4 \mathrm{~h}$ & none & 2837 \\
\hline n.a. & 114 & MDZ-1089-58A & $0.01 \underline{\mathrm{M}} \mathrm{HNO}_{3}$ & $4 \mathrm{~h}$ & none & 2760 \\
\hline n.a. & 115 & MDZ-1089-58A & $2 \underline{\mathrm{M}} \mathrm{HNO}_{3}$ & $4 \mathrm{~h}$ & none & 1801 \\
\hline n.a. & 116 & MDZ-1089-58A & $5 \underline{\bar{M}} \mathrm{HNO}_{3}$ & $4 h$ & none & 1455 \\
\hline n.a. & 117 & MDZ-1089-58A & PFP & $4 \mathrm{~h}$ & none & 732 \\
\hline n.a. & 118 & MDZ-1089-60A & $2 \underline{\mathrm{M}} \mathrm{HNO}_{3}$ & $4 \mathrm{~h}$ & none & 2815 \\
\hline n.a. & 119 & MDZ-1089-58A & DI WATER & $5 \mathrm{~h}^{\mathrm{c}}$ & none & 2840 \\
\hline n.a. & 120 & MDZ-1089-58A & $0.01 \underline{\mathrm{M}} \mathrm{HNO}_{3}$ & $5 \mathrm{~h}^{\mathrm{c}}$ & none & 1588 \\
\hline n.a. & 121 & MDZ-1089-58A & $2 \mathrm{M} \mathrm{HNO}_{3}$ & $5 \mathrm{~h}^{\mathrm{c}}$ & none & 1807 \\
\hline n.a. & 122 & MDZ-1089-58A & $5 \underline{\mathrm{M}} \mathrm{HNO}_{3}$ & $5 \mathrm{~h}^{\mathrm{c}}$ & none & 1678 \\
\hline n.a. & 123 & MDZ-1089-60A & $2 \underline{\mathrm{M}} \mathrm{HNO}_{3}$ & $5 \mathrm{~h}^{\mathrm{c}}$ & none & 2801 \\
\hline n.a. & 124 & MDZ-1089-60A & $0.01 \underline{\mathrm{M}} \mathrm{HNO}_{3}$ & $5 \mathrm{~h}^{\mathrm{c}}$ & none & 3284 \\
\hline n.a. & 125 & MDZ-1089-60A & $5 \underline{\mathrm{M}} \mathrm{HNO}_{3}$ & $5 \mathrm{~h}^{\mathrm{c}}$ & none & 1590 \\
\hline n.a. & 126 & MDZ-1089-65B & $0.01 \mathrm{M} \mathrm{HNO}_{3}$ & $5 \mathrm{~h}^{\mathrm{c}}$ & none & 1895 \\
\hline n.a. & 127 & MDZ-1089-65B & $2 \underline{\mathrm{M}} \mathrm{HNO}_{3}$ & $5 \mathrm{~h}^{\mathrm{c}}$ & none & 3446 \\
\hline n.a. & 128 & MDZ-1089-65B & $5 \underline{\mathrm{M}} \mathrm{HNO}_{3}$ & $5 \mathrm{~h}^{\mathrm{c}}$ & none & 1481 \\
\hline n.a. & 129 & MDZ-1089-65B & DI WATER & $5 h^{c}$ & none & 2696 \\
\hline n.a. & 130 & MDZ-1089-60A & DI WATER & $5 h^{c}$ & none & 4268 \\
\hline $12 / 20 / 93$ & 131 & MDZ-1089-65B & $0.01 \mathrm{M} \mathrm{HNO} 3$ & $5 \mathrm{~h}$ & $2.26 \mathrm{E}+04$ & 4490 \\
\hline $12 / 20 / 93$ & 132 & MDZ-1089-65B & $0.01 \underline{\mathrm{M}} \mathrm{HNO}_{3}$ & $5 \mathrm{~h}$ & $2.26 \mathrm{E}+05$ & 2943 \\
\hline $12 / 20 / 93$ & 133 & MDZ-1089-65B & $0.01 \underline{\mathrm{M}} \mathrm{HNO}_{3}$ & $25 \mathrm{~h}$ & $5.10 \mathrm{E}+06$ & 707 \\
\hline $12 / 20 / 93$ & 134 & MDZ-1089-65B & $2 \underline{\mathrm{M}} \mathrm{HNO}_{3}$ & $5 \mathrm{~h}$ & $2.26 \mathrm{E}+04$ & 2507 \\
\hline $12 / 20 / 93$ & 135 & MDZ-1089-65B & $2 \mathrm{M} \mathrm{HNO} 3$ & $5 \mathrm{~h}$ & $2.26 \mathrm{E}+05$ & 2334 \\
\hline
\end{tabular}


Table G-1. (contd)

\begin{tabular}{|c|c|c|c|c|c|c|}
\hline $\begin{array}{l}\text { Date } \\
\text { Irrad. }\end{array}$ & $\begin{array}{c}\text { Bead } \\
\text { Sample }\end{array}$ & $\begin{array}{c}\text { Coated } \\
\text { Particle ID } \\
\end{array}$ & $\begin{array}{l}\text { Contact } \\
\text { Solution }\end{array}$ & $\begin{array}{c}\text { Solution } \\
\text { Contact Time }\end{array}$ & $\begin{array}{l}\text { Dose } \\
\text { (rad) }\end{array}$ & $\begin{array}{c}\mathrm{K}_{\mathrm{d}^{\mathrm{a}}} \\
(\mathrm{mL} / \mathrm{g}) \\
\end{array}$ \\
\hline $12 / 20 / 93$ & 136 & MDZ-1089-65B & $2 \underline{\mathrm{M}} \mathrm{HNO}_{3}$ & $25 \mathrm{~h}$ & $5.10 E+06$ & 445 \\
\hline $12 / 20 / 93$ & 137 & MDZ-1089-65B & $5 \underline{\mathrm{M}} \mathrm{HNO}_{3}$ & $5 \mathrm{~h}$ & $2.26 \mathrm{E}+04$ & 1795 \\
\hline $12 / 20 / 93$ & 138 & MDZ-1089-65B & $5 \underline{\mathrm{M}} \mathrm{HNO}_{3}$ & $5 \mathrm{~h}$ & $2.26 \mathrm{E}+05$ & 1950 \\
\hline $12 / 20 / 93$ & 139 & MDZ-1089-65B & $5 \mathrm{M} \mathrm{HNO}_{3}$ & $25 \mathrm{~h}$ & $5.10 \mathrm{E}+06$ & 453 \\
\hline $12 / 20 / 93$ & 140 & MDZ-1089-60A & $0.01 M \mathrm{HNO}_{3}$ & $5 \mathrm{~h}$ & $2.26 \mathrm{E}+04$ & 3370 \\
\hline $12 / 20 / 93$ & 141 & MDZ-1089-60A & $0.01 \underline{\mathrm{M}} \mathrm{HNO}_{3}$ & $5 \mathrm{~h}$ & $2.26 \mathrm{E}+05$ & 2821 \\
\hline $12 / 20 / 93$ & 142 & MDZ-1089-60A & $0.01 \underline{\mathrm{M}} \mathrm{HNO}_{3}$ & $25 \mathrm{~h}$ & $5.10 \mathrm{E}+06$ & 2621 \\
\hline $12 / 20 / 93$ & 143 & MDZ-1089-60A & $2 \mathrm{M} \mathrm{HNO}_{3}$ & $5 \mathrm{~h}$ & $2.26 \mathrm{E}+04$ & 2618 \\
\hline $12 / 20 / 93$ & 144 & $\mathrm{MDZ}-1089-60 \mathrm{~A}$ & $2 \mathrm{M} \mathrm{HNO}_{3}$ & $5 \mathrm{~h}$ & $2.26 \mathrm{E}+05$ & 2952 \\
\hline $12 / 20 / 93$ & 145 & MDZ-1089-60A & $2 \underline{\mathrm{M}} \mathrm{HNO}_{3}$ & $25 \mathrm{~h}$ & $5.10 \mathrm{E}+06$ & 371 \\
\hline $12 / 20 / 93$ & 146 & MDZ-1089-60A & $5 \underline{\mathrm{M}} \mathrm{HNO}_{3}$ & $5 \mathrm{~h}$ & $2.26 \mathrm{E}+04$ & 1455 \\
\hline $12 / 20 / 93$ & 147 & MDZ-1089-60A & $5 \underline{\mathrm{M}} \mathrm{HNO}_{3}$ & $5 \mathrm{~h}$ & $2.26 \mathrm{E}+05$ & 1985 \\
\hline $12 / 20 / 93$ & 148 & MDZ-1089-60A & $5 \mathrm{M} \mathrm{HNO}_{3}$ & $25 \mathrm{~h}$ & $5.10 \mathrm{E}+06$ & 292 \\
\hline n.a.b & 149 & MDZ-1089-58A & $0.01 \underline{\mathrm{M}} \mathrm{HNO}_{3}$ & $4 h^{c}$ & none & 1362 \\
\hline n.a. & 150 & MDZ-1089-65B & $0.01 \underline{\mathrm{M}} \mathrm{HNO}_{3}$ & $4 \mathrm{~h}^{\mathrm{c}}$ & none & 2838 \\
\hline n.a. & 151 & MDZ-1089-60A & $0.01 \underline{\mathrm{MNO}} \mathrm{HNO}_{3}$ & $24 \mathrm{~h}^{\mathrm{c}}$ & none & 2542 \\
\hline n.a. & 152 & MDZ-1089-60A & $2 \mathrm{M} \mathrm{HNO} 3$ & $24 h^{c}$ & none & 1055 \\
\hline n.a. & 153 & MDZ-1089-60A & $5 \underline{\mathrm{M}} \mathrm{HNO}_{3}$ & $24 \mathrm{~h}^{\mathrm{c}}$ & none & 537 \\
\hline n.a. & 154 & MDZ-1089-65B & $0.01 \underline{\mathrm{M}} \mathrm{HNO}_{3}$ & $24 \mathrm{~h}^{\mathrm{c}}$ & none & 1517 \\
\hline n.a. & 155 & MDZ-1089-65B & $2 \underline{\mathrm{M}} \mathrm{HNO}_{3}$ & $24 h^{c}$ & none & 544 \\
\hline n.a. & 156 & MDZ-1089-65B & $5 \underline{\mathrm{M}} \mathrm{HNO}_{3}$ & $24 h^{c}$ & none & 778 \\
\hline n.a. & 157 & MDZ-1089-58A & DI WATER & $24 \mathrm{~h}^{\mathrm{c}}$ & none & 1347 \\
\hline n.a. & 158 & MDZ-1089-58A & $0.01 \mathrm{M} \mathrm{HNO}_{3}$ & $24 \mathrm{~h}^{\mathrm{c}}$ & none & 393 \\
\hline n.a. & 159 & MDZ-1089-58A & $2 \underline{\mathrm{M}} \mathrm{HNO}_{3}$ & $24 h^{c}$ & none & 257 \\
\hline n.a. & 160 & MDZ-1089-58A & $5 \mathrm{M} \mathrm{HNO}_{3}$ & $24 \mathrm{~h}^{\mathrm{c}}$ & none & 306 \\
\hline
\end{tabular}

aAll $\mathrm{K}_{\mathrm{d}}$ values obtained for americium in $2 \underline{\mathrm{M}} \mathrm{HNO}_{3} \mathrm{AT} 25^{\circ} \mathrm{C}$.

bNot applicable is represented by n.a.

cNo thermal cycle.

Variation in $\mathrm{K}_{\mathrm{d}}(\mathrm{Am})$ with Radiation Dose for Individual Batches of Particle Coatings

The changes in $\mathrm{K}_{\mathrm{d}}(\mathrm{Am})$ from $2 \mathrm{M} \mathrm{HNO}_{3}$ with radiation dose are plotted for individual batches of particle coatings in Figs. G-1 to G-9. The concentration of CMPO in TBP is listed in the caption of each figure.

Variation in $\mathrm{K}_{\mathrm{d}}(\mathrm{Am})$ with Radiation Lose for Different Acid Contact Solutions

The $K_{d}(A m)$ value is plotted versus the dose for specific irradiation solutions in Figs. G-10 through G-14. The symbols in these graphs refer to different particle coatings. A guide to the coating thicknesses and the CMPO concentration in TBP for these series is presented in Table G-2. 
Table G-2. Guide to Coating Parometers for Particles Used in Irradiations

\begin{tabular}{ccc}
\hline $\begin{array}{c}\text { Coated Particle } \\
\text { Identification }\end{array}$ & $\begin{array}{c}\text { Coating } \\
\text { Thickness } \\
(\mu \mathrm{m})\end{array}$ & $\begin{array}{c}\text { CMPO/TBP } \\
\text { Concentration } \\
\text { (mol/L) }\end{array}$ \\
\hline C-55 & 0.45 & 1.5 \\
K-113 or MDK-113 & 1.4 & 1.36 \\
K-119 or MDK-119 & 1.4 & 1.36 \\
LMC-30A & 1.0 & 1.0 \\
Z-22A or MDZ-22A & 1.25 & 1.2 \\
Z-46A or MDZ-46A & 1.0 & 1.5 \\
Z-53A or MDZ-53A & 1.25 & 0.8 \\
Z-58A or MDZ-58A & saturated & 1.2 \\
Z-60A & saturated & 1.36 \\
Z-65B & saturated & 0.58 \\
\hline
\end{tabular}

The coating thickness is based on two assumptions: (1) the coating has uniform thickness over 9- $\mu \mathrm{m}$-diameter spherical particles, and (2) no CMPO/TBP coats the evaporation flask. The saturated particles were loaded with solvent until they could absorb no more.

Variation in $\mathrm{K}_{\mathrm{d}}(\mathrm{Am})$ with Contact Time for Different Acid Contact Solutions

The $\mathrm{K}_{\mathrm{d}}(\mathrm{Am})$ value is plotted versus contact time for particle coatings in Figs. G-15 through G-17. The series in these graphs refer to different contact solutions. A guide to the coating thicknesses and the CMPO concentration in TBP for these series is presented above in Table G-2.

Variation in $\mathrm{K}_{\mathrm{d}}(\mathrm{Am})$ with Acid Contact Time and Radiation Dose for Specific Particle Coatings and Contact Solutions

The variations of $\mathrm{K}_{\mathrm{d}}(\mathrm{Am})$ with solution contact time and radiation dose for MACS particles coated with $0.58,1.2$, and $1.36 \underline{\mathrm{M}}$ CMPO/TBP are plotted below in Figs. G-18 to G-27. Each figure contains data for only one contact solution. The $\mathrm{K}_{\mathrm{d}}(\mathrm{Am})$ values corresponding to the $1.0 \times 10^{2}$ rad dose were not exposed to the ${ }^{60} \mathrm{Co} \gamma$-ray source; a nonzero dose was required because of the log scale.

\section{Rarticles Coated with 1.2M CMPO/TBP}

The particles coated with 1.2M CMPO/TBP (MDZ-1089-58A) were exposed to three radiation doses in four different contact solutions. The $\mathrm{K}_{d}(\mathrm{Am})$ value corresponding to zero contact time and the $1.0 \times 10^{2} \mathrm{rad}$ dose is an average of several measurements. The individual $\mathrm{K}_{\mathrm{d}}$ measurements were scattered over a wide range, indicating the coating was not homogeneous (Table G-3).

The uncertainty in the average $\mathrm{K}_{\mathrm{d}}(\mathrm{Am})$ is almost entirely due to the scatter in the individual measurements. The large uncertainty in the unexposed particle $K_{d}$ value prevents the accurate measurement of small changes in the partitioning coefficient. 


\section{Particles Coated with 1.36M CMPO/TBP}

The particles coated with 1.36M CMPO/TBP (MDZ-1089-60A) were exposed to three radiation doses in three different contact solutions. The $K_{d}(A m)$ value corresponding to zero contact time and the $1.0 \times 10^{2} \mathrm{rad}$ dose is an average of $\varepsilon$ ew measurements. The individual $\mathrm{K}_{\mathrm{d}}$ measurements were distributed from 3300 to 3500 and the average was $3410 \pm 60$. This particle coating was the most homogeneous one used in irradiations.

\section{Particles Coated with 0.58M CMPO/TBP}

The particles coated with $0.58 \mathrm{M}$ CMPO/TBP (MDZ-1089-65B) were exposed to three radiation doses in three different contact solutions. The $\mathrm{K}_{\mathrm{d}}(\mathrm{Am})$ value corresponding to zero contact time and the $1.0 \times 10^{2} \mathrm{rad}$ dose is an average of several measurements. The individual $\mathrm{K}_{\mathrm{d}}$ measurements were scattered over a wide range, indicating the coating was not homogeneous (Table G-4).

The uncertainty in the average $\mathrm{K}_{\mathrm{d}}(\mathrm{Am})$ is due almost entirely to the scatter in the individual measurements. The large uncertainty in the unexposed particle $\mathrm{K}_{\mathrm{d}}$ value obscures the accurate measurement of small changes in the partitioning coefficient.

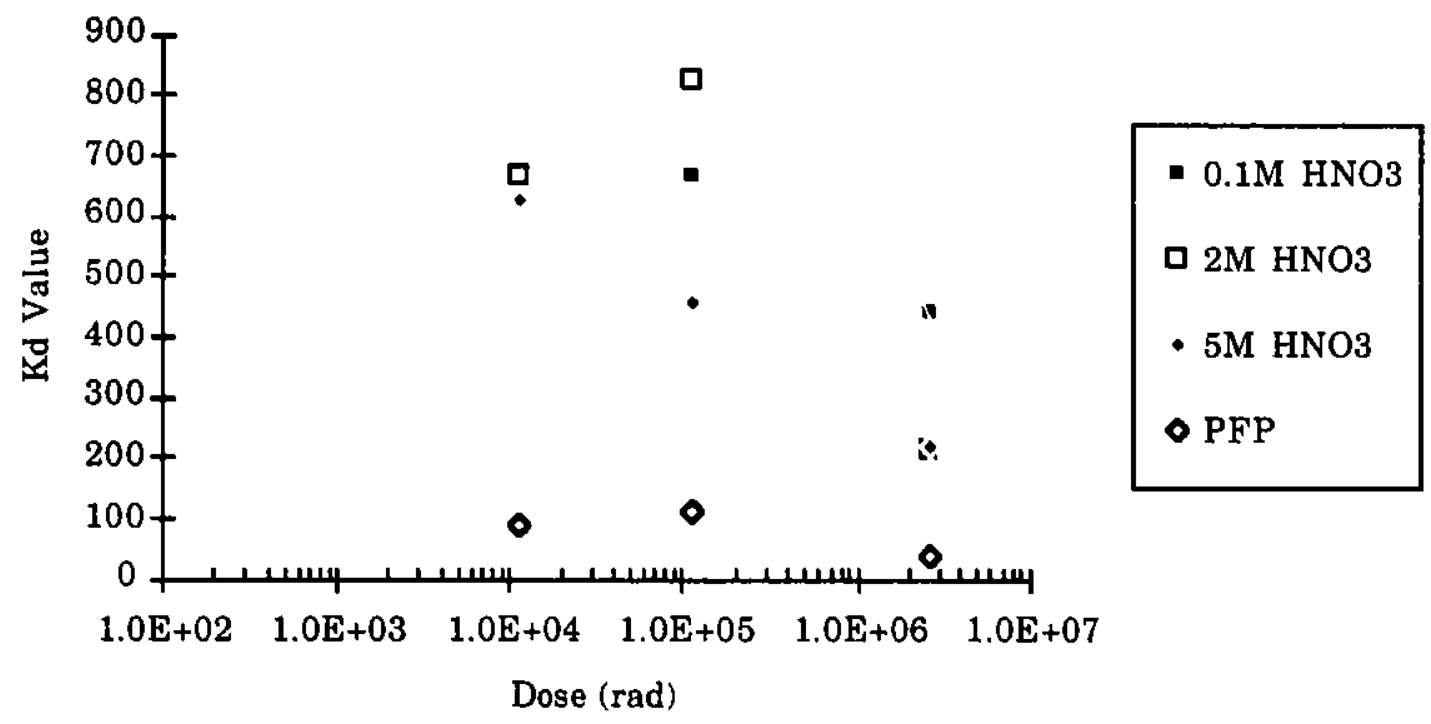

Fig. G-1. Variation in $\mathrm{K}_{\mathrm{d}}(\mathrm{Am})$ from $2 \underline{\mathrm{M}} \mathrm{HNO}_{3}$ with Absorbed Dose for MACS Particles MDK-1064-113 Coated with 1.36M CMPO/TBP 


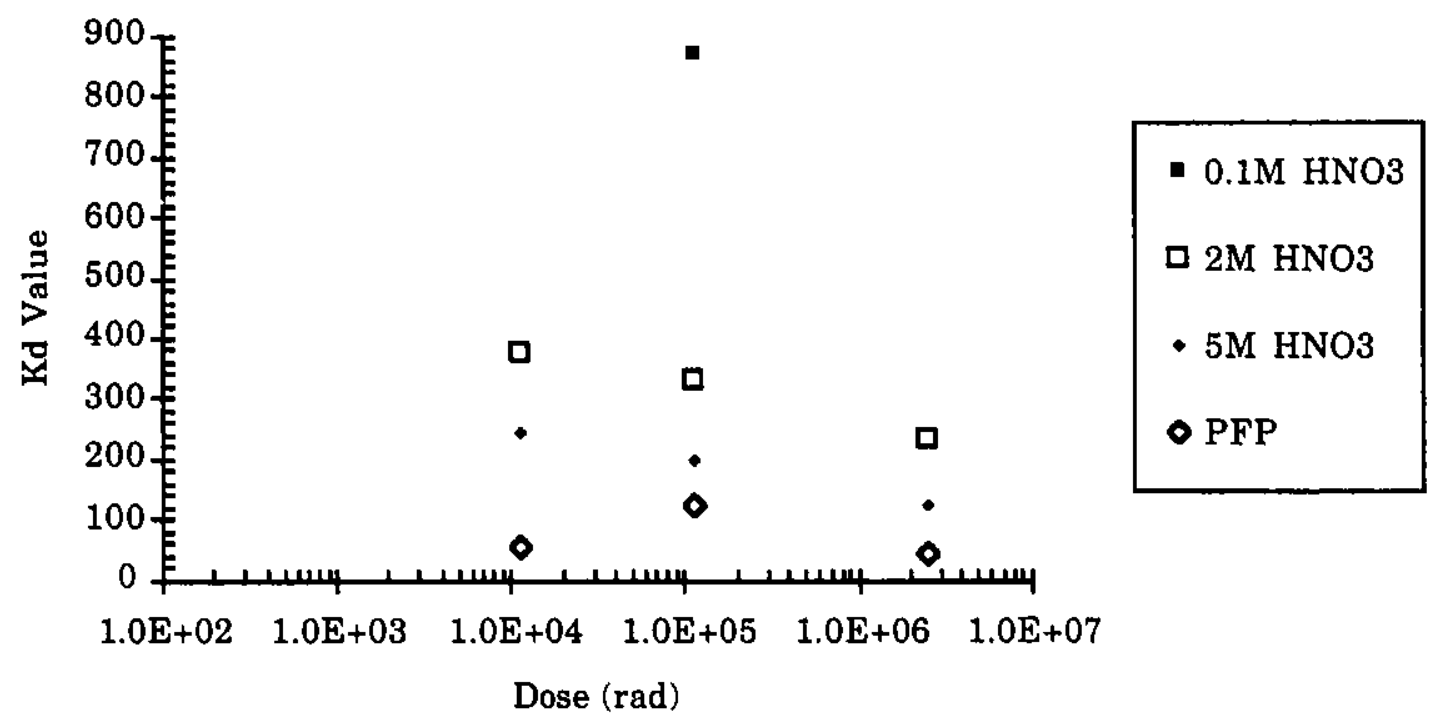

Fig. G-2. Variation in $\mathrm{K}_{\mathrm{d}}(\mathrm{Am})$ from $2 \underline{\mathrm{M}} \mathrm{HNO}_{3}$ with Absorbed Dose for MACS Particles MDK-1064-119 Coated with 1.36M CMPO/TBP

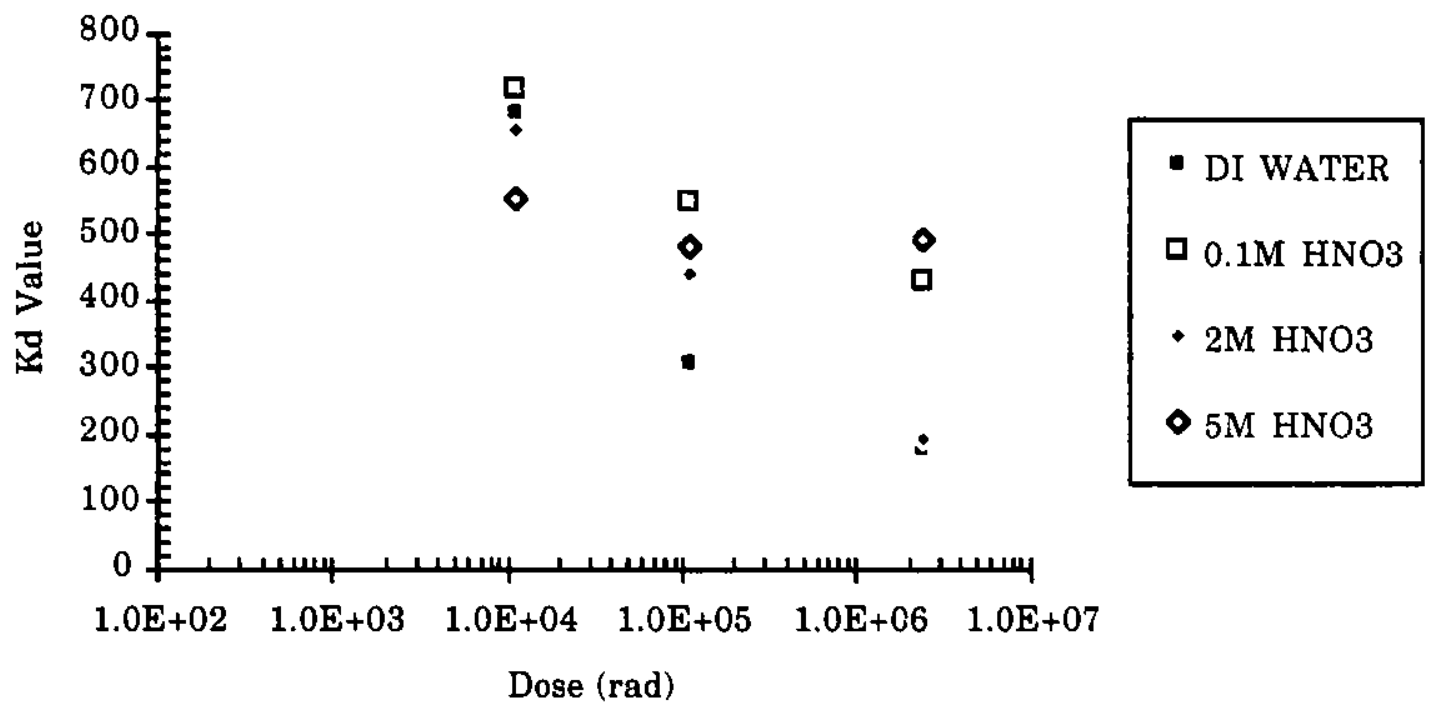

Fig. G-3. Variation in $\mathrm{K}_{\mathrm{d}}(\mathrm{Am})$ from $2 \mathrm{M} \mathrm{HNO}_{3}$ with Absorbed Dose for MACS Particles MDZ-1089-22A Coated with 1.2M CMPO/TBP 


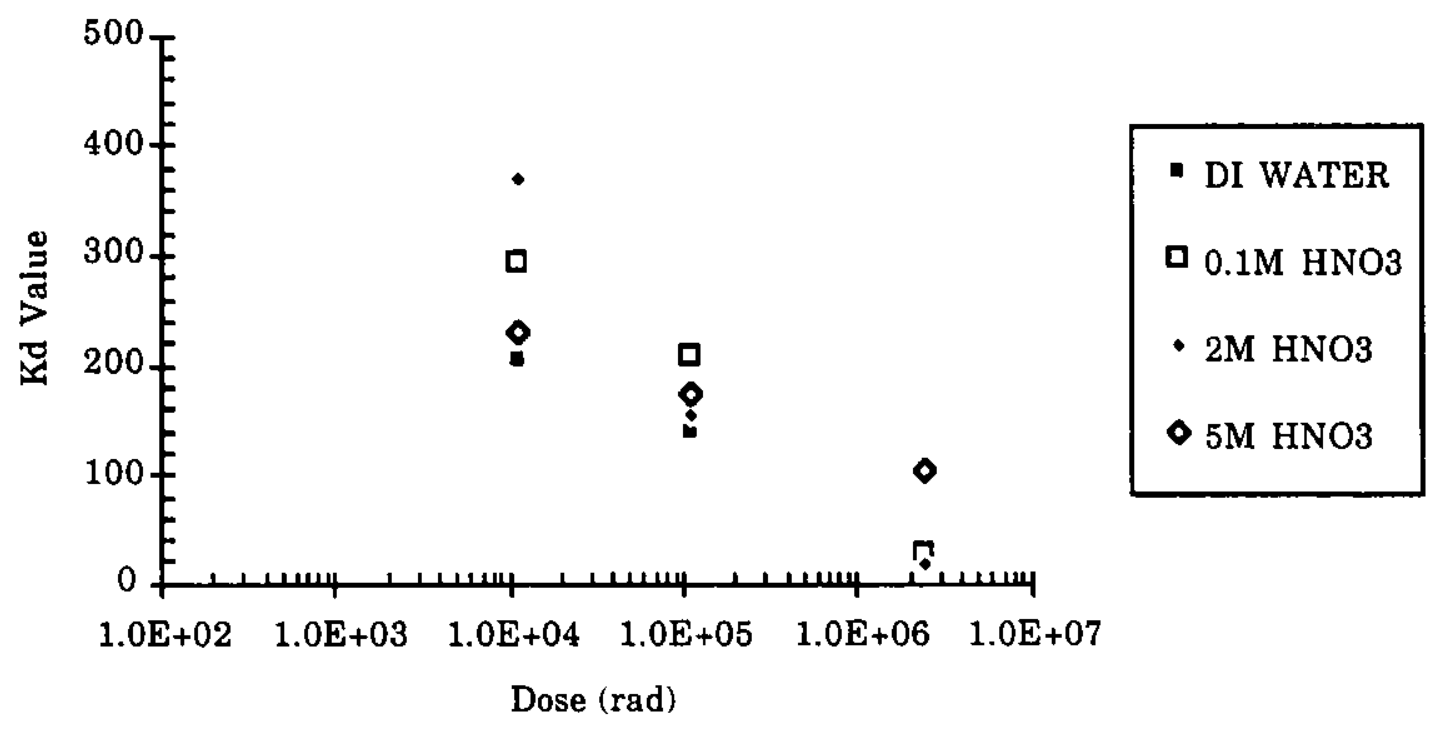

Fig. G-4. Variation in $\mathrm{K}_{\mathrm{d}}(\mathrm{Am})$ from $2 \mathrm{M} \mathrm{HNO}_{3}$ with Absorbed Dose for MACS Particles MDZ-1089-46A Coated with 1.5 $\mathrm{M}$ CMPO/TBP

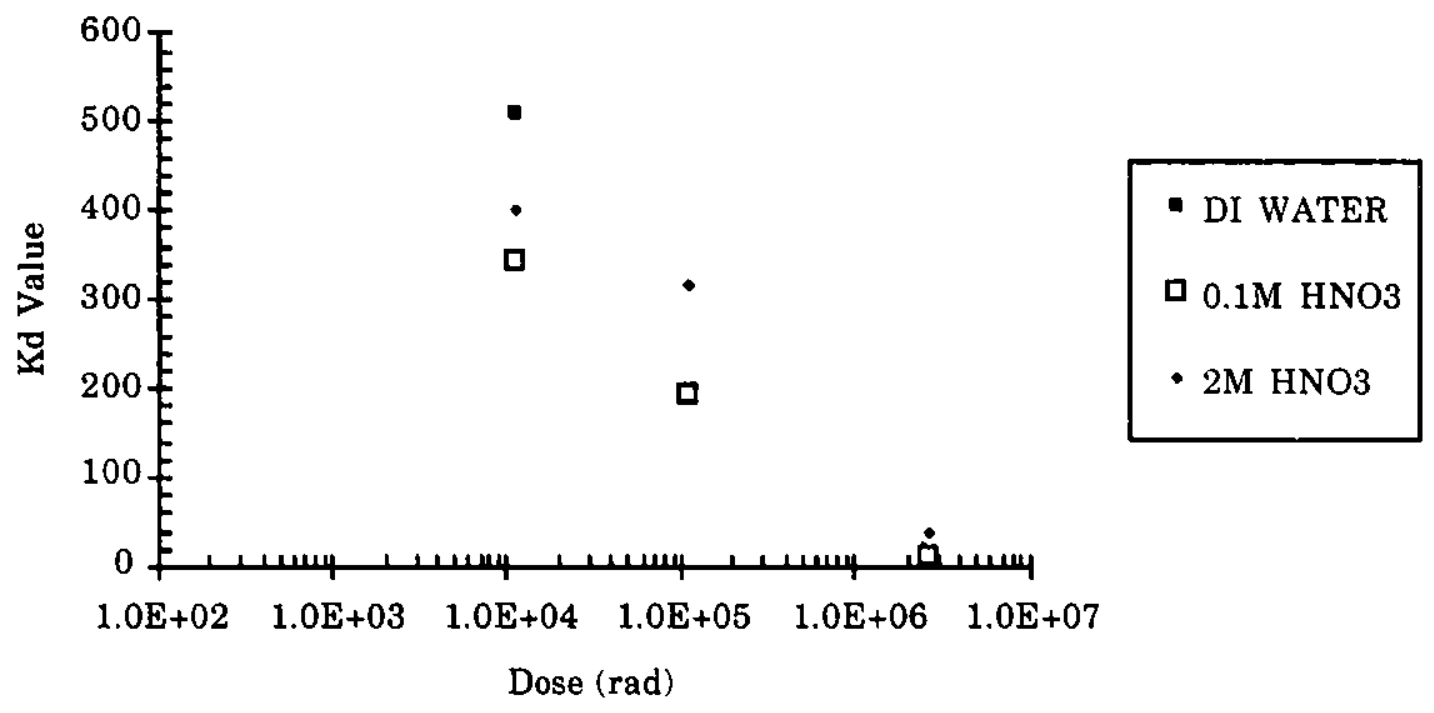

Fig. G-5. Variation in $\mathrm{K}_{\mathrm{d}}(\mathrm{Am})$ from $2 \underline{\mathrm{M}} \mathrm{HNO}_{3}$ with Absorbed Dose for MACS Particles MDZ-1089-53A Coated with 0.8M CMPO/TBP 


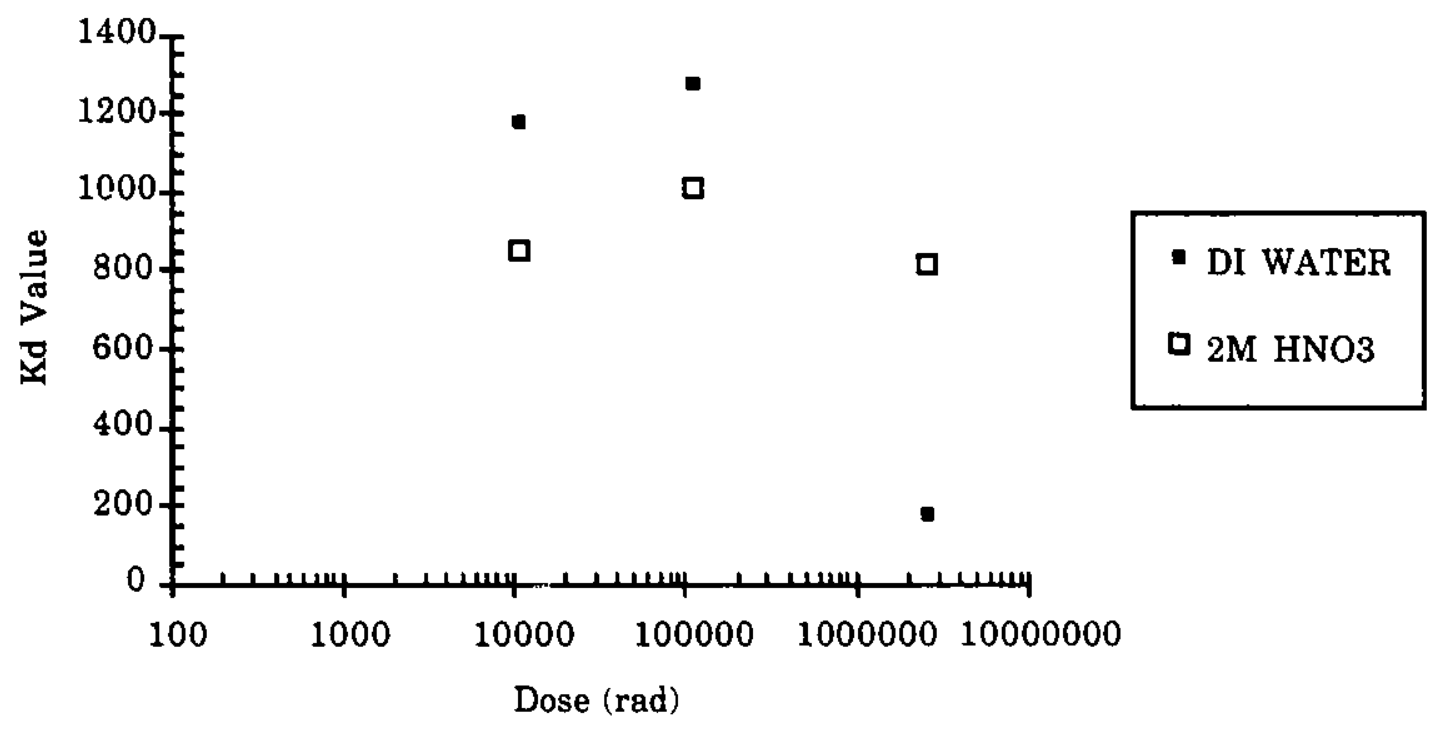

Fig. G-6. Variation in $\mathrm{K}_{\mathrm{d}}(\mathrm{Am})$ from $2 \mathrm{M} \mathrm{HNO}_{3}$ with Absorbed Dose for MACS Particles LMC-1064-55 Coated with 1.5 $\underline{\mathrm{M}}$ CMPO/TBP

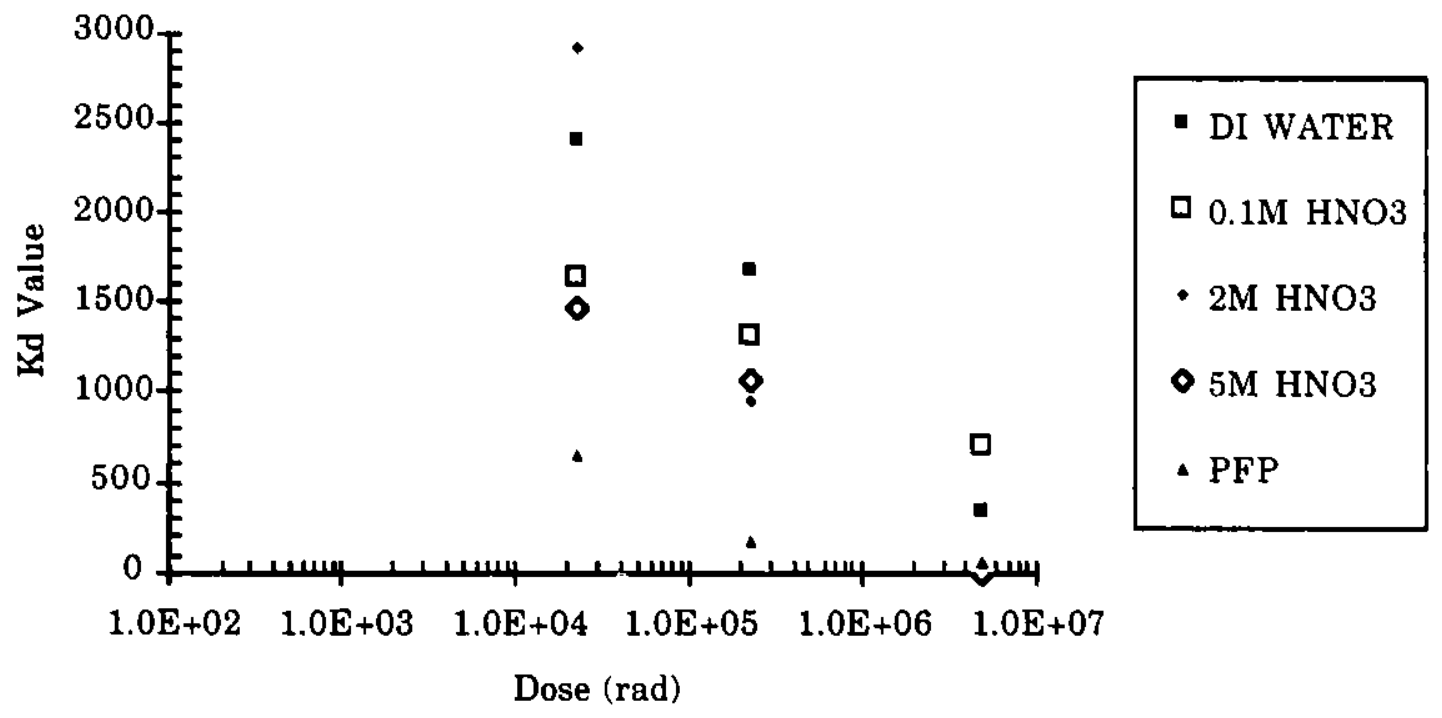

Fig. G-7. Variation in $\mathrm{K}_{\mathrm{d}}(\mathrm{Am})$ from $2 \underline{\mathrm{M}} \mathrm{HNO}_{3}$ with Absorbed Dose for MACS Particles MDZ-1089-58A Coated with 1.2M CMPO/TBP 


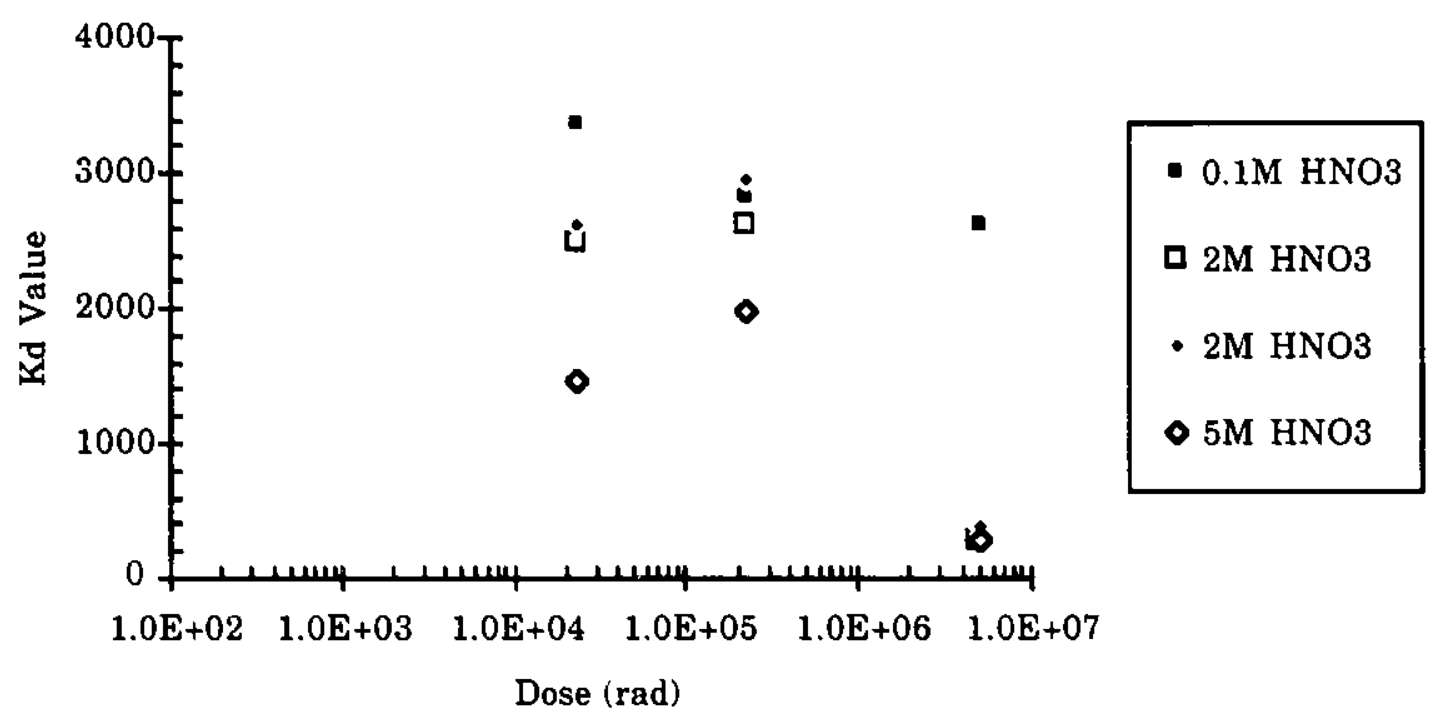

Fig. G-8. Variation in $\mathrm{K}_{\mathrm{d}}(\mathrm{Am})$ from $2 \underline{\mathrm{M}} \mathrm{HNO}_{3}$ with Absorbed Dose for MACS Particles MDZ-1089-60A Coated with 1.36M CMPO/TBP

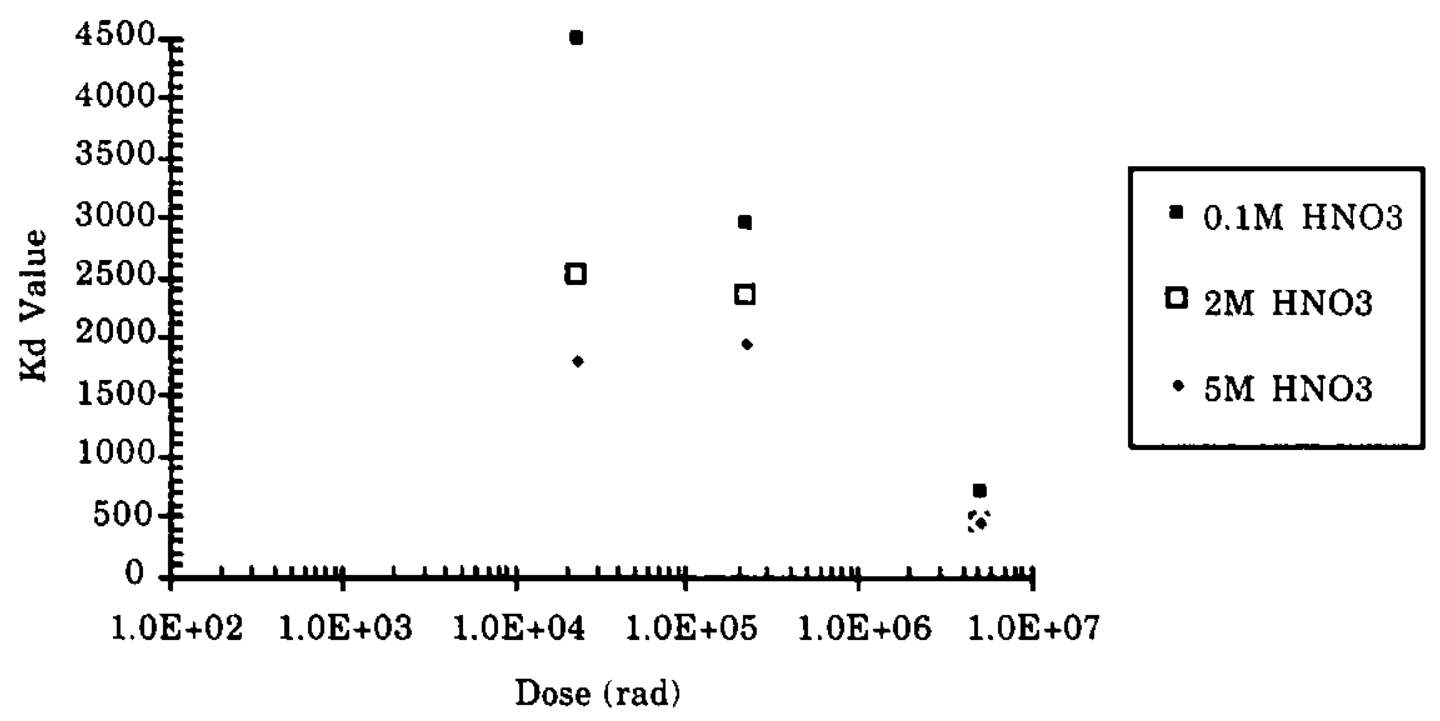

Fig. G-9. Variation in $\mathrm{K}_{\mathrm{d}}(\mathrm{Am})$ from $2 \underline{\mathrm{M}} \mathrm{HNO}_{3}$ with Absorbed Dose for MACS Particles MDZ-1089-65B Coated with 0.58M CMPO/TBP 


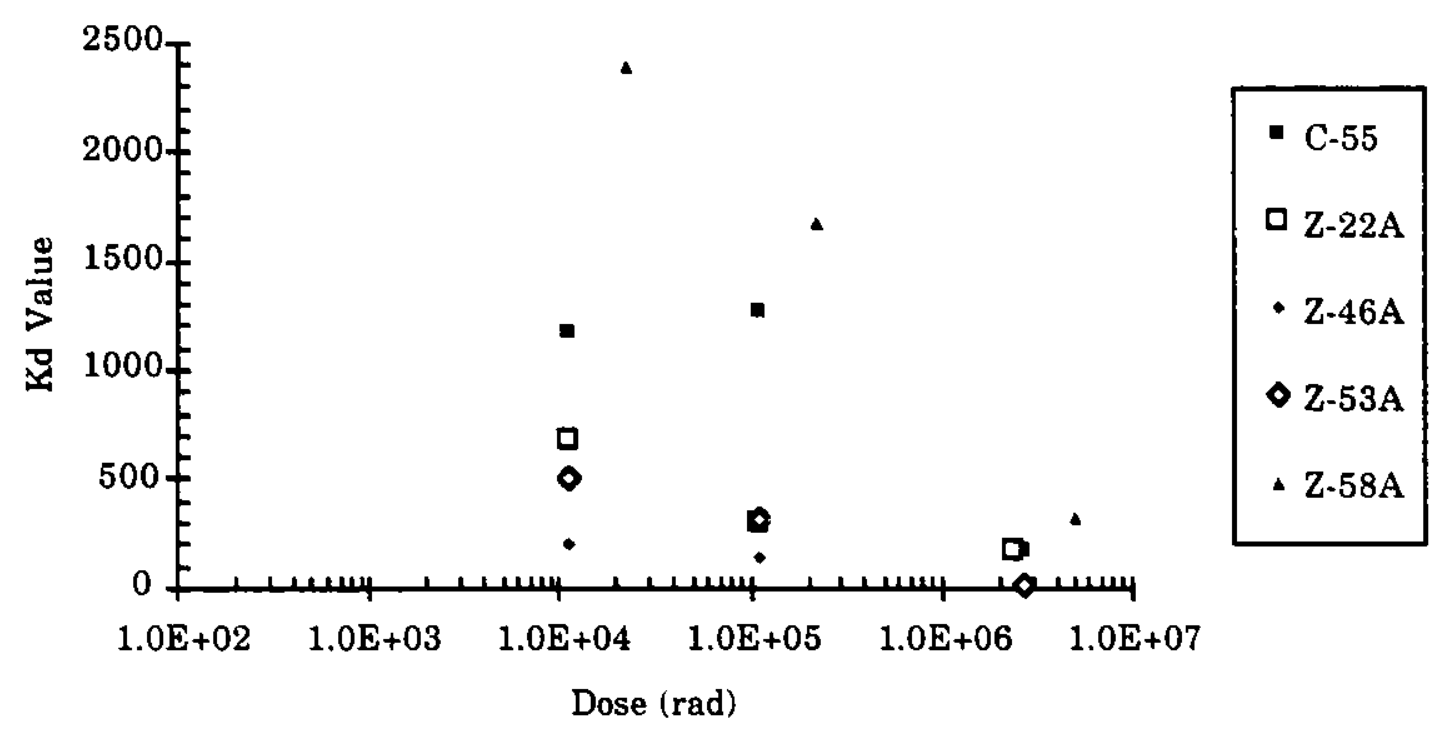

Fig. G-10. Variation in $\mathrm{K}_{\mathrm{d}}(\mathrm{Am})$ from $2 \mathrm{M} \mathrm{HNO}_{3}$ with Absorbed Dose for Particles Contacted with Deionized Water during Irradiation

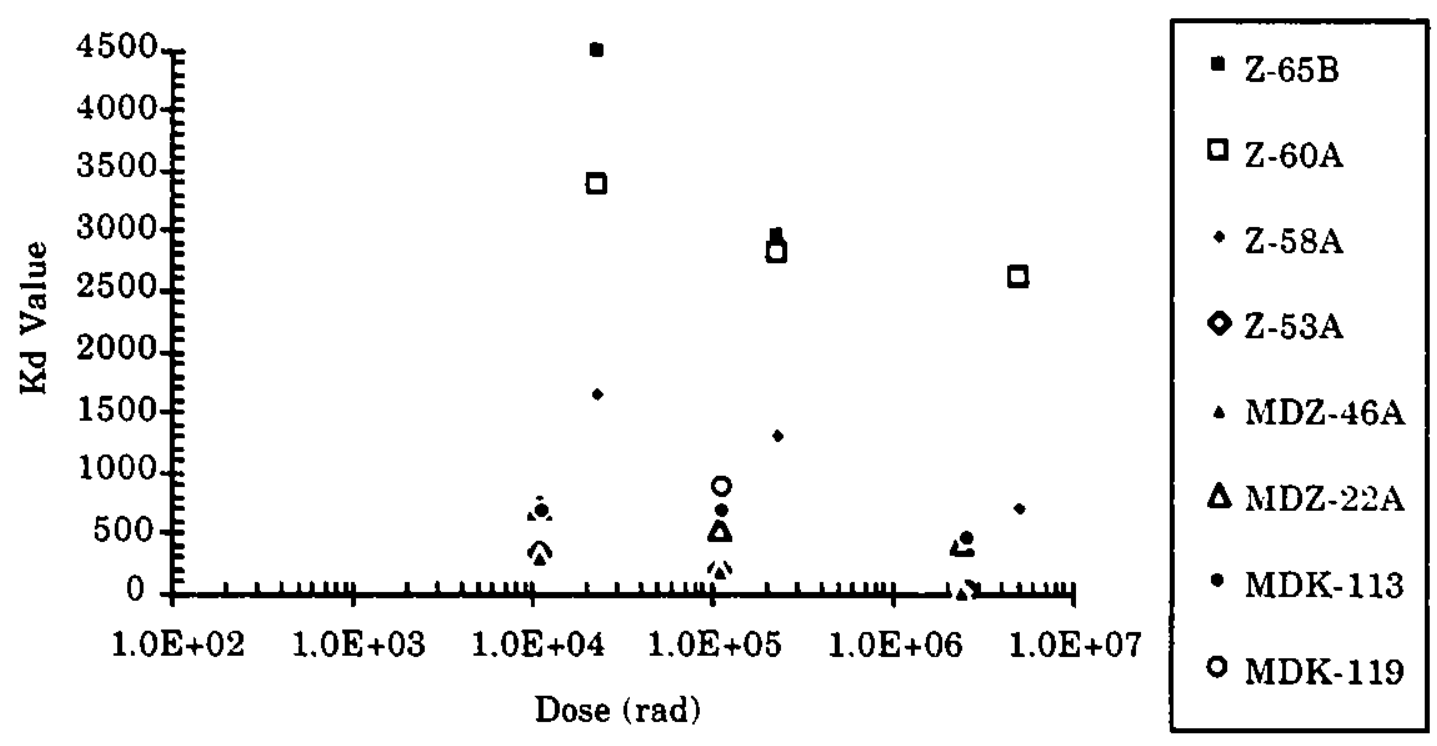

Fig. G-11. Variation in $\mathrm{K}_{\mathrm{d}}(\mathrm{Am})$ from $2 \mathrm{M} \mathrm{HNO}_{3}$ with Absorbed Dose for Particles Contacted with $0.1 \mathrm{M} \mathrm{HNO} \mathrm{HN}_{3}$ during Irradiation 


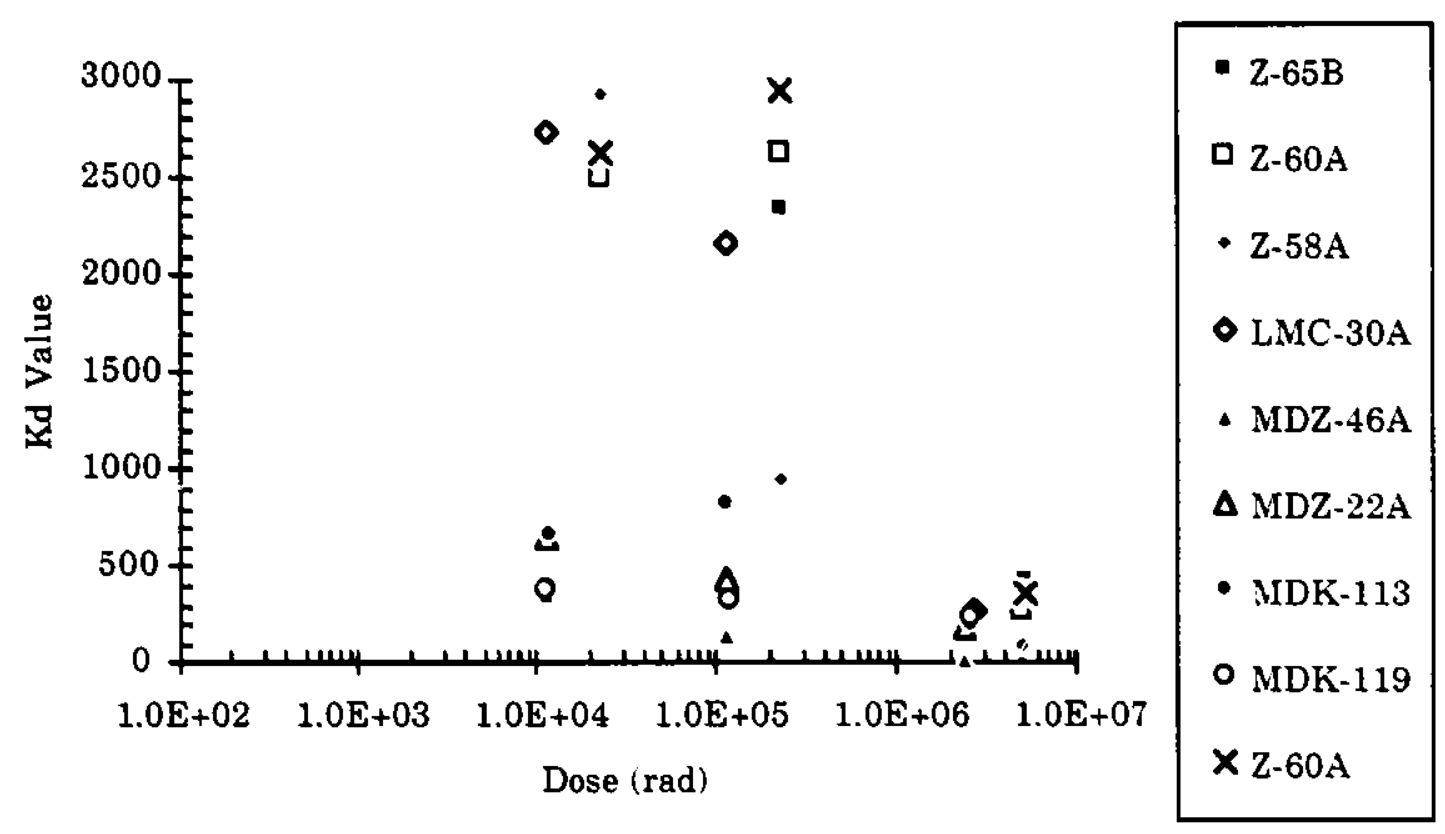

Fig. G-12. Variation in $\mathrm{K}_{\mathrm{d}}(\mathrm{Am})$ from $2 \mathrm{M} \mathrm{HNO}_{3}$ with Absorbed Dose for Particles Contacted with $2 \mathrm{M} \mathrm{HNO} 3$ during Irradiation

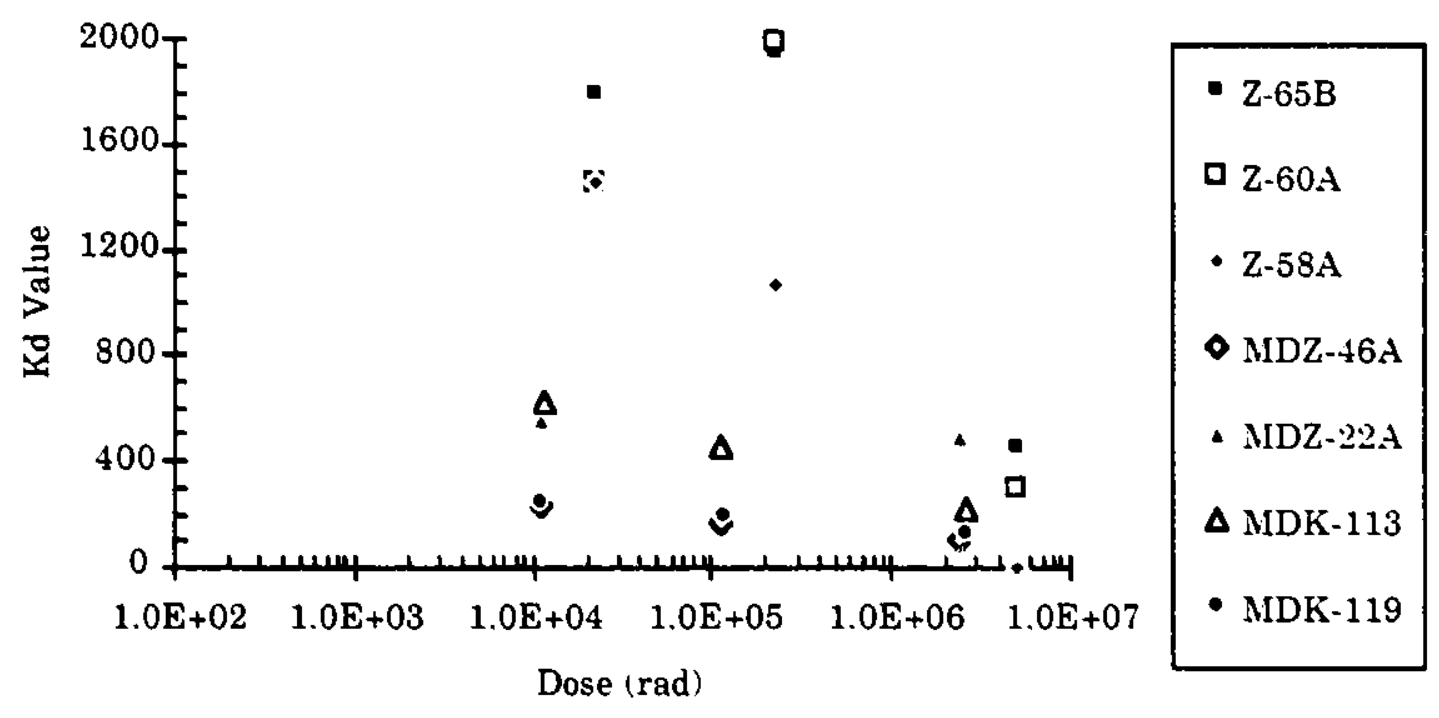

Fig. G-13. Variation in $\mathrm{K}_{\mathrm{d}}(\mathrm{Am})$ from $2 \mathrm{M} \mathrm{HNO}_{3}$ with Absorbed Dose for Particles Contacted with $5 \underline{\mathrm{M}} \mathrm{HNO}_{3}$ during Irradiation 


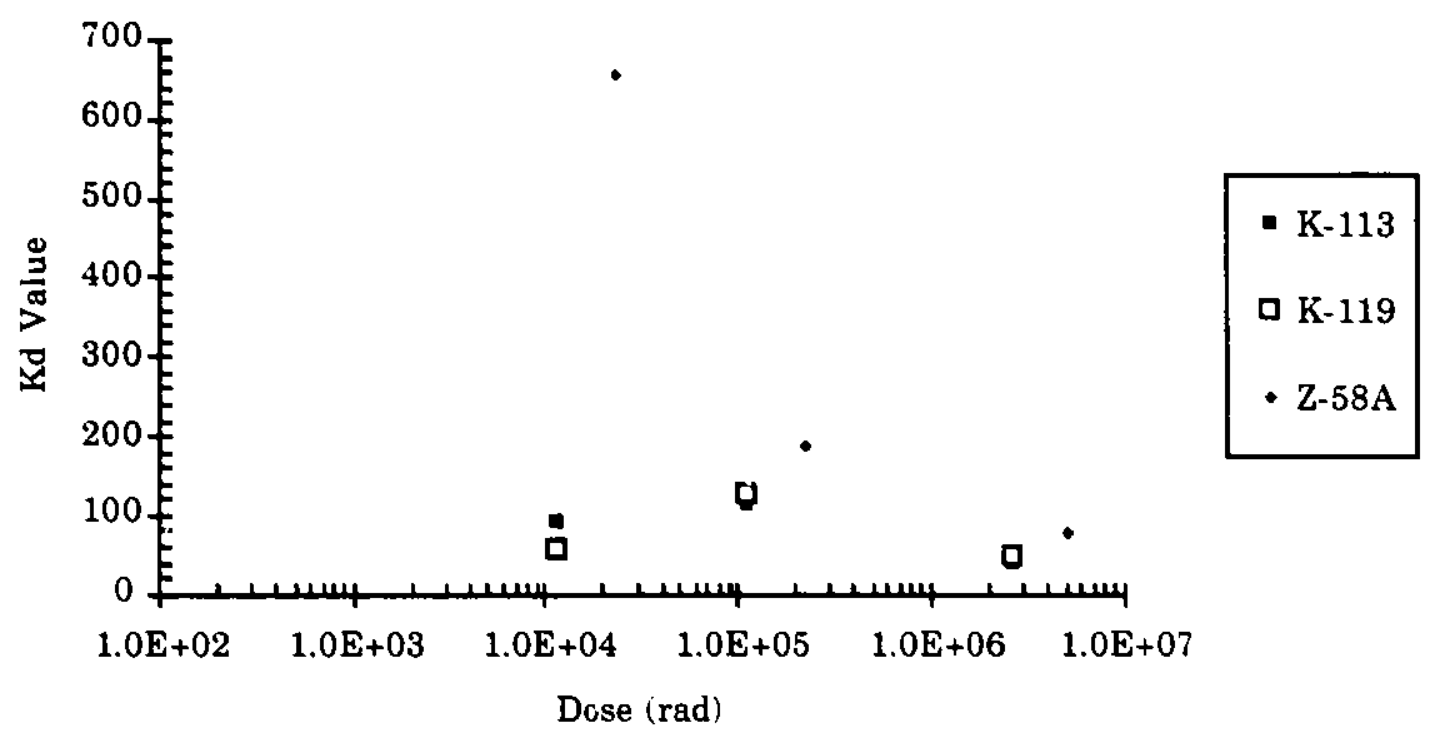

Fig. G-14. Variation in $\mathrm{K}_{\mathrm{d}}(\mathrm{Am})$ from $2 \mathrm{MNO}_{3}$ with Absorbed Dose for Particles Contacted with Dissolved PFP Sludge Simulant during Irradiation

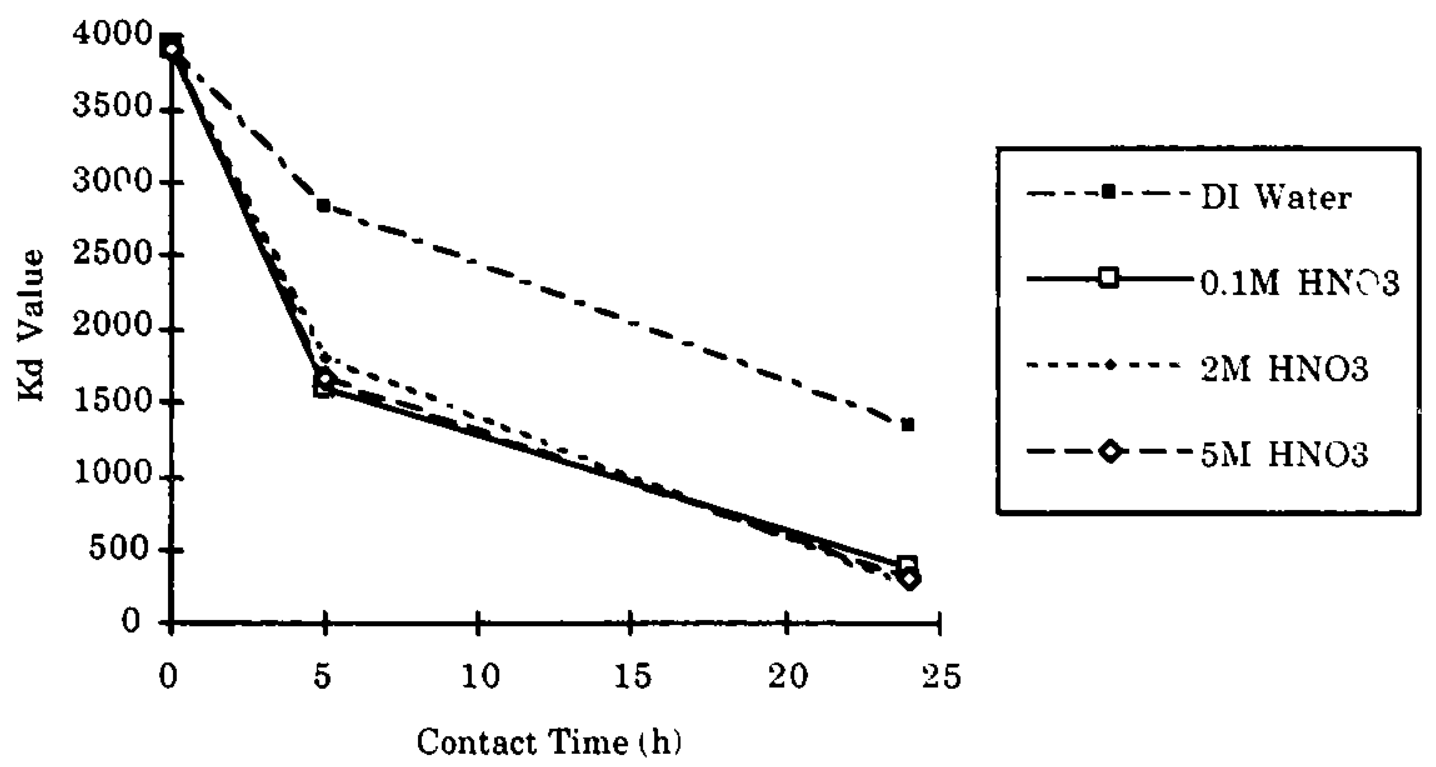

Fig. G-15. Variation in $\mathrm{K}_{\mathrm{d}}(\mathrm{Am})$ from $2 \underline{\mathrm{M}} \mathrm{HNO}_{3}$ with Solution Contact Time for MACS Particles MDZ-1089-58A Coated with 1.2M CMPO/TBP 


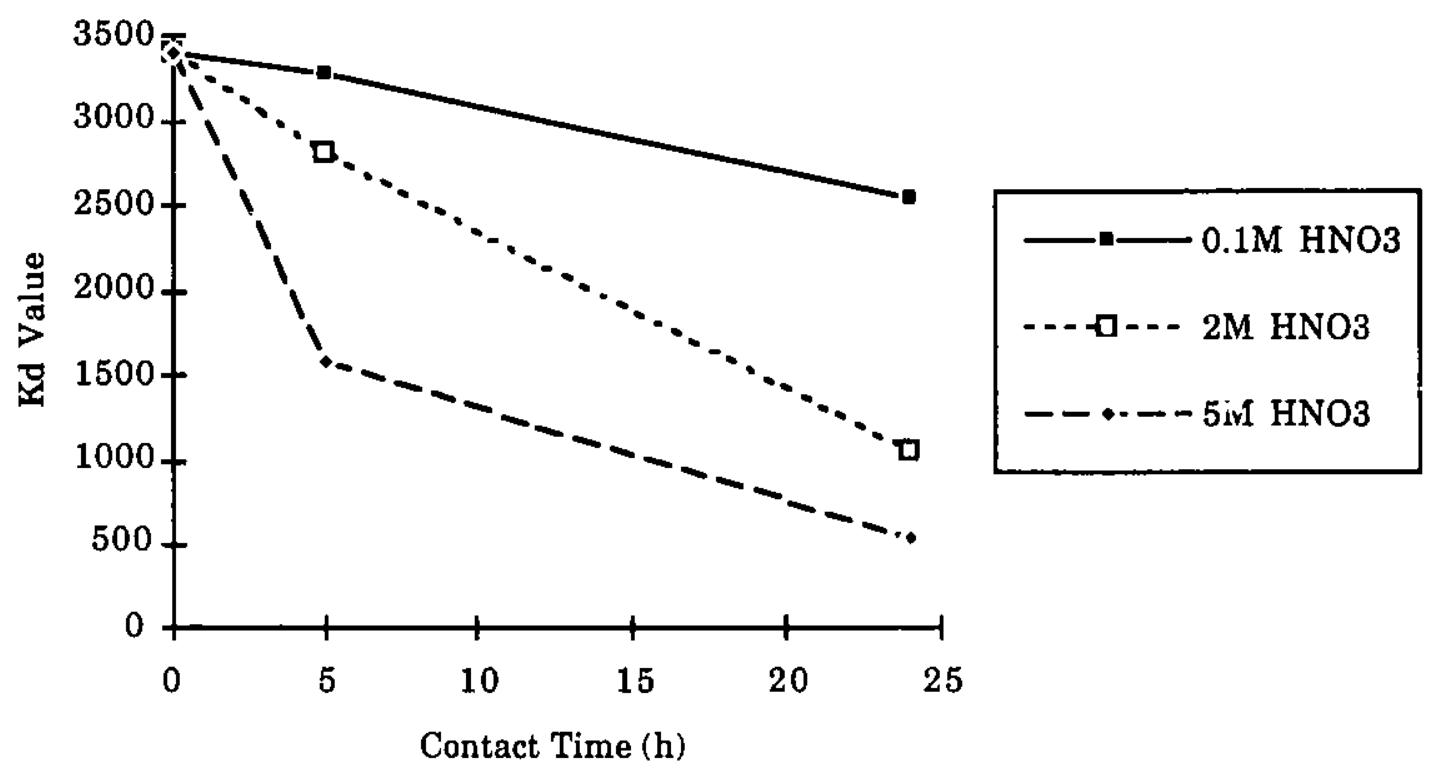

Fig. G-16. Variation in $\mathrm{K}_{\mathrm{d}}(\mathrm{Am})$ from $2 \mathrm{M} \mathrm{HNO}_{3}$ with Solution Contact Time for MACS Particles MDZ-1089-60A Coated with 1.36M CMPO/TBP

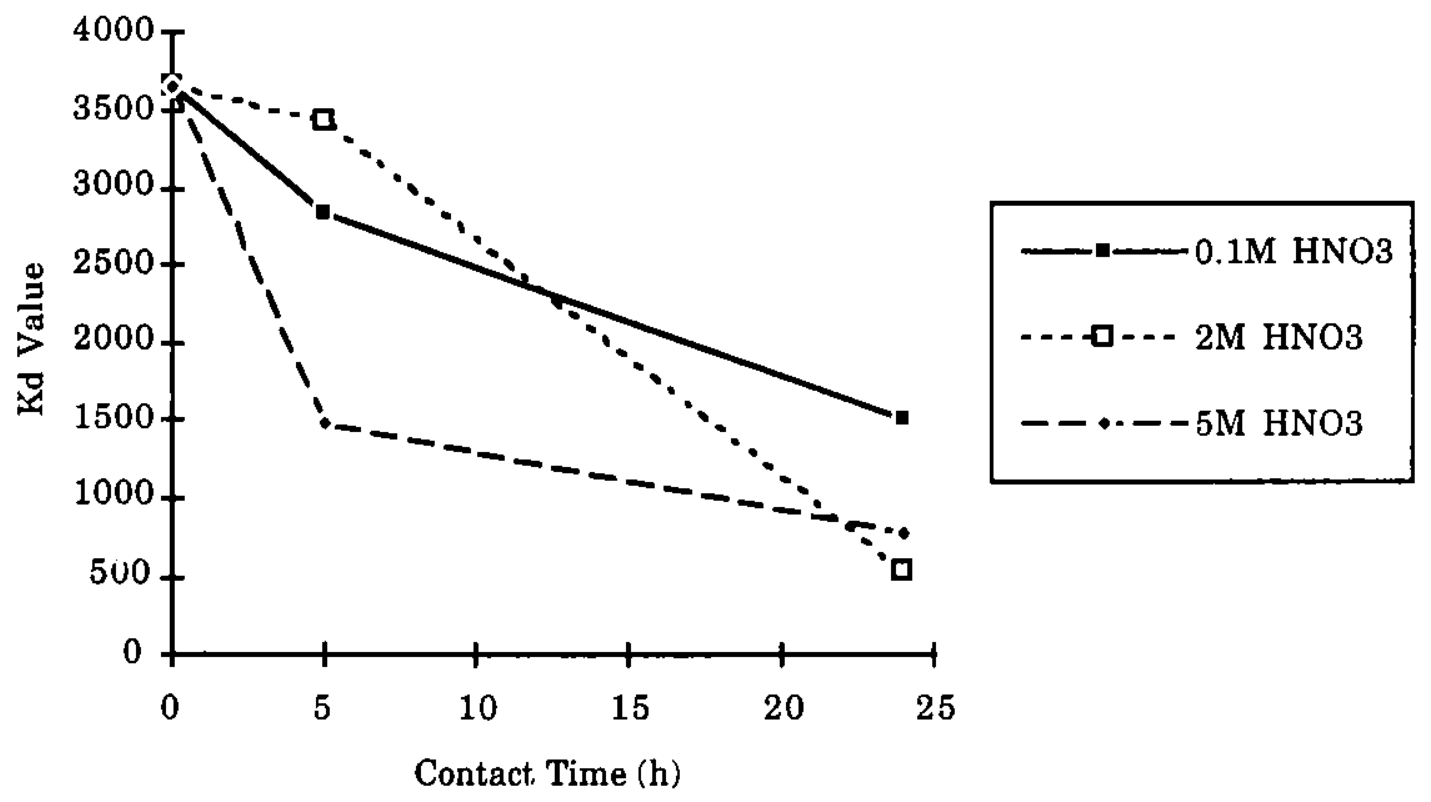

Fig. G-17. Variation in $\mathrm{K}_{\mathrm{d}}(\mathrm{Am})$ from $2 \underline{\mathrm{M}} \mathrm{HNO}_{3}$ with Solution Contact Time for MACS Particles MDZ-1089-65B Coated with 0.58 $\mathrm{M}$ CMPO/TBP 


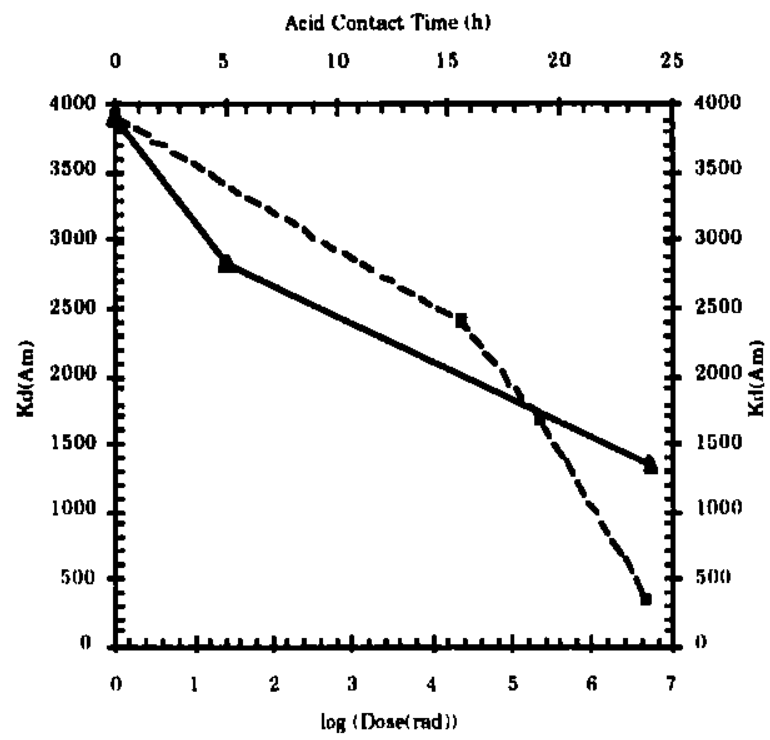

- Radiation $\longrightarrow$ Acid Contact

Fig. G-18. Variation in $\mathrm{K}_{\mathrm{d}}(\mathrm{Am})$ from $2 \mathrm{M} \mathrm{HNO}_{3}$ with Solution Contact Time and Radiation Dose for MACS Particles MDZ-1089-58A Coated with 1.2M CMPO/TBP in Contact with Deionized Water

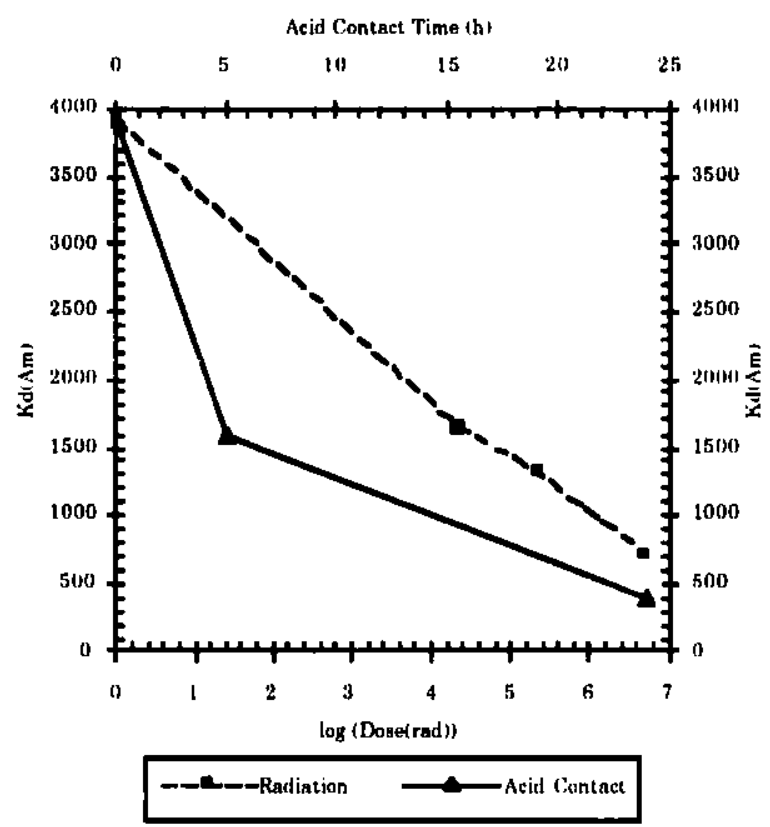

Fig. G-19. Variation in $\mathrm{K}_{\mathrm{d}}(\mathrm{Am})$ from $2 \underline{\mathrm{M}} \mathrm{HNO}_{3}$ with Solution Contact Time and Radiation Dose for MACS Particles MDZ-1089-58A Coated with 1.2M CMPO/TBP in Contact with $0.1 \underline{\mathrm{M}} \mathrm{HNO}_{3}$ 


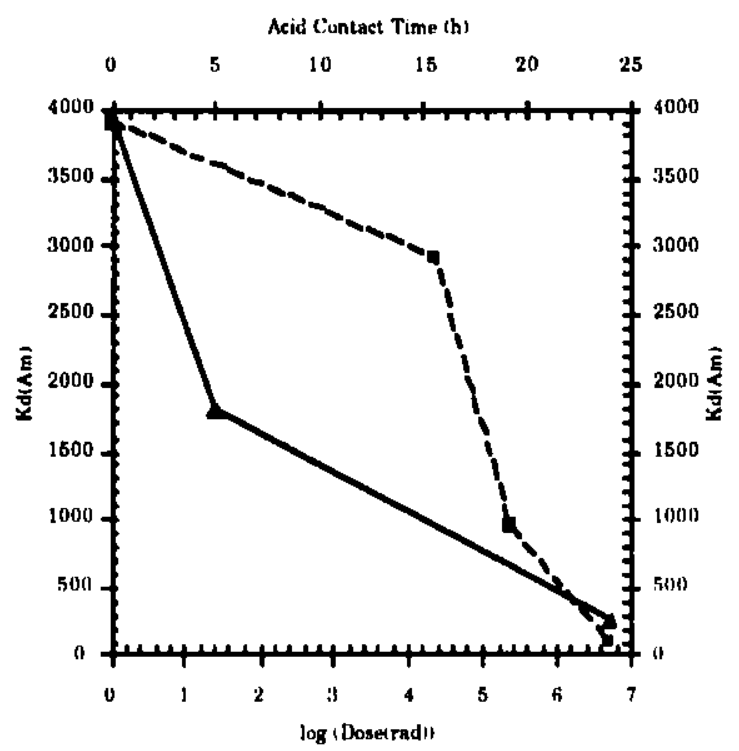

- - Acid Cantact

Fig. G-20. Variation in $\mathrm{K}_{\mathrm{d}}(\mathrm{Am})$ from $2 \mathrm{M} \mathrm{HNO}_{3}$ with Solution Contact Time and Radiation Dose for MACS Particles MDZ-1089-58A Coated with 1.2M CMPO/TBP in Contact with $2 \underline{\mathrm{M}} \mathrm{HNO}_{3}$

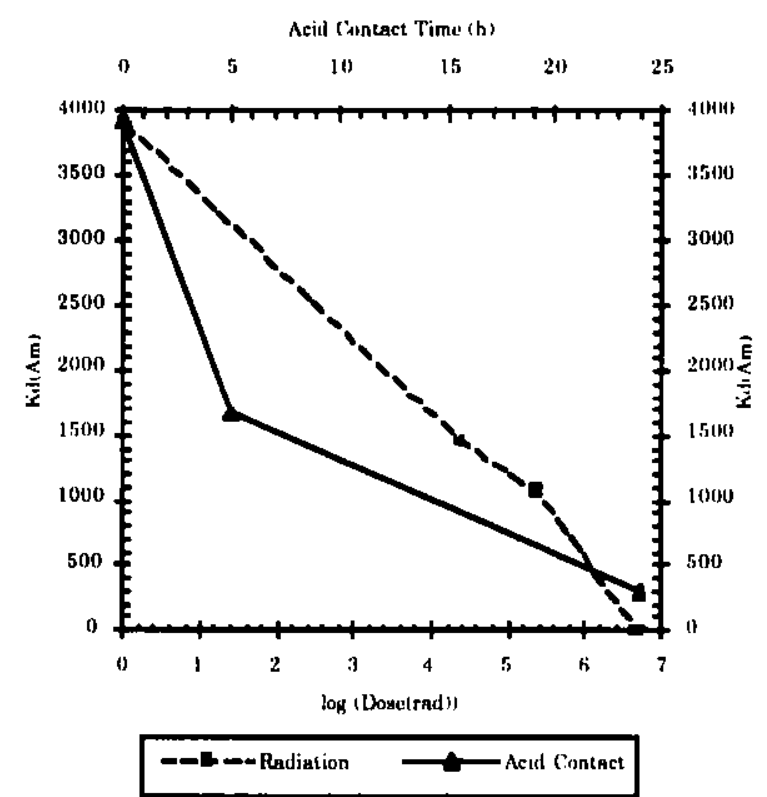

Fig. G-21. Variation in $\mathrm{K}_{\mathrm{d}}(\mathrm{Am})$ from $2 \mathrm{M} \mathrm{HNO}_{3}$ with Solution Contact Time and Radiation Dose for MACS Particles MDZ-1089-58A Coated with 1.2M CMPO/TBP in Contact with $5 \underline{\mathrm{M}} \mathrm{HNO}_{3}$ 


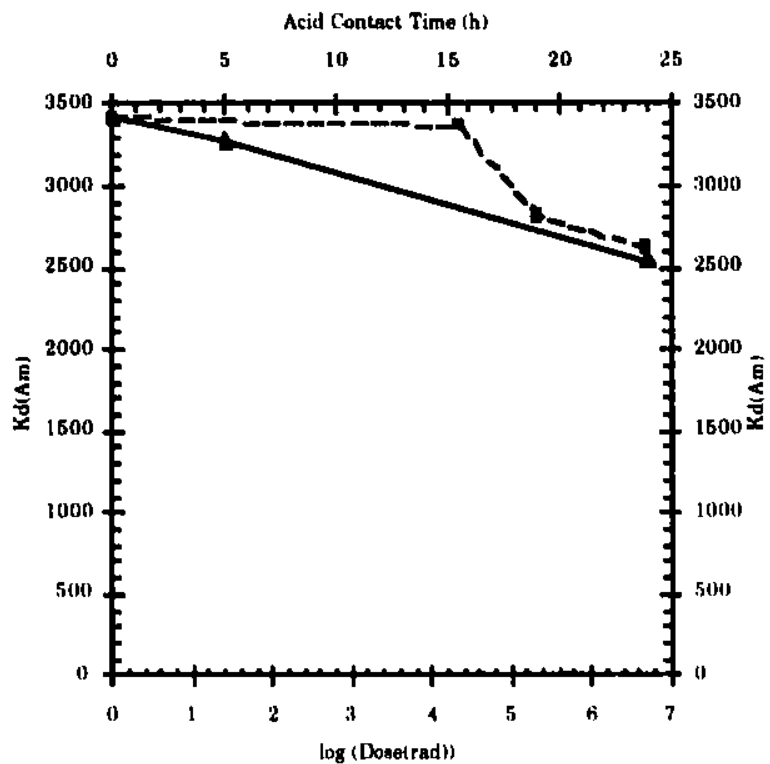

- Acid Contact

Fig. G-22. Variation in $\mathrm{K}_{\mathrm{d}}(\mathrm{Am})$ from $2 \underline{\mathrm{M}} \mathrm{HNO}_{3}$ with Solution Contact Time and Radiation Dose for MACS Particles MDZ-1089-60A Coated with 1.36M CMPO/TBP in Contact with $0.1 \mathrm{M} \mathrm{HNO}_{3}$

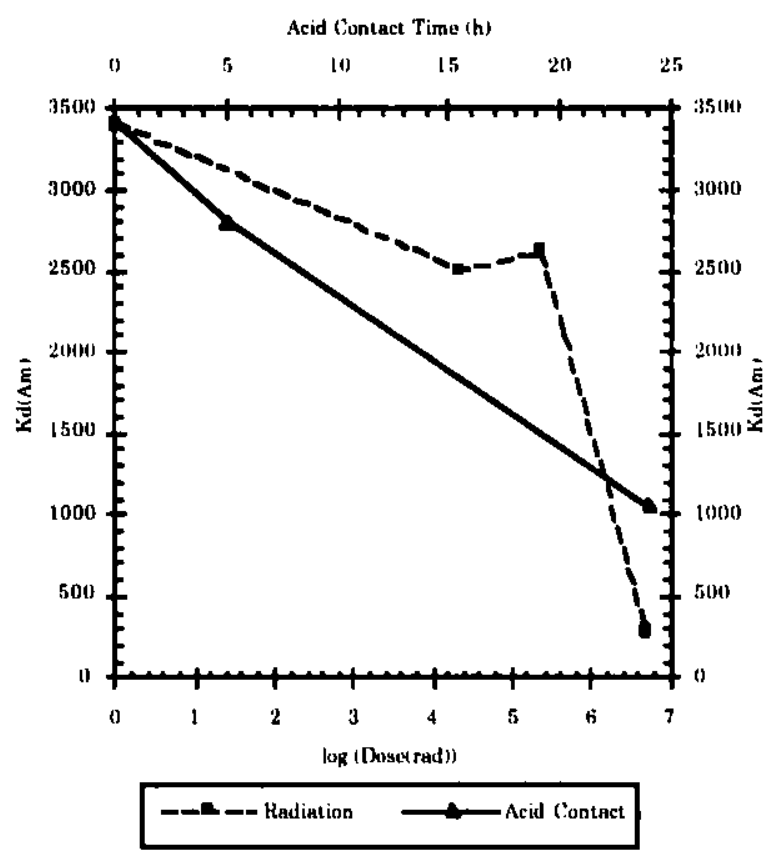

Fig. G-23. Variation in $\mathrm{K}_{\mathrm{d}}(\mathrm{Am})$ from $2 \underline{\mathrm{M}} \mathrm{HNO}_{3}$ with Solution Contact Time and Radiation Dose for MACS Particles MDZ-1089-60A Coated with $1.36 \mathrm{M}$ CMPO/TBP in Contact with $2 \underline{\mathrm{M}} \mathrm{HNO}_{3}$ 


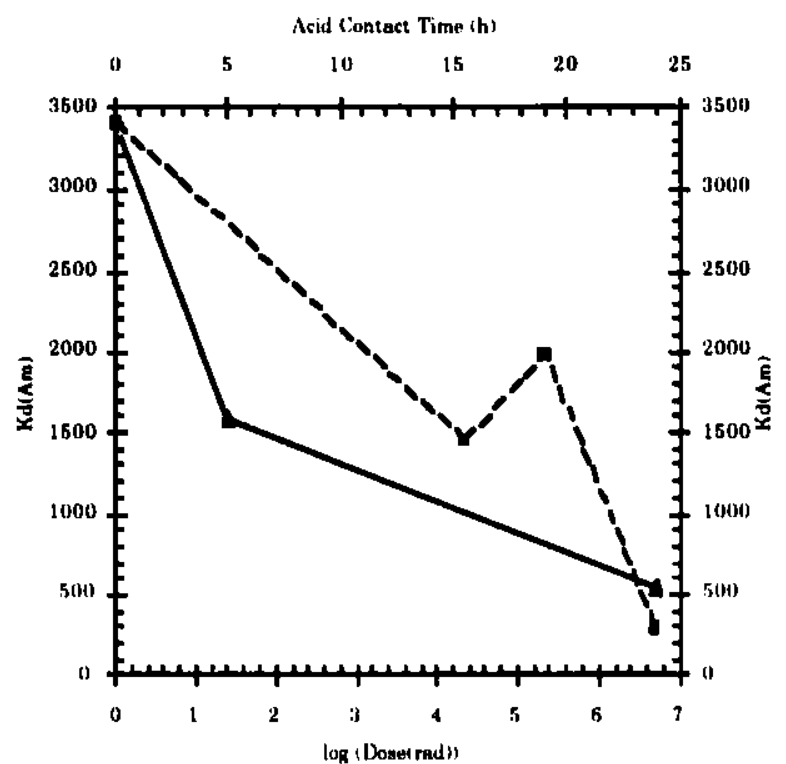

- - - Kadiation $\longrightarrow$ Acid Contact

Fig. G-24. Variation in $\mathrm{K}_{\mathrm{d}}(\mathrm{Am})$ from $2 \mathrm{M} \mathrm{HNO}_{3}$ with Solution Contact Time and Radiation Dose for MACS Particles MDZ-1089-60A Coated with $1.36 \underline{\mathrm{M}} \mathrm{CMPO} / \mathrm{TBP}$ in Contact with $5 \mathrm{M} \mathrm{HNO}_{3}$

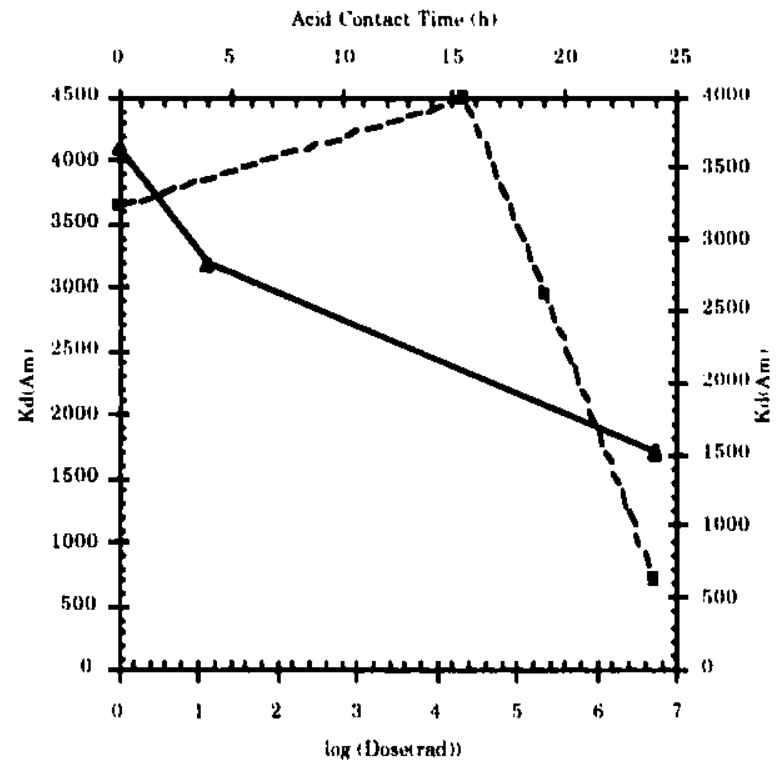

- E-E Radiation Acid Contact

Fig. G-25. Variation in $\mathrm{K}_{\mathrm{d}}(\mathrm{Am})$ from $2 \mathrm{M} \mathrm{HNO}_{3}$ with Solution Contact Time and Radiation Dose for MACS Particles MDZ-1089-65B Coated with $0.58 \mathrm{M}$ CMPO/TBP in Contact with $0.1 \mathrm{M} \mathrm{HNO}_{3}$ 


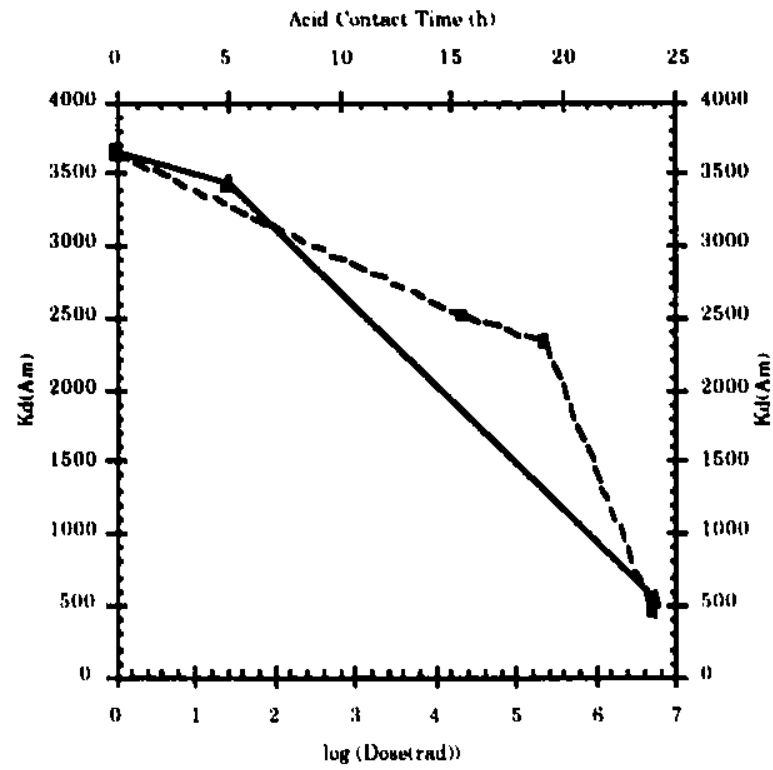

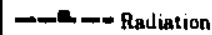

Acid Contact

Fig. G-26. Variation in $\mathrm{K}_{\mathrm{d}}(\mathrm{Am})$ from $2 \mathrm{M} \mathrm{HNO} 3$ with Solution Contact Time and Radiation Dose for MACS Particles MDZ-1089-65B Coated with $0.58 \mathrm{M}$ CMPO/TBP in Contact with $2 \mathrm{M} \mathrm{HNO}_{3}$

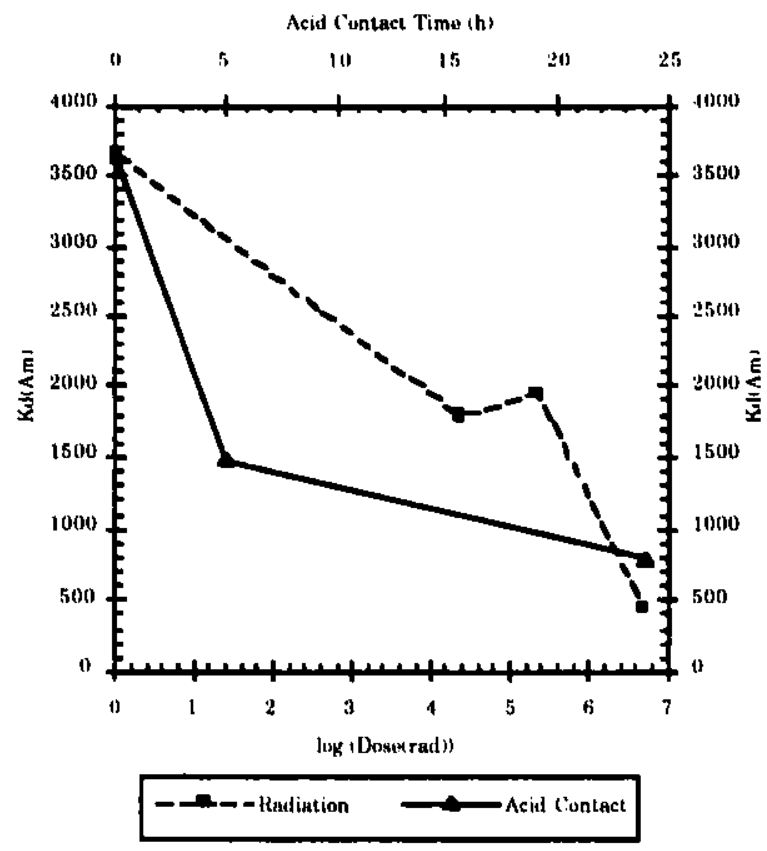

Fig. G-27. Variation in $K_{d}(\mathrm{Am})$ from $2 \underline{M} \mathrm{HNO}_{3}$ with Solution Contact Time and Radiation Dose for MACS Particles MDZ-1089-65B Coated with $0.58 \underline{\mathrm{M}} \mathrm{CMPO} / \mathrm{TBP}$ in Contact with $5 \underline{\mathrm{M}} \mathrm{HNO}_{3}$ 
Table G-3. $\quad \mathrm{K}_{\mathrm{d}}(\mathrm{Am})$ Values from $2 \mathrm{M} \mathrm{HNO}_{3}$ for Particle Coating MDZ-1089-58A with1.2M CMPO/TBP

\begin{tabular}{cc}
\hline $\begin{array}{c}\text { Particle Mass } \\
(\mathrm{mg})\end{array}$ & $\begin{array}{c}\left.\mathrm{K}_{\mathrm{d}} \mathrm{Am}\right)^{\mathrm{a}} \\
(\mathrm{mL} / \mathrm{g})\end{array}$ \\
\hline 5.6 & $3064 \pm 46$ \\
4.9 & $3024 \pm 52$ \\
8.5 & $4252 \pm 38$ \\
6.7 & $3649 \pm 44$ \\
2.8 & $3804 \pm 118$ \\
1.2 & $4318 \pm 328$ \\
3.2 & $4065 \pm 108$ \\
13.9 & $5192 \pm 26$ \\
Average $\mathbf{K}_{\mathbf{d}}(\mathbf{A m})$ & $\mathbf{3 9 2 0 \pm 6 7 0}$ \\
\hline
\end{tabular}

aThe confidence level of the uncertainty is $68.3 \%(1 \sigma)$.

Table G-4. $\mathrm{K}_{\mathrm{d}}(\mathrm{Am})$ Values from $2 \underline{\mathrm{M}} \mathrm{HNO}_{3}$ for MACS Particles MDZ-1089-65B Coated with 0.58M CMPO/TBP

\begin{tabular}{cc}
\hline $\begin{array}{c}\text { Particle Mass } \\
(\mathrm{mg})\end{array}$ & $\begin{array}{c}\mathrm{K}_{\mathbf{d}}(\mathrm{Am})^{\mathrm{a}} \\
(\mathrm{mL} / \mathrm{g})\end{array}$ \\
\hline 1.9 & $3986 \pm 188$ \\
8.2 & $4689 \pm 43$ \\
4.9 & $4156 \pm 70$ \\
3.2 & $3654 \pm 100$ \\
13.3 & $2748 \pm 19$ \\
0.9 & $2544 \pm 269$ \\
Average $\mathbf{K}_{\mathbf{d}}(\mathbf{A m})$ & $\mathbf{3 6 4 0} \pm \mathbf{7 7 0}$ \\
\hline
\end{tabular}

aThe confidence level of the uncertainty is $68.3 \%(1 \sigma)$. 


\section{APPENDIX H}

\section{UNCERTAINTY CALCULATION}

The estimate for uncertainty in the $K_{d}$ value uses conventional radiation-counting statistics and approximations that minimize the uncertainty of the $K_{d}$ values. Equation $H-1$ is the general expression for the error or uncertainty in a multivariate function (Eq. H-2):

$$
(\Delta f)^{2}=\left(\frac{\partial f}{\partial x_{1}}\right)^{2}\left(\Delta x_{1}\right)^{2}+\left(\frac{\partial f}{\partial x_{2}}\right)^{2}\left(\Delta x_{2}\right)^{2}+\left(\frac{\partial f}{\partial x_{3}}\right)^{2}\left(\Delta x_{3}\right)^{2}+\ldots
$$

where

$$
f=f\left(x_{1}, x_{2}, x_{3}, \ldots\right)
$$

The expression for $K_{d}$ is

where

$$
\mathrm{K}_{\mathrm{d}}=\left(\frac{\mathrm{C}_{0}-\mathrm{C}_{\mathrm{f}}}{\mathrm{C}_{\mathrm{f}}}\right)\left(\frac{\mathrm{V}}{\mathrm{m}}\right)
$$

$$
\begin{aligned}
& \mathrm{C}_{0}=\text { initial stock solution count rate (before contact), } \mathrm{cpm} / \mathrm{mL} \\
& \mathrm{C}_{\boldsymbol{f}}=\text { final solution count rate (after contact), } \mathrm{cpm} / \mathrm{mL} \\
& \mathrm{V}=\text { contact volume of Am solution, } \mathrm{mL} \\
& \mathrm{m}=\text { mass of particles, } \mathrm{g}
\end{aligned}
$$

We assumed that the only parameters contributing to the error were $C_{0}, C_{f}$, and $m$. Equation $\mathrm{H}-2$ can then be rewritten as

$$
\mathrm{K}_{\mathrm{d}}=\mathrm{K}_{\mathrm{d}}\left(\mathrm{C}_{0}, \mathrm{C}_{\mathrm{i}}, \mathrm{m}\right)
$$

We further assumed that pipetting errors were negligible and that the uncertainty in counting the stock solution and sample supernatant is $0.5 \%$. The uncertainty in the mass of the particles is $\pm 0.0002 \mathrm{~g}$, since there is an uncertainty of $\pm 0.0001 \mathrm{~g}$ in both the empty and loaded mass measurements of the culture tubes used for the contacts. Equation H-1 cannot be used to account for any uncertainties or errors that are introduced through the performing the experiment but do not appear as dependent variables in Eq. H-3 (e.g., aliquot volume, particle dispersion, active area). Therefore, the uncertainties calculated are probably too small.

Some of the $K_{d}$ values reported are averages of several measurements. The uncertainties of these averages must reflect the scatter in the sampling and the uncertainty of each individual $\mathrm{K}_{\mathrm{d}}$ value. It is reasonable to combine the standard deviation of the population $\left(\sigma_{\mathrm{p}}\right)$ and the average uncertainty of individual measurements $\left(\sigma_{\mathrm{m}}\right)$ as vectors in $\sigma$-space (Eq. $\mathrm{H}-5$ ) to obtain an uncertainty for the average $\left(\sigma_{\vec{x}}\right)$ as follows:

$$
\sigma_{\bar{x}}=\sqrt{\sigma_{\mathrm{p}}^{2}+\sigma_{\mathrm{m}}^{2}}
$$


If the components of $\sigma_{\mathrm{p}}$ and $\sigma_{\mathrm{m}}$ are approximately the same size, $\sigma_{\mathrm{x}}^{-}$forms the diagonal of a square in $\sigma$-space and is approximately 1.4 times the size of either component. This method may overestimate the uncertainty if the number of samples is small and one sample has a value far from the others. If a material is not homogeneous, however, the standard deviation $\sigma_{p}$ expressing the scatter in the sample values is critical in expressing the nonhomogeneity. The uncertainty of the dependent variable in the individual samples of an nonhomogeneous material can be quite small while the uncertainty in the dependent variable for the whole material can be large. 


\section{GLOSSARY}

ANL Argonne National Laboratory.

CMPO Octyl(phenyl)-N,N-diisobutylcarbamoylmethylphosphine oxide.

CMT Chemical Technology Division.

HLW High-level waste.

LET Linear energy transfer. Refers to the rate at which radiation loses energy to an absorber. Heavy charged particles such as protons and $\alpha$-particles deposit most of their energy in a short path and are called high LET radiation. Electrons and $\gamma$-rays deposit energy over a much larger range and are called low LET radiation.

LLW Low-level waste.

MACS Magnetically assisted chemical separation.

PFP Plutonium finishing plant.

SST Single shell tank.

TBP Tributyl phosphate.

TRU Transuranic. Refers to elements with atomic numbers $>92$. Waste classified as TRU contains $>100 \mathrm{nCi} / \mathrm{g}$ of total alpha activity emitted by transuranic elements. 


\section{REFERENCES}

\section{CEMBER}

H. Cember, Introduction to Health Physics, 2nd Ed., Pergamon Press, New York, pp. 97120 (1983).

\section{CHIARIZIA}

R. Chiarizia and E. P. Horwitz, Solvent Extr. Ion Exch., 4, pp. 677-723 (1986).

\section{DAVIS}

W. Davis, Jr., Radiolytic Behavior in Science and Technology of Tributylphosphate; W. W. Schulz and J. D. Navratil, Eds.; CRC Press, Boca Raton, FL, Vol. 1, pp. 221-265 (1984).

\section{DRAGONIC}

I. G. Dragonic and Z. D. Dragonic, The Radiation Chemistry of Water, Academic Press, New York (1971).

\section{EVANS}

R. D. Evans, The Atomic Nucleus, Robert E. Krieger Publishing Company, Malabar, FL, pp. $632-668$ (1955).

\section{HORWITZ}

E. P. Horwitz and D. G. Kalina, Solvent Extr. Ion Exch. 2, pp. 179-200 (1984).

\section{LEONARD-1985}

R. A. Leonard, G. F. Vandegrift, D. G. Kalina, D. F. Fischer, R. W. Bane, L. Burris, E. P. Horwitz, R. Chiarizia, and H. Diamond, The Extraction and Recovery of Plutonium and Americium from Nitric Acid Solutions by the TRUEX Process - Continuing Development Studies, Argonne National Laboratory Report ANL-85/45 (1985).

\section{LEONARD- 1987}

R. A. Leonard, G. F. Vandegrift, E. C. Gay, D. R. Fredrickson, C. S. Sabau, D. J. Chaiko, L. Burris, E. P. Horwitz, R. Chiarizia, H. Diamond, R. C. Gatrone, G. A. Clark, and K. A. Martin, ANL, unpublished information (1987).

\section{NASH}

K. L. Nash, R. C. Gatrone, G. A. Clark, P. G. Rickert, and E. P. Horwitz, Sep. Sci. Technol. 23, pp. 1355-1372 (1988).

\section{NUNEZ-1994}

L. Nuñez, B. A. Buchholz, M. Ziemer, G. Dyrkacz, M. Kaminski, G. F. Vandegrift, K. J. Atkins, F. M. Bos, G. R. Elder, and C. A. Swift, Development Program for Magnetically Assisted Chemical Separation: Evaluation of Cesium Removal from Hanford Tank Supernatant, Argonne National Laboratory Report ANL-94/47 (1994).

\section{NUNEZ-1995}

L. Nuñez, M. Kaminski, C. Bradley, B. A. Buchholz, S. B. Aase, H. E. Tuazon, and G. F. Vandegrift, Magnetically Assisted Chemical Separation (MACS) Process: Preparation and Optimization of TRU Removal Particles - Vol. 1, Argonne National Laboratory Report ANL-95/1 (1995). 
SCHMITZ

F. Schmitz, Chemistry Division, Argonne National Laboratory, personal communication (1993).

SIMONZADEH

N. Simonzadeh, A. M. Crabtree, L. E. Trevorrow, and G. F. Vandegrift, Radiolysis and Hydrolysis of TRUEX.NPH Solvent, Argonne National Laboratory Report ANL-90/14 (1992).

TEMPLIN

Reactor Physics Constants, ANL-5800, 2nd Ed., L. T. Templin, Ed., Washington, DC (1963)

TSE

P.-K. Tse and G. F. Vandegrift, Development of Supercritical Fluid Chromatography for Analysis of TRUEX Process Solvents, Argonne National Laboratory Report ANL-89/21 (1989).

TSOULFANIDIS

N. Tsoulfandis, Measurement and Detection of Radiation, Hemisphere Publishing Corporation, p. 571 (1986).

VANDEGRIFT

G. F. Vandegrift, R. A. Leonard, M. J. Steindler, E. P. Horwitz, L. J. Basile, H. Diamond, D. G. Kalina, and L. Kaplan, Transuranic Decontamination of Nitric Acid Solutions by the TRUEX Solvent Extraction Process - Preliminary Development Studies, Argonne National Laboratory Report ANL-84/45 (1984).

WOODS

R. J. Woods and A. K. Pikaev, Applied Radiation Chemistry: Radiation Processing, John Wiley \& Sons, New York (1994). 
Distribution for ANL-95/19

Internal:

S. Aase

J. E. Battles

J. E. Harmon

M. D. Kaminski

M. J. Steindler

B. A. Buchholz (15)

J. J. Laidler

C. E. Till

J. A. Carr

C. C. McPheeters

J. Gregar

L. Nunez (10)

H. E. Tuazon

G. F. Vandegrift

TIS Files

\section{External:}

DOE-OSTI (2)

ANL-E Library (2)

ANL-W Library

Manager, Chicago Operations Office, DOE

J. Haugen, DOE-CH

Chemical Technology Division Review Committee Members:

E. R. Beaver, Monsanto Company, St. Louis, MO

D. L. Douglas, Consultant, Bloomington, MN

R. K. Genung, Oak Ridge National Laboratory, Oak Ridge, TN

J. G. Kay, Drexel University, Philadelphia, PA

G. R. St. Pierre, Ohio State University, Columbus, $\mathrm{OH}$

J. Stringer, Electric Power Research Institute, Palo Alto, CA

J. B. Wagner. Arizona State University. Tempe, AZ

P. Colton, Pacific Northwest Laboratory. Richland. WA

T. Fryberger, USDOE, Office of Technology Development, Germantown, MD

W. L. Kuhn, Pacific Northwest Laboratory, Richland, WA

I. R. Tasker. Waste Policy Institute, Gaithersburg, MD

J. Watson. Oak Ridge National Laboratory, Oak Ridge. T.N 